


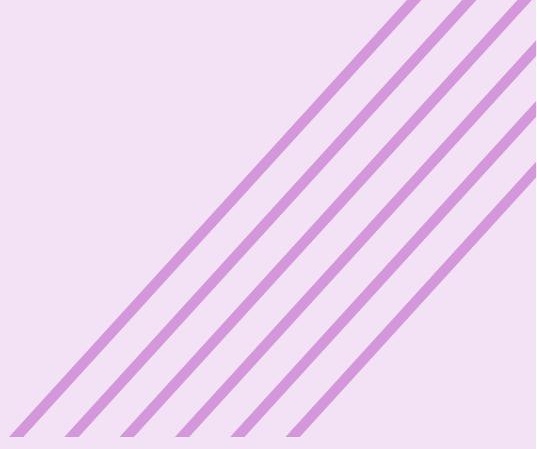

Cardona Jiménez, Jairo León

La importancia de la risa en la salud de los adultos mayores institucionalizados / Jairo León Cardona Jiménez, [...et al.]. -1. ${ }^{\text {a }}$ ed.- Medellín: Corporación Universitaria Remington, 2020.

113 p.; $16,5 \times 23 \mathrm{~cm}$

ISBN PDF-Internet: 978-958-53218-0-9

DOI: https://doi.org/10.22209/9789585321809

1. Ancianos. 2. Asilos de ancianos - Medellín. 3. Edad adulta. 4. Vejez. 5. Risa. 6. Terapias alternativas. 7. Terapia I. Cardona Jiménez, Jairo León. II. Tít.

CDD: 615.547 / C268

(c) Corporación Universitaria Remington

Primera edición, diciembre de 2020

\section{Fondo Editorial Remington}

Lina María Yassin Noreña, editora jefe fondo.editorial@uniremington.edu.co

Calle 51 nro. 51-27, Edificio Uniremington

Telefax: (57) (4) 3221000, extensión 3001 - 3008

Medellín, Colombia

\section{Coordinadora de procesos editoriales}

Diana Cecilia Molina Molina

Diagramador editorial

Mauricio Morales C.

\section{Corrector de estilo}

Juan David Villa Rodríguez

\section{Fotografía}

Cortesía de los autores

\section{Nota legal}

Las opiniones expresadas por el autor no constituyen ni comprometen la posición oficial o institucional de la Corporación Universitaria Remington.

Todos los derechos reservados. Ninguna porción de este libro podrá ser reproducida, almacenada en algún sistema de recuperación o transmitida en cualquier forma o por cualquier medio -mecánicos, fotocopias, grabación y otro-, excepto por citas breves en revistas impresas, sin la autorización previa y por escrito del Comité Editorial Institucional de la

- Corporación Universitaria Remington. 


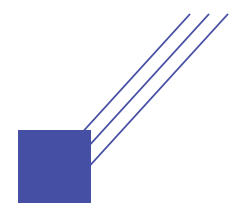
Agradecimientos

Nuestros más sinceros agradecimientos para todos los adultos mayores que nos acompañaron, rieron, cantaron y gozaron. Al personal directivo de las diferentes instituciones que abrieron sus puertas, creyeron y disfrutaron y a la Corporación Universitaria Remington por su financiación y disposición. 


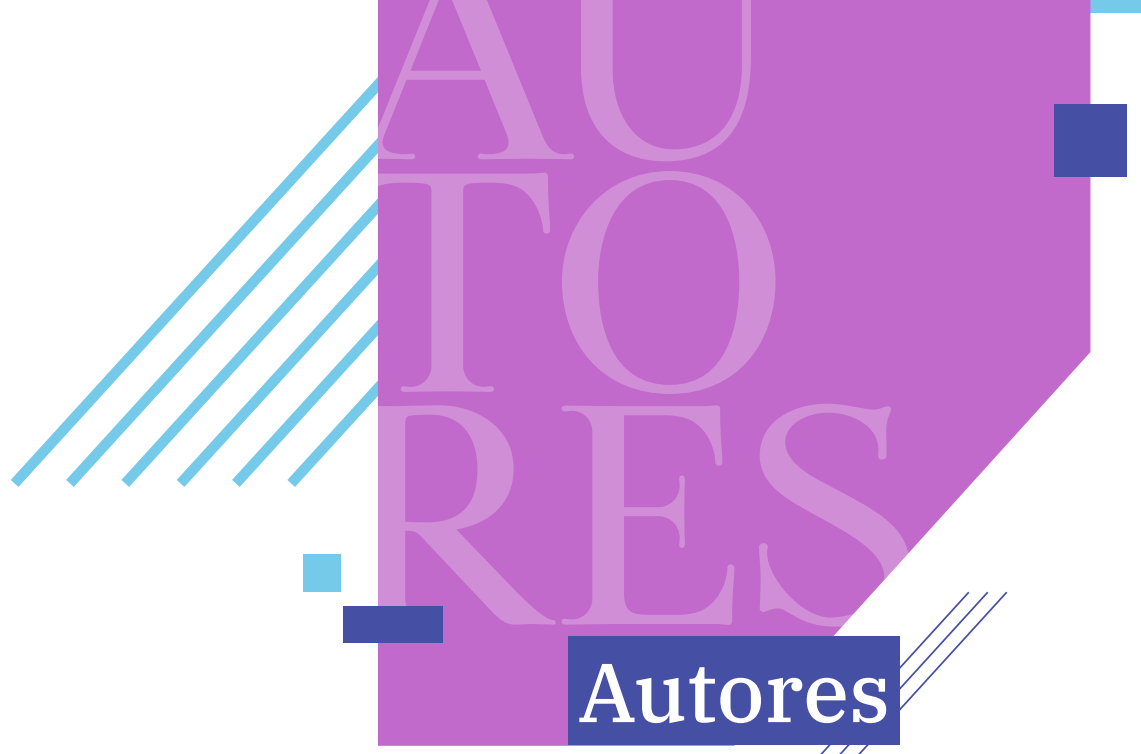

\section{Autores}

\section{Jairo León Cardona Jiménez}

Nutricionista dietista, Universidad de Antioquia. Especialización en Educación para la Salud, Universidad Antonio Nariño. Maestría en Epidemiología, Universidad de Antioquia. Docente, Facultad de Ciencias de la Salud e integrante del Grupo de Investigación en Neurociencias y Envejecimiento (GISAM), Corporación Universitaria Remington.

Contacto: jairoleon01@gmail.com

\section{María Eucaris Henao Villa}

Psicóloga y magíster en en Diseño, Gestión y Dirección de Proyectos, Fundación Universitaria Iberoamericana. Docente, Facultad de Ciencias de la Salud e integrante del grupo GISAM, Corporación Universitaria Remington.

Contacto: henaomunera21@gmail.com 


\section{Ángela Quintero Echeverri}

Psicóloga, Universidad de Antioquia. Tecnóloga en Sistematización de Datos, Politécnico Colombiano Jaime Isaza Cadavid. Docente en las áreas de matemáticas, estadística y ciencias sociales e integrante del grupo GISAM. Adscrita a Colciencias como investigadora Junior.

Contacto: angiecheve@yahoo.es

\section{María Mercedes Villamil Gallego}

Trabajadora social, Universidad de Antioquia. Magíster en Filosofía, Universidad Pontificia Bolivariana. Docente investigadora Facultad de Humanidades e integrante del grupo GISAM, Corporación Universitaria Remington.

Contacto: mercevill@hotmail.com

\section{Edwin Andrés Higuita David}

Microbiólogo, bioanalista y magíster en Ciencias Básicas Biomédicas, Universidad de Antioquia. Director General de Laboratorios, Universidad del Sinú, Montería.

Contacto: andreshiguitad@gmail.com

\section{Lina M. Ramírez Velásquez}

Médica, Corporación Universitaria Remington. Médica en el área de urgencias de la Clínica León XIII. Contacto: linis119@hotmail.com 


\section{José D. Domínguez Sierra}

Médico, Corporación Universitaria Remington. Médico en una institución de cuarto nivel de complejidad. Presentará el examen de residencia durante el pregrado de Medicina.

Contacto: jdominguezsierra11@gmail.com

\section{Juan C. Ortiz Pérez}

Médico general, Corporación Universitaria Remington. Subdirector científico de la ESE Hospital San Antonio del municipio de Cisneros. Contacto: juankop4487@gmail.com

\section{Julieth A. Franco Mira}

Médica, Corporación Universitaria Remington. Investigadora judicial, Tecnológico de Antioquia. Estudiante de postgrado en Patología en la Universidad de Cartagena. Trabaja en el proyecto de investigación sobre la concordancia entre el diagnóstico clínico y los hallazgos morfológicos en las autopsias practicadas en el Hospital Universitario del Caribe (HUC).

Contacto: juliethfranco13@gmail.com

\section{Flor V. Correa Gil}

Médica, Corporación Universitaria Remington. Estudiante de postgrado en Ginecología y Obstetricia e Integrante del grupo de investigación SAM, Corporación Universitaria Remington.

Contacto: dr.vacogi@gmail.com 


\section{Luisa F. Arboleda Restrepo}

Médica, Corporación Universitaria Remington. Estudiante de postgrado en Oftalmología General y de parametrización de diferentes tecnologías utilizadas en el área de oftalmología, Universidad del Sinú.

Contacto: luisa-tata@hotmail.com

\section{Germán Sebastián Yepes Cano}

Estudiante de último semestre del programa de Medicina, Corporación Universitaria Remington. Fue estudiante de Ingeniería Mecatrónica del Instituto Tecnológico Metropolitano. Auxiliar de investigación del grupo GISAM.

Contacto: germanid@hotmail.com

\section{Kate Thurlow}

Ciencias Biomédicas, Universidad de Newcastle. Maestría en Genética de las Enfermedades Humanas, University College of London, en la que obtuvo una distinción. Trabaja en múltiples departamentos del Instituto de Psiquiatría, Psicología y Neurociencia del King’s College London, donde ha llevado a cabo una investigación sobre la demencia y ha colaborado con pacientes y personal de residencias. Comenzará un doctorado en el Van Andel Institute de Michigan.

Contacto: katethurlow1@gmail.com 


\section{Tabla de contenido}

Presentación.

Capítulo I .16

Efectos de la terapia de la risa y teatro sobre la salud de los adultos mayores residentes en un hogar gerontológico de Medellín, 2016

María Eucaris Henao Villa, Jairo León Cardona Jiménez, Ángela Quintero Echeverri y María Mercedes Villamil Gallego

Capítulo II .34

Cambios fisiológicos y niveles de cortisol en adultos mayores residentes en hogares gerontológicos después de la aplicación de terapia de la risa

María Mercedes Villamil Gallego, Jairo León Cardona Jiménez, Edwin Andrés Higuita David, María Eucaris Henao Villa, Ángela Quintero Echeverri, Lina M. Ramírez Velásquez y José D. Domínguez Sierra

Capítulo III. . .

Efectos clínicos de la terapia de la risa en los adultos mayores de un centro geriátrico en la ciudad de Medellín Juan C. Ortiz Pérez, Julieth A. Franco Mira, Flor V. Correa Gil, Luisa F. Arboleda Restrepo, Jairo León Cardona Jiménez, María Eucaris Henao Villa, María Mercedes Villamil Gallego y Ángela Quintero Echeverri

Capítulo IV

Efectos de la terapia de la risa en el nivel de depresión de adultos mayores internados en centros gerontológicos, 2015 Ángela Quintero Echeverri, Jairo León Cardona Jiménez, María Eucaris Henao Villa y María Mercedes Villamil Gallego 
Capítulo V .......................................... 83

Evaluación inmunológica en adultos mayores residentes

en hogares gerontológicos después de la aplicación

de terapia de la risa 2015

Jairo León Cardona Jiménez, María Eucaris Henao Villa,

María Mercedes Villamil Gallego, Ángela Quintero Echeverri,

Germán Sebastián Yepes Cano y Andrés Higuita David

Capítulo VI

Effect of Laughter Therapy on the Level of Depression in the Institutionalized female elderly

María Mercedes Villamil Gallego, María Eucaris Henao Villa, Ángela Quintero Echeverri, Kate Thurlow y Jairo León Cardona Jiménez. 


\section{Lista de Figuras}

Figura 1-1. Cambios en promedio del puntaje de autoestima, estrés y depresión, antes y después de la aplicación de terapias complementarias.

Figura 1-2. Cambios en el puntaje de autoestima, estrés y depresión, antes

y después de la aplicación de terapias complementarias, según género.

Figura 1-3. Cambios en el puntaje de autoestima, estrés y depresión, según tipo de terapia complementaria.

Figura 1-4. Cambios en el puntaje de autoestima, estrés y depresión, antes

y después de la aplicación de terapias complementarias, según grupo de edad.

Figura 3-1. Cambio en la sintomatología en los adultos mayores después

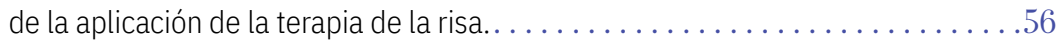

Figura 4-1. Distribución porcentual total y por centros gerontológicos de los cambios en la escala Yesavage.

Figura 4-2. Cambios en el puntaje de depresión de los adultos según la clasificación de la escala Yesavage después de la aplicación de la terapia de la risa.

Figure 6-1. Changes in median score of both normal and mild depression before and after treatment with laughter therapy. 


\section{Lista de Tablas}

Tabla 1-1. Variables sociodemográficas en centro gerontológico. . . . . . . . . . . . . 22

Tabla 1-2. Cambios en el puntaje de autoestima, estrés y depresión, antes y después de la aplicación de terapias complementarias, según escolaridad. . . . . . . . . 25

Tabla 2-1. Datos sociodemográficos. .39

Tabla 2-2. Sintomatología referida por los adultos mayores antes y después de la aplicación de la terapia de la risa.

Tabla 2-3. Cambio en los signos vitales en los adultos mayores después

de la aplicación de la terapia de la risa.. . . . . . . . . . . . . . . 42

Tabla 2-4. Cambios en el cortisol posterior a terapia de la risa. . . . . . . . . . . . . . 43

Tabla 3-1. Variables sociodemográficas de los adultos residentes en el hogar gerontológico Colonia Belencito, Medellín, Antioquia.. . . . . . . . . . . . 55

Tabla 3-2. Cambio en los signos vitales en los adultos mayores después de la aplicación de la terapia de la risa.. . . . . . . . . . . . . . . . 57

Tabla 4-1. Variables sociodemográficas de adultos mayores residentes en centros gerontológicos.

Tabla 4-2. Cambio en cada ítem de la escala Yesavage después de la terapia de la risa según sede. .74

Tabla 4-3. Diferencias en las medidas de Yesavage según variables sociodemográficas antes y después de la aplicación de la terapia de la risa. . . . . .76

Tabla 5-1. Cambios en las citocinas en adultos mayores internados después de la aplicación de la terapia de la risa...

Tabla 5-2. Cambios en las citocinas en las mujeres adultas mayores internadas después de la aplicación de la terapia de la risa.

Tabla 5-3. Cambios en las citocinas en hombres adultos mayores internados después de la aplicación de la terapia de la risa.

Table 6-1. Effects on different systems of the body resulting from laughter therapy. . . . .99

Table 6-2. Frequency of positive responses to GDS-15 questions to indicate depression before and after the application of laughter therapy, the difference in number of responses before and after therapy and the change noted.. . . . . . . . . . . 102

Table 6-3. Changes in the raw score and level of depression according to the GDS-15 from original testing to testing after the application of laughter therapy. . . 


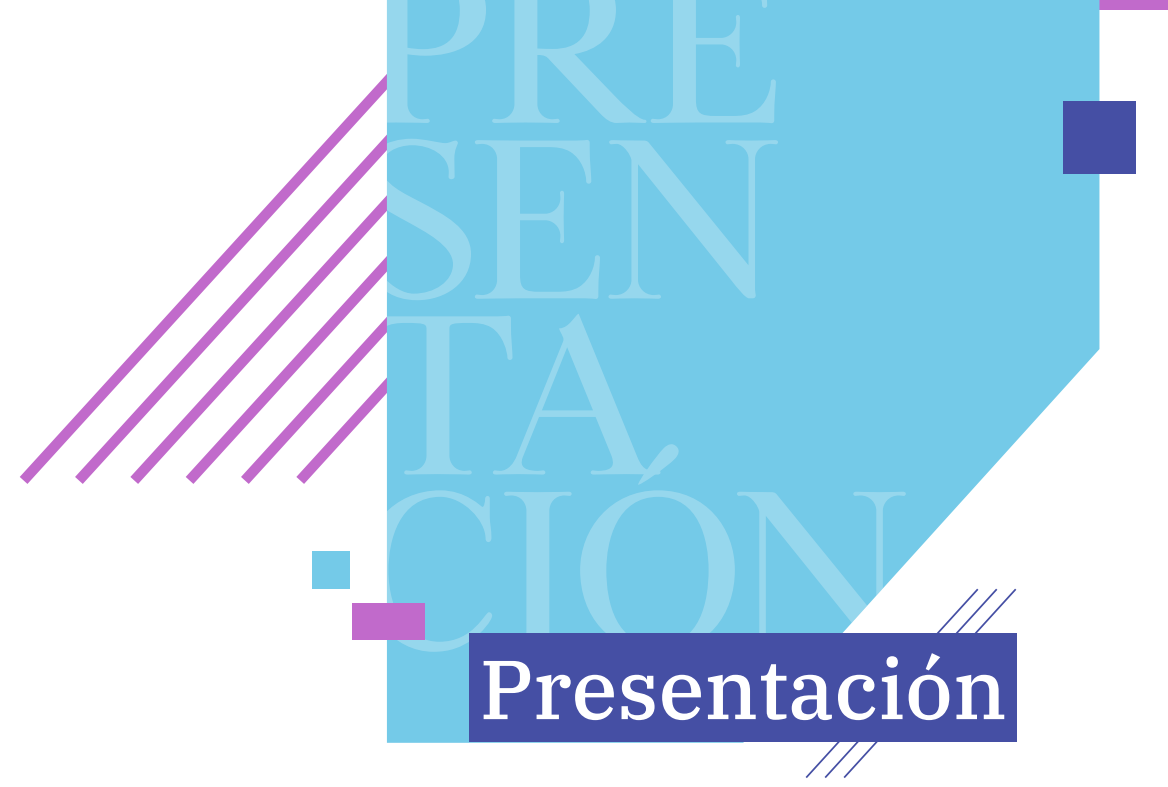

Tnvestigar sobre el efecto de las terapias complementarias en los _contextos institucionales que vivencia el adulto mayor se convierte en un gran reto para la Corporación Universitaria Remington por la tendencia mundial de aumento de esta población y a su vez la necesidad imperante de mejorar su calidad de vida (una vida más sana y de disfrute). Es necesario promocionar la salud tal y como lo señala la medicina familiar y comunitaria: prevenir, mejorar la salud y realizar un mayor control sobre la misma con el fin de alcanzar un estado adecuado de bienestar mental, físico y social, como lo expresa la Carta de Ottawa y la Ley 1315 de 2009 (Colombia).

La población de 60 años y más está creciendo a pasos agigantados: para el año 2050 una de cada cinco personas corresponderá al grupo de adultos mayores (Organización Mundial de la Salud, OMS). Según datos del informe Perspectivas de la población mundial 2019, en 2018 el número de personas de 65 años o más será mayor que el número de niños menores de cinco años; además, el número de personas de 80 años o más será el triple: pasará de 143 millones en 2019 a 426 millones en 2050. En la década 2020-2030, el número de personas de 60 años o más aumentará en un 34\%: de 1.000 millones en 2019 a 1.400 millones, y en 2050 los adultos mayores serán más del doble y alcanzarán los 2.100 millones (División de Población 
del Departamento de Asuntos Económicos y Sociales [DAES] de las Naciones Unidas).

En América Latina y el Caribe, el número de personas de 60 años o más aumentará en 2030 de un 11\% a un 17\% y en 2050 uno de cada cuatro habitantes será mayor de 60 años (Federación Iberoamericana de Asociaciones de Personas Adultas Mayores [FIAPAM]). Colombia no es ajeno a este crecimiento: de acuerdo con el Departamento Administrativo Nacional de Estadística (DANE) el 9,1\% de la población es adulta mayor y según el Estudio Nacional de Salud, Bienestar y Envejecimiento, antes del 2021 habrá un mayor de 60 años por cada dos adolescentes (SABE Colombia).

Entonces, se puede afirmar que los adultos mayores serán los protagonistas del futuro. Pero con el advenimiento de la vejez sobrevienen las enfermedades; algunas estadísticas informadas por el SABE Colombia 2015 muestran que: el 60,7\% de aquellos padece de hipertensión arterial; en segundo lugar están quienes tienen síntomas depresivos con un $41 \%$, mientras un $25,8 \%$ tiene artritis-artrosis, un $18,5 \%$ prevalencia de diabetes mellitus, un $11,4 \%$ sufre de enfermedad pulmonar crónica y un 5,3\% de cáncer. Otras enfermedades reportadas fueron deterioro visual, auditivo y cognoscitivo, osteoporosis, enfermedad isquémica cardíaca y enfermedad cerebro-vascular. El 84,8\% de los adultos mayores tienen más de una condición crónica de salud (multimorbilidad).

Así las cosas, la vejez se ha convertido en un desafío mundial porque muestra una exigencia alta para los servicios de salud; y, además, convoca a los Estados y a la ciudadanía en general a trabajar y velar por condiciones óptimas en las diferentes dimensiones del ser (social, política, familiar, personal). Por ello, aquí se presentan investigaciones realizadas en algunos centros gerontológicos de Medellín donde se utilizaron las terapias complementarias para apoyar la salud de los adultos mayores.

El capítulo I identifica los cambios en el estrés, la mejoría en la salud, la depresión y la autoestima en los adultos mayores de un centro gerontológico de Medellín, gracias a la aplicación de las terapias complementarias (terapia de la risa y teatro). El capítulo II analiza los 
efectos clínicos de la terapia de la risa en el ámbito somático (la astenia y la adinamia) y en el orgánico (la disnea, constipación, incontinencia); también los cambios en el cortisol. El capítulo III da cuenta de algunos cambios psíquicos (depresión, ansiedad y anorexia) y de otros fisiológicos (presión arterial, constipación, dolor abdominal...) después de la risoterapia. El capítulo IV versa sobre el impacto de la risoterapia en el nivel de depresión en dos grupos de ancianos internados en hogares gerontológicos. El capítulo $V$ analiza los cambios en la respuesta inmunológica de los adultos mayores de dos centros gerontológicos. Por último, el capítulo VI busca reconocer el impacto en los niveles de depresión de la terapia de la risa en un grupo de mujeres adultas.

Finalmente, es necesario puntualizar que actualmente las terapias complementarias tienen gran relevancia debido a los beneficios en la salud física y psicológica de los adultos mayores, y a que son más económicas y no tienen efectos secundarios. Hay que decir que estas terapias, como su nombre lo indica, complementan a las tradicionales (por tanto, no sustituyen a la medicina tradicional) y que la risoterapia, geloterapia o terapia de la risa es una de ellas.

Entre los beneficios de esta terapia están la disminución de la depresión, la ansiedad y el estrés, el aumento de la autoestima y el favorecimiento de la creatividad. Asimismo, fortalece el sistema inmunitario, reduce el ronquido, aumenta la capacidad pulmonar, fortalece el corazón, reduce la tensión arterial, libera endorfinas que contrarrestan el dolor, genera bienestar y mejora la comunicación.

Esperamos que con la lectura de este libro puedan ampliar su comprensión de los beneficios de esta terapia, y que lo disfruten. 



\title{
Efectos de la terapia de la risa y teatro sobre la salud de los adultos mayores residentes en un hogar gerontológico de Medellín, 2016
}

\author{
María Eucaris Henao Villa ${ }^{1}$, Jairo León Cardona Jiménez ${ }^{1}$, \\ Ángela Quintero Echeverri² y María Mercedes Villamil Gallego ${ }^{3}$
}

\section{Introducción}

El adulto mayor debe afrontar diversas situaciones, entre ellas el padecimiento de enfermedades, la pérdida del trabajo, de familiares y amigos, y, en algunos casos, el alejamiento de la familia. Su vulnerabilidad lleva a un aumento en el nivel de dependencia que obliga muchas veces, a internarlos en los centros geriátricos. ${ }^{[1]}$ La internación geriátrica puede generar en el adulto mayor deficiencias en las relaciones interpersonales, puesto que se ve limitado y pierde su independencia e intimidad, se siente aislado debido a la separación de sus seres queridos, y lo asalta un sentimiento de inutilidad, de haberse convertido en una carga. ${ }^{[2]}$

En la mayoría de los casos, el adulto mayor que está internado tiende a volverse sedentario, lo cual ocasiona o agrava las enfermedades crónicas, que a su vez lleva al aumento del uso de medicamentos e incluso, a la hospitalización e invalidez. La actividad física, por el contrario, puede lograr beneficios en los sistemas: cardiovascular, músculo-esquelético, respiratorio y endocrino, además de disminuir la depresión y la ansiedad. ${ }^{[3]}$

1 Facultad de Ciencias de la Salud y grupo GISAM, Uniremington.

2 Grupo GISAM, Uniremington.

3 Facultad de Humanidades y grupo GISAM, Uniremington. Contacto: mercevill@hotmail.com 
Las terapias complementarias están siendo adoptadas por los beneficios en la salud física y psicológica, por ser baratas y por no tener efectos secundarios; estas terapias amplían o complementan las terapias tradicionales, por lo que no sustituyen la medicina tradicional, y una de ellas es la risoterapia, geloterapia o terapia de la risa. ${ }^{[4]}$

En el mundo se han gestado terapias vinculadas con el arte que han tenido resultados sorprendentes en la salud general de sus practicantes; así que la medicina tradicional ha tenido que incluirlas como alternativas en la promoción de la salud. Dentro de estas opciones, la expresión corporal o movimiento creativo como actividad física terapéutica es un ejemplo de multidisciplinariedad con gran influencia en la salud física y mental; esto lo demuestra un estudio hecho en Costa Rica que investigó los efectos agudos y crónicos de un programa variado de movimiento creativo (baile popular, expresión corporal, técnicas de relajación, juegos recreativos, improvisación, educación somática, teatro, taichí, danza, aromaterapia), considerando variables psicológicas y cognitivas de personas adultas mayores semiinstitucionalizadas: el estudio halló un aumento significativo de su autoestima, un efecto positivo en la memoria a corto plazo y tiempo de reacción, beneficios en los estados de ánimo y vigor, todo lo cual es primordial para mejorar la calidad de vida. ${ }^{[5]}$

También en Costa Rica, un trabajo llevado a cabo con 191 personas adultas mayores con niveles de actividad y participación social halló que aquellas tenían altas creencias de autoeficacia, mayor percepción de control interno, satisfacción con la vida actual, bienestar con redes de apoyo emocional de familia y amigos, y ausencia de indicadores de estados depresivos. ${ }^{[6]}$ Otro estudio comparó a 92 adultos mayores que realizaban actividad física con otros 92 que no desarrollaban actividad físico-deportiva y llevaban un estilo de vida sedentario; los primeros manifestaron una adecuada autoestima personal y más bienestar psicológico. ${ }^{[7]}$ Así que, en general, disfrutar una alta autoestima se correlaciona en forma positiva con la realización de actividad física: ${ }^{[8]}$ los adultos mayores activos son más felices que los sedentarios. ${ }^{[9]}$

El teatro es otra de las terapias complementarias actuales. Se trata de un arte que representa conflictos propios de la vida humana, y una 
combinación de diversos elementos, como la gestualidad, el discurso, la música, los sonidos y la escenografía. El teatro permite crear una forma de expresar y representar las emociones a través de la comunicación gestual para lograr una mayor y mejor integración interpersonal y, por tanto, una mejor calidad de vida, pues se trata de crear un espacio de libertad, de expresión y de transformación. Quienes lo practican alcanzan una mayor comunicación verbal y no verbal, lo que se traduce en el aumento del contacto con el otro, la creatividad, la desinhibición y la asertividad. ${ }^{[10]}$

Asimismo, numerosos estudios avalan la terapia de la risa y el humor en diferentes campos de intervención médica, clínica, educativa, psicoterapéutica y social; afirman aquellos que es una técnica psicoterapéutica que tiende a producir beneficios mentales y emocionales gracias a la relajación de todo el cuerpo cuando el paciente ríe a carcajadas. Esta terapia se desarrolla mediante actividades lúdicas en grupo cuyo objetivo es que los competidores salgan de las sesiones más positivos y satisfechos con su vida.

La risa es una expresión de alegría y bienestar que produce una liberación emocional en la cual el organismo fomenta una fuerza psicofisiológica por las contorsiones del diafragma. Estas contracciones son acompañadas por una comunicación facial determinada que involucra 50 músculos alrededor de la boca con secreciones lagrimales. La risa pone en movimiento 300 músculos de todo el cuerpo (pared abdominal, cabeza, cuello, espalda, hombros, brazos, manos y pies), ${ }^{[11]}$ y sirve para superar problemas físicos, psicológicos y sociales, e impacta especialmente en la reducción de la ansiedad. ${ }^{[12]}$

El efecto benéfico de la terapia de la risa se demuestra en el espacio psicosocial y en la salud; así mismo, se han obtenido resultados favorables en personas internadas en hospitales y se ha visto la mejoría tanto en niños como en la población en general. ${ }^{[13]}$ Un estudio realizado con adultas mayores de un centro gerontológico concluyó que la terapia de la risa mejora la calidad de vida, aporta cambios emocionales positivos, alivia el estrés, y en el ámbito social presenta un incremento de la confianza en los demás. ${ }^{[14]}$ 
Por otro lado, en varias investigaciones se ha percibido que las personas mejoran en enfermedades emocionales como la depresión, que los resultados del ejercicio de reír mejoran la calidad de vida en pacientes depresivos: ${ }^{[15,16]}$ hay un cambio de energía y una ampliación expectativa en el gusto por vivir. Se trata de una disminución significativa de la depresión ( $p<0,032)$ especialmente en aquellos con depresión inicial establecida, y de una mejoría en el sueño. ${ }^{[17,18]}$ Además de un incremento de la autoestima y la esperanza, unido a una actitud positiva ante situaciones del día a día. ${ }^{[19,20,21]}$ Bennett y col., a su vez, hallaron que participantes de un grupo de humor disminuyeron de manera importante el estrés. ${ }^{[22]}$

Hay que decir que estos modelos terapéuticos complementarios han surgido independientemente de los tratamientos médicos y farmacológicos convencionales empleados en la cura de algunas patologías físicas y psicológicas (drama terapia, musicoterapia, risoterapia, entre otros). Específicamente, la realización de actividades lúdicas en las instituciones de atención o centros de protección social se han ido convirtiendo en un método para que el adulto mayor exteriorice sus sentimientos y sienta el acompañamiento. ${ }^{[23]}$

Por lo anterior, este trabajo pretende identificar los cambios en el grado de estrés, depresión y autoestima antes y después de la aplicación de la terapia de la risa y el teatro en los ancianos residentes en centros gerontológicos de la Red de Asistencia Social al Adulto Mayor de Medellín (2016).

\section{Metodología}

Se realizó un estudio de tipo exploratorio y diseño cuasiexperimental para comparar los valores adquiridos antes y después de las sesiones de la terapia de la risa y del teatro con las escalas de depresión Yesavage (versión reducida), ${ }^{[24]}$ escala de autoestima de Rosenberg[25] y escala de estrés percibido. ${ }^{[26]}$ Antes de aplicarlos, se usó el test minimental con el fin de evaluar si el adulto tenía las capacidades cognitivas para participar en las actividades y responder los mencionados test. ${ }^{[27]}$ 
Las escalas fueron aplicadas por los integrantes del Grupo de Investigación GISAM y cuatro alumnos del programa de Medicina de la Uniremington antes y después de las actividades, con el acompañamiento de la Fundación Mediclaun de Payasos Hospitalarios de Medellín.

La escala de depresión geriátrica Yesavage, de la cual existe una versión completa de 30 ítems y una reducida de 15 ítems, es una de las más utilizadas para evaluar la depresión de los ancianos. La escala reducida ha sido validada en Colombia en dos ocasiones por los resultados fiables que presagian moderadamente los resultados de depresión. Agrupa en tres niveles la depresión: normal, con puntaje de 0 a 5; leve, de 6 a 10, y severa de 11 a 15.

La escala de autoestima de Rosenberg (EAR) ha sido traducida a varios idiomas y validada en distintos países. Schmitt y Allik ${ }^{[28]}$ realizaron un estudio multicultural administrando la EAR en 53 naciones: en 48 de ellas hubo una confiabilidad sobre 0,75. En Colombia fue validada recientemente por su alta consistencia interna y aceptable solución factorial. Está compuesta por 10 ítems, con cuatro opciones que van desde "muy de acuerdo" a "muy en desacuerdo".

La escala de estrés percibido (perceived stress scale, PSS) es un instrumento de autoinforme que evalúa el nivel de estrés percibido durante el último mes y que consta de 14 ítems con un formato de respuesta de cinco puntos ( 0 = nunca, 1 = casi nunca, 2 = de vez en cuando, 3 = a menudo, 4 = muy a menudo). Esta herramienta también ha sido validada en Colombia.

El tamaño de la muestra fue de 33 personas mayores de 60 años (25 en terapia de la risa y ocho en teatro) de un hogar gerontológico de la Red de Asistencia Social al Adulto Mayor; a cada uno de los adultos mayores se les preguntó si querían participar y en caso afirmativo eligieron entre las dos opciones.

Las variables sociodemográficas consultadas fueron género, edad, estrato socioeconómico de procedencia, nivel educativo y estado civil. El análisis de estadística se desarrolló con el programa SPSS, versión 21 para Windows. En el análisis univariado se utilizaron frecuencias 
absolutas y proporciones, y el indicador prueba t de student para muestras emparejadas. El nivel de significancia se fijó en $p \leq 0,05$.

Las sesiones de las terapias tuvieron una duración de 10 a 15 minutos cada una. La actividad fue desarrollada por profesionales de la Fundación Mediclaun, personas con experiencia en las artes lúdicas, recreativas y teatrales. Al ingresar a los espacios donde se encontraban los ancianos, permitieron que ellos jugaran entre sí para luego incorporar las actividades lúdicas con herramientas como flautas, juguetes e instrumentos de cuerda. Luego los invitaron a intervenir respondiendo interrogatorios, cantando e imitando la música. Se llevaron a cabo ocho sesiones, una semanal, y participaron 25 adultos mayores.

En las actividades de teatro participaron ocho adultos que no lo hicieron en la terapia anterior. Al inicio de cada sesión, el profesor realizó actividades de relajación y facilitó un espacio para que las personas exploraran su subjetividad e integraran aspectos no reconocidos en sí mismos. A través de las interacciones se fue generando un proceso creativo que sirvió para que expresaran sus propias vivencias y simbolizaran de algún modo las experiencias de sus realidades; es decir, se partió de las propias potencialidades del adulto. Se montaron dos presentaciones cuyos guiones fueron creados por los participantes. Para el desarrollo de esta actividad se practicaron dos sesiones semanales durante seis meses, cada una de dos horas.

\section{Aspectos éticos}

Para la recolección de la información, los adultos mayores firmaron un consentimiento informado que especificaba el manejo confidencial y anónimo según Resolución 8430 de 1993 del Ministerio de Salud. [29] Se trata de un estudio sin riesgos. Además, se obtuvo la aprobación del Comité de Ética de la Corporación Universitaria Remington. 


\section{Resultados}

A continuación se presentan los resultados que permiten apreciar los cambios generados en el estrés, depresión y autoestima luego de la aplicación de las terapias complementarias (risa y teatro) en los adultos mayores institucionalizados.

En la población estudiada, el 63,6\% es de género masculino y el $51,5 \%$ tiene entre 76 y 99 años de edad; en cuanto al estrato socioeconómico de procedencia, el 63,7\% está entre cero, uno y dos. El $63,6 \%$ hizo la primaria completa o algún grado de ella; se destaca que el 9,1\% alcanzó educación superior. El 60,6\% de los participantes son solteros, seguidos de los viudos y separados $(18,2 \%$ y $15,2 \%$, respectivamente); solo el 6,0\% afirmó contar con pareja. El 75,8\% dijo recibir visitas de las familias y amigos (Tabla 1-1).

Tabla 1-1. Variables sociodemográficas en centro gerontológico.

\begin{tabular}{|l|l|c|c|}
\hline \multirow{4}{*}{ Género } & Femenino & 12 & 36,4 \\
\cline { 2 - 4 } & Masculino & 21 & 63,6 \\
\hline \multirow{4}{*}{ Edad (en años) } & Promedio & 76,1 & \\
\cline { 2 - 4 } & $60-75$ & 16 & 48,5 \\
\cline { 2 - 4 } & $76-99$ & 17 & 51,5 \\
\hline \multirow{5}{*}{ Estrato de origen } & 0 & 3 & 9,1 \\
\cline { 2 - 4 } & 1 & 9 & 27,3 \\
\cline { 2 - 4 } & 2 & 9 & 27,3 \\
\cline { 2 - 4 } & 3 & 6 & 18,2 \\
\cline { 2 - 4 } & 4 & 1 & 3,0 \\
\hline \multirow{5}{*}{ Escolaridad } & NS/NR & 4 & 15,2 \\
\cline { 2 - 4 } & Ninguno & 21 & 12,1 \\
\cline { 2 - 4 } & Primaria completa e incompleta & 5 & 15,6 \\
\cline { 2 - 4 } & Secundaria completa e incompleta & 2 & 3,2 \\
\cline { 2 - 4 } & Técnico completo & 1 & 3,0 \\
\cline { 2 - 4 } & Tecnología completa & 2 & 6,1 \\
\hline
\end{tabular}


Continuación de la Tabla 1-1.

\begin{tabular}{|c|l|c|c|}
\hline \multirow{4}{*}{ Estado civil } & Con pareja & 2 & 6,0 \\
\cline { 2 - 4 } & Separado(a) & 5 & 15,2 \\
\cline { 2 - 4 } & Soltero(a) & 20 & 60,6 \\
\cline { 2 - 4 } & Viudo(a) & 25 & 18,2 \\
\hline \multirow{3}{*}{ Reciben visitas } & Sí & 8 & 24,2 \\
\cline { 2 - 4 } & No & 19 & \\
\hline \multirow{3}{*}{ Minimental } & Promedio & 21 & 63,6 \\
\cline { 2 - 4 } & Bajo & 12 & 36,4 \\
\cline { 2 - 4 } & Normal & & \\
\cline { 2 - 4 } & &
\end{tabular}

Se presentaron cambios en el puntaje de autoestima (se incrementó el promedio de 28 puntos a 29), el estrés disminuyó de 18 a 15 de manera significativa $(p=0,027)$ y la depresión también lo hizo (Figura 1-1).

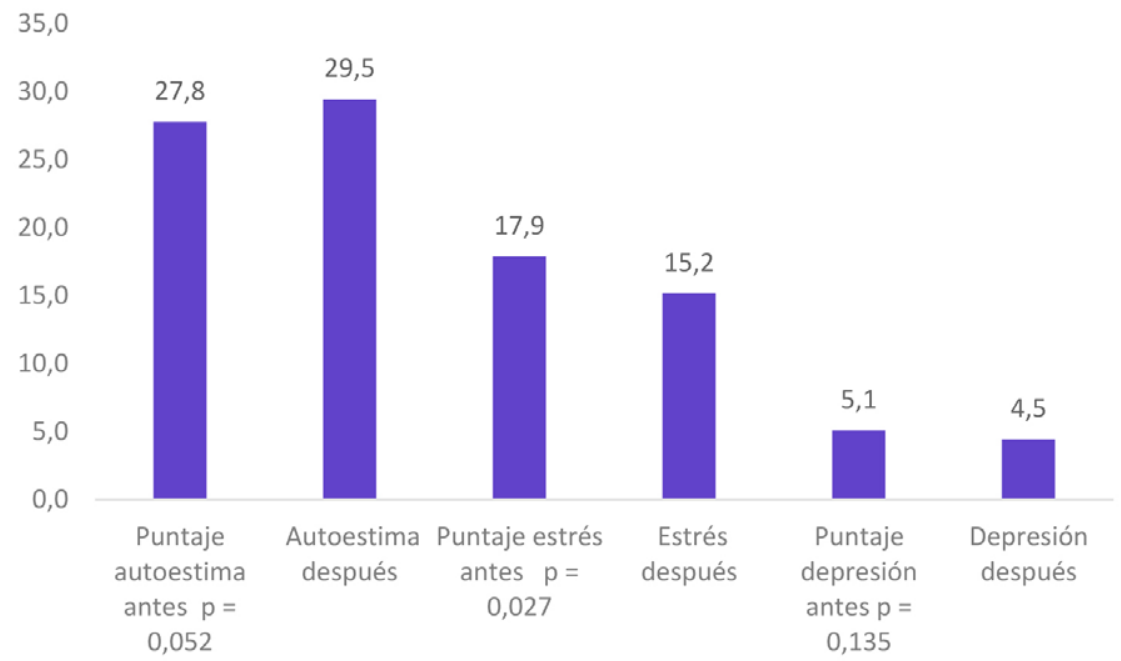

*Prueba t de student para muestras emparejadas $p<0,05$.

Figura 1-1. Cambios en promedio del puntaje de autoestima, estrés y depresión, antes y después de la aplicación de terapias complementarias. 
En la población valorada, tanto en hombres como en mujeres disminuyeron la depresión y el estrés, y creció la autoestima, siendo el cambio más significativo en los hombres ( $p=0,034)$. En el género femenino se presentó un descenso importante del estrés (Figura 1-2).

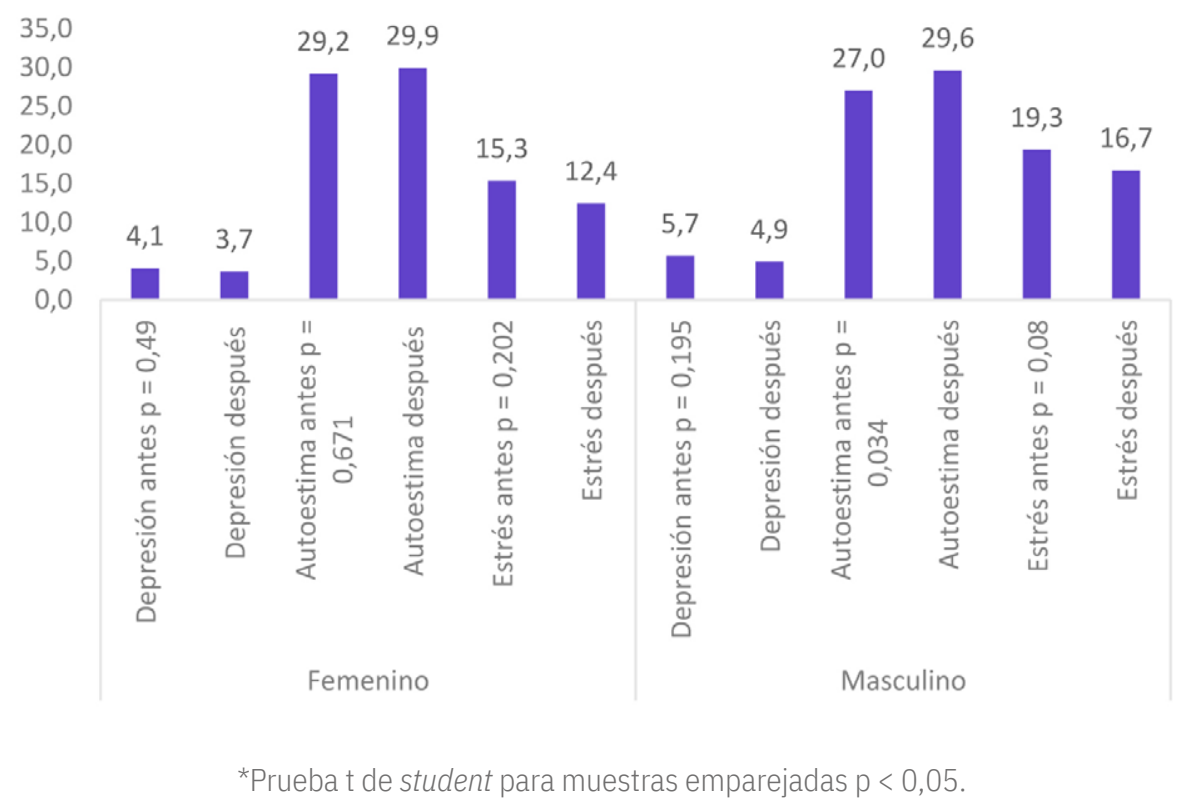

Figura 1-2. Cambios en el puntaje de autoestima, estrés y depresión, antes y después de la aplicación de terapias complementarias, según género.

Asimismo, se mostraron cambios positivos en la medición de las escalas entre los que estudiaron primaria completa o algún grado de esta; sin embargo, no es claro el cambio que se dio en los tres adultos que alcanzaron educación superior. Posiblemente, la significancia que se muestra en quienes estudiaron primaria completa o algún grado de esta se deba a que es un número apreciable dentro de la muestra (21 adultos, que corresponden al 63,6\%) (Tabla 1-2). 
Tabla 1-2. Cambios en el puntaje de autoestima, estrés y depresión, antes y después de la aplicación de terapias complementarias, según escolaridad.

\begin{tabular}{|l|c|c|c|c|c|c|c|c|c|}
\hline \multirow{2}{*}{$\begin{array}{c}\text { Escolaridad } \\
\text { alcanzada }\end{array}$} & \multicolumn{3}{|c|}{ Promedio depresión } & \multicolumn{3}{c|}{ Promedio estrés } & \multicolumn{3}{c|}{ Promedio autoestima } \\
\cline { 2 - 11 } & Antes & Después & Valor $\mathbf{p}$ & Antes & Después & Valor $\mathbf{p}$ & Antes & Después & Valor $\mathbf{p}$ \\
\hline Ninguna & 7,5 & 7,3 & 0,761 & 21,8 & 19,3 & 0,319 & 28,3 & 26,8 & 0,312 \\
\hline Primaria & 5,1 & 3,9 & 0,024 & 18,1 & 13,6 & 0,011 & 26,8 & 30,3 & 0,006 \\
\hline Secundaria & 3,6 & 3,6 & 1,0 & 16,6 & 17,8 & 0,458 & 29,6 & 32,0 & 0,162 \\
\hline Superior & 4,0 & 6,0 & 0,438 & 13,7 & 16,3 & 0,508 & 31,3 & 26,0 & 0,323 \\
\hline *Prueba t de student para muestras emparejadas $p<0,05$. \\
\hline \multicolumn{10}{|c|}{} \\
\hline
\end{tabular}

La Figura 1-3 hace referencia al tipo de terapia y a la diferencia entre el primer y segundo momento; en ambas terapias, teatro y risa, mejoraron en el puntaje de las tres escalas; en teatro mejoró más el estrés y en terapia de la risa mejoró más la autoestima (ambos al borde line, 0,051 y 0,062 , respectivamente).

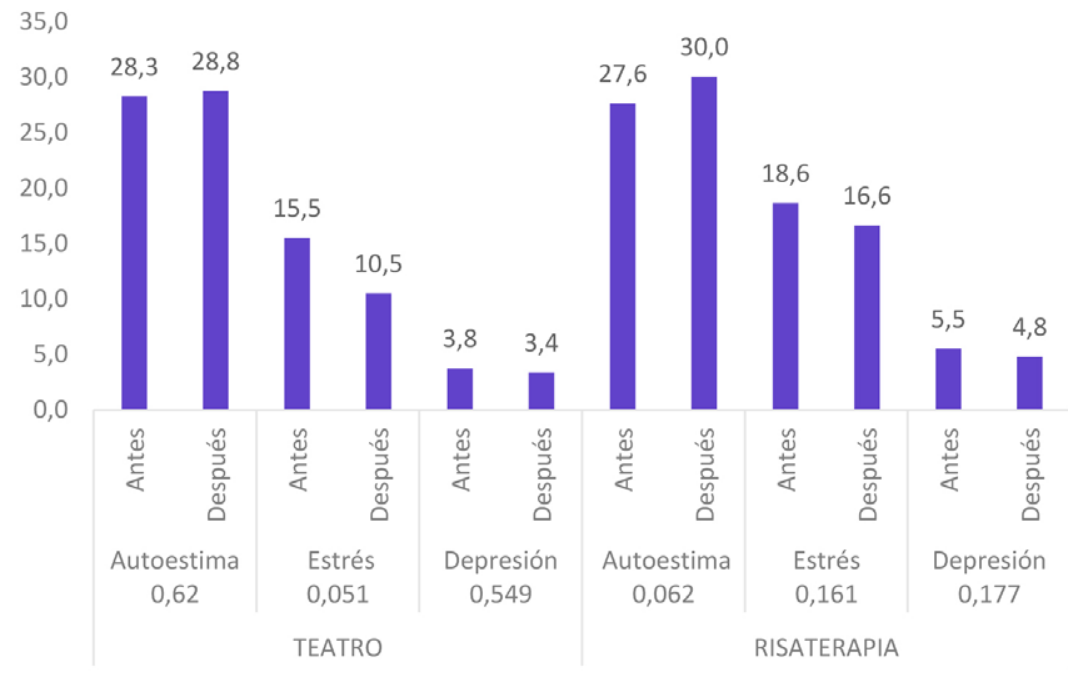

*Prueba t de student para muestras emparejadas $p<0,05$.

Figura 1-3. Cambios en el puntaje de autoestima, estrés y depresión, según tipo de terapia complementaria. 
Hubo un cambio significativo en el incremento de la autoestima en los menores de 75 años. En los mayores de esta edad mejoraron todos los indicadores, pero sin llegar a alcanzar significancia estadística. En los mayores de 76 el estrés fue el ítem que más bajó (Figura 1-4).

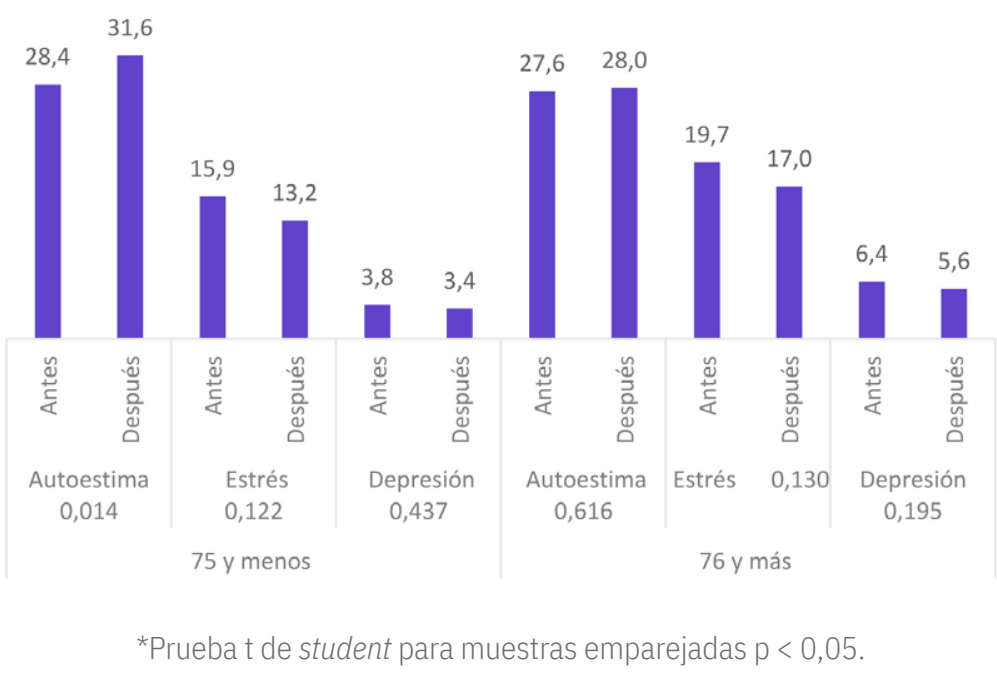

Figura 1-4. Cambios en el puntaje de autoestima, estrés y depresión, antes y después de la aplicación de terapias complementarias, según grupo de edad.

\section{Discusión}

Varios trabajos reportan los efectos de las terapias complementarias en la salud de los adultos mayores internados. En referencia al teatro, se reportan incrementos en la autoestima superiores al 10\%; los efectos producidos parecen relacionarse con los derivados de la actividad física. ${ }^{[7,8]}$ La teoría de la identidad social sugiere que existe una relación entre la autoestima personal y la autoestima colectiva: "Las personas construyen un marco de referencia para su identidad social”; de esta manera, una valoración positiva del grupo asegura una valoración positiva de sí mismo. ${ }^{[7]}$ Otra explicación la propone la teoría de la proyección: por medio de los procesos o los resultados artísticos (una danza, una pintura, una escena) se expresa el yo. ${ }^{[4]}$ 
Los adultos mayores internados mejoraron en los tres aspectos evaluados (autoestima, depresión y estrés) con la aplicación de las terapias complementarias de teatro y risa. Estas terapias ya han demostrado sus beneficios en diferentes estudios y por medio de ellas se aprecia que las personas exteriorizan sus emociones, expresan sus propias vivencias y simbolizan de algún modo las experiencias de sus realidades. ${ }^{[4]}$

El teatro permite crear una forma de expresar y representar los problemas emocionales, a su vez que logra una mejor integración interpersonal, puesto que a través de la creatividad y la comunicación se presenta un aumento en la desinhibición, la asertividad y la confianza en sí mismo y en el otro, todo lo cual favorece a la calidad de vida. ${ }^{[10]}$ Por medio del teatro aumentan las capacidades psicológicas, ${ }^{[4]}$ concepto que coincide con los resultados de este estudio. Además, la expresión corporal, debido a su enfoque holístico, es un tipo de actividad física integral que favorece, como se ha demostrado, el aumento de la autoestima, una mayor frecuencia cardiaca y el apoyo social, todo lo cual se convierte en bienestar psicológico para los adultos mayores ${ }^{[7]}$.

Las ventajas de las terapias complementarias son múltiples, incluidos en ellas los tres aspectos de este estudio (autoestima, depresión y estrés en adultos mayores). Y con esto concuerdan otros autores: Lachira $^{[20]}$ demostró que por medio de la risoterapia aplicada a personas mayores sube la autoestima; Jaimes y col. ${ }^{[13]}$ reportaron que esta terapia disminuye el estrés; y también la depresión disminuye entre los adultos mayores. ${ }^{[14,15,16]}$

El humor produce efectos psicológicos y fisiológicos que son similares a los beneficios del ejercicio aeróbico. ${ }^{[18]}$ Algunos estudios concluyen que la actividad física mejora la autoestima ${ }^{[7,8]}$ y que los adultos mayores activos son más felices que los sedentarios. ${ }^{[9]}$ Por tanto, como se infiere en esta investigación, es beneficioso aplicar esta terapia.

Se pudo hallar, asimismo, que la autoestima, la depresión y el estrés mejoraron de acuerdo con el grado de escolaridad; Blanco y col..6] hallaron que el nivel educativo tiene relaciones positivas con la actividad física; y en este estudio la mejora en los puntajes de las escalas aplicadas es clara para los adultos que alcanzaron a hacer la primaria completa o 
algún grado de esta, aunque no fue así para los de mayor grado educativo, posiblemente por el bajo número de participantes con esta escolaridad (esto no permite observar los efectos de las terapias en ellos).

También se halló un cambio significativo en el incremento de la autoestima en los menores de 75 años, lo cual concuerda con el estudio antes mencionado, ${ }^{[6]}$ según el cual la actividad física presenta correlaciones negativas con la edad. Por otro lado, se incrementó en forma significativa la autoestima en los hombres, mientras en el género femenino hubo un descenso importante del estrés.

Aunque la autoestima, la depresión y el estrés mejoraron con la aplicación del teatro y la risoterapia, esta última mejoró más la autoestima, mientras el teatro mejoró más el estrés.

Finalmente, hay que reiterar que el adulto mayor es más vulnerable que las otras poblaciones etarias por el padecimiento de enfermedades y la pérdida del trabajo, de familiares y amigos, y esta vulnerabilidad se acentúa con la internación; ${ }^{[1]}$ por ende, las terapias complementarias deberían aplicarse más en esta población, de suerte que se constituya en un elemento preventivo y en una opción en los tratamientos alternativos.

\section{Conclusiones}

Terapias complementarias como el teatro y la risa generan efectos benéficos en la salud mental de los adultos mayores; además, su aplicación es de bajo presupuesto y no requiere mayor esfuerzo físico. Por todo esto debería masificarse su aplicación.

Desafortunadamente, su aplicación aún no es la esperada según los buenos resultados reportados en diferentes estudios (la terapia de la risa ha sido más aplicada y documentada que la del teatro). Con este panorama, es importante seguir estudiándolas dentro de la promoción y prevención de la salud de distintas poblaciones para evaluar sus efectos y encaminar aún más su desarrollo y aplicación por distintos profesionales. 
En estudios futuros sería pertinente estudiar muestras de mayor heterogeneidad y tamaño con el fin de ampliar la información sobre los beneficios de estas terapias complementarias en la salud integral de las personas adultas.

\section{Referencias}

1. Rodríguez N. Factores que influyen sobre la calidad de vida de los ancianos que viven en geriátricos. Psicología y Psicopedagogía. Publicación virtual de la Facultad de Psicología y Psicopedagogía de la USAL. 2007; 17: 1-8. Disponible en: http://psico.usal.edu.ar/archivos/psico/otros/factores_que_influyen_ sobre_la_calidad_de_vida.pdf

2. Cerquera AM. Relación entre los procesos cognitivos y el nivel de depresión en las adultas mayores institucionaliza-das en el asilo San Antonio de Bucaramanga. Univ. Psychol. 2008; 7 (1): 271-281. Disponible en: http://www.scielo.org.co/pdf/rups/v7n1/v7n1a20.pdf

3. Martín R. Actividad física y calidad de vida en el adulto mayor. Una revisión narrativa. Rev. Haban. Cienc. Méd. 2018; 17 (5): 813-825. Disponible en: http://www.revhabanera.sld.cu/index.php/rhab/article/view/2418

4. Ruiz C, Rojo C, Ferrer M, Jiménez L, Ballesteros M. Terapias complementarias en los cuidados. Humor y risoterapia. Index Enferm. 2005; 14 (48-49): 37-41. Disponible en: http://scielo.isciii.es/scielo. php?script=sci_arttext\&pid=S1132-12962005000100008

5. Rodríguez V. El mejoramiento de la salud a través de la expresión corporal: un enfoque holístico. Rev. Reflexiones. 2008; 87 (1): 127-137. Disponible en https://revistas.ucr.ac.cr/index.php/reflexiones/article/view/11490/10836

6. Blanco M, Salazar M. Predictores socioemocionales y cognitivos: su papel en la comprensión del envejecimiento con éxito en el contexto costarricense. Universitas Psychologica. 2017; 16 (1): 1-16. Disponible en: http://dx.doi.org/10.11144/Javeriana.upsy16-1.pscc 
7. García A, Marín M, Bohórquez M. Autoestima como variable psicosocial predictora de la actividad física en personas mayores. Revista de Psicología del Deporte. 2012; 21 (1): 195-200. Disponible en: https://www.redalyc.org/pdf/2351/235124455026.pdf

8. Organización Panamericana de la Salud. La salud de los adultos mayores: una visión compartida. 2011; 11-293. Disponible en: https:// iris.paho.org/bitstream/handle/10665.2/51598/9789275332504_spa. pdf?sequence $=1 \&$ isAllowed $=y$

9. Bohórquez $\mathbf{M}$, Lorenzo M, García A. Felicidad y actividad física en personas mayores. Escritos de Psicología. 2013; 6 (2): 6-12. Disponible en: https://www. redalyc.org/pdf/2710/271028444002.pdf

10. Rodríguez F, Caballero N, Martin P. Dramaterapia en personas con trastorno mental grave. Norte de Salud Mental. 2014; 12 (50): 13-20. Disponible en: https://psiquiatria.com/article.php?ar=tratamientos\&wurl=dramaterap ia-en-personas-con-trastorno-mental-grave

11. Martín J. El uso de la risa y el humor en psicoterapia. 2002; 1-9. Disponible en: https://www.fundacionforo.com/uploads/pdfs/archivo26.pdf

12. Christian R, Ramos J, Susanibar C, Balarezo G. Risoterapia: un nuevo campo para los profesionales de la salud. Rev. Soc. Per. Med. Inter. 2004; 17 (2): 57-63. Disponible en:

http://files.risoterapia-adultos.webnode.cl/200000005-bfa03c0997/a05.pdf

13. Jaimes J, Claro A, Perea S, Jaimes E. La risa, un complemento esencial en la recuperación del paciente. Med. Uis. 2011; 24 (1): 91-95. Disponible en: https://revistas.uis.edu.co/index.php/revistamedicasuis/article/ view/2584/2906

14. Villamil M, Quintero A, Henao E, Cardona J. Terapia de la risa en un grupo de mujeres adultas. Rev. Fac. Nac. Salud Pública. 2013; 31 (2): 202-208. Disponible en: http://www.scielo.org.co/pdf/rfnsp/v31n2/v31n2a06.pdf

15. Martos F. Revisión teórica sobre el efecto del sentido del humor y la risa en el estrés, la ansiedad y la depresión. [Tesis]. Universidad de Jean. Andalucía. 2018. Disponible en: http://tauja.ujaen.es/bitstream/10953.1/8308/1/Martos_ Alcantara_Francisco_Jose_TFM.pdf 
16. Quintero A, Henao M, Villamil M, León J. Cambios en la depresión y el sentimiento de soledad después de la terapia de la risa en adultos mayores internados. Biomédica. 2015; 35: 90-100. Disponible en: http://www.scielo. org.co/pdf/bio/v35n1/v35n1a12.pdf

17. Cusco L. Efectos emocionales que produce la risoterapia en pacientes geriátricos con depresión en la casa hogar Miguel León Cuenca, septiembre 2017-febrero 2018. [Tesis]. Universidad Católica de Cuenca. Cuenca. 2018. Disponible en: http://186.5.103.99/bitstream/reducacue/8214/1/9BT2018ETI35.pdf

18. Santos $\mathbf{P}$, Moro L, Jenaro C. Desarrollo de un taller de risoterapia con un grupo de personas mayores. Rev. Fac. Nac. Salud Pública. 2018; 36 (1): 17-26.

19. Angulo G, Trujillo J. Efectividad del taller de risoterapia "Magia en Acción Margrey" en el control de la depresión del adulto mayor en el Centro Geronto Geriátrico Ignacia Rodulfo vda. de Canevaro. [Tesis]. Universidad Privada Norbert Wiener. Lima. 2016. Disponible en: http://repositorio.uwiener.edu.pe/xmlui/ bitstream/handle/123456789/2211/TITULO\%20-\%20Gracy\%20Irene\%20 Angulo\%20Rojas.pdf?sequence=1\&isAllowed $=\mathrm{y}$

20. Lachira L. Risoterapia: intervención de enfermería en el incremento de la autoestima en adultos mayores del club “Mis Años Felices”. 2013. [Tesis]. Universidad Nacional Mayor de San Marcos. Lima. 2014. Disponible en: https:// core.ac.uk/download/pdf/323352514.pdf

21. Lindozzi M. La risa y el humor en la vejez. [Tesis]. Universidad Abierta Interamericana. Rosario. 2013. Disponible en: http://imgbiblio.vaneduc.edu. ar/fulltext/files/TC112376.pdf

22. Bennett M, Zeller J, Rosenberg L, McCann J. The Effect of Mirthful Laughter on Stress and Natural Killer Cell Activity. Alternative Therapies. 2003; 9 (2): 38-44. Disponible en: https://digitalcommons.wku.edu/cgi/viewcontent. cgi? article $=1008 \&$ context=nurs_fac_pub

23. Carmona M. La risoterapia como complemento a otras terapias médicas. Revista de Enfermería CyL. 2015; 7 (1): 73-79. Disponible en: http://www.revistaenfermeriacyl.com/index.php/revistaenfermeriacyl/ article/view/140/126 
24. Bacca A, González A, Uribe Rodríguez A. Validación de la escala de depresión de Yesavage (versión reducida) en adultos mayores colombianos. Pensamiento Psicológico. 2005; 153-63. Disponible en: http://www.redalyc.org/articulo.oa?id=80112046006

25. Rojas C, Zegers B, Förster C. La escala de autoestima de Rosenberg: validación para Chile en una muestra de jóvenes adultos, adultos y adultos mayores. Rev. Méd. Chile. 2009; 137 (6): 791-800. Disponible en: http://dx.doi.org/10.4067/ S0034-98872009000600009

26. Campo A, Bustos G, Romero A. Consistencia interna y dimensionalidad de la escala de estrés percibido (EEP-10 y EEP-14) en una muestra de universitarias de Bogotá, Colombia. Rev. Aquichan. 2009; 9: 271-80. Disponible en: https:// www.redalyc.org/pdf/741/74112147007.pdf

27. Folstein, M, Folstein, S, McHugh, P. “Mini-Mental State”: A Practical Method for Grading the Cognitive State of Patients for the Clinician. Journal of Psychiatric Research. 1975; 12 (3): 189-198. Disponible en: https://www.sciencedirect. com/science/article/abs/pii/0022395675900266

28. Schmitt DP, Allik J. Simultaneous Administration of the Rosenberg Self-Esteem Scale in 53 Nations: Exploring the Universal and Culture-Specific Features of Global Self-Esteem. J Pers Soc Psychol. 2005; 89: 623-42. Disponible en: http://psych.ut.ee/ jyri/en/Schmitt-Allik_JPSP2005.pdf

29. Ministerio de Salud. Resolución 8430 de octubre 4 de 1993. Por la cual se establecen las normas científicas, técnicas y administrativas para la investigación en salud. Bogotá; 1993. Disponible en: https://www.minsalud. gov.co/sites/rid/Lists/BibliotecaDigital/RIDE/DE/DIJ/RESOLUCION-8430DE-1993.PDF 


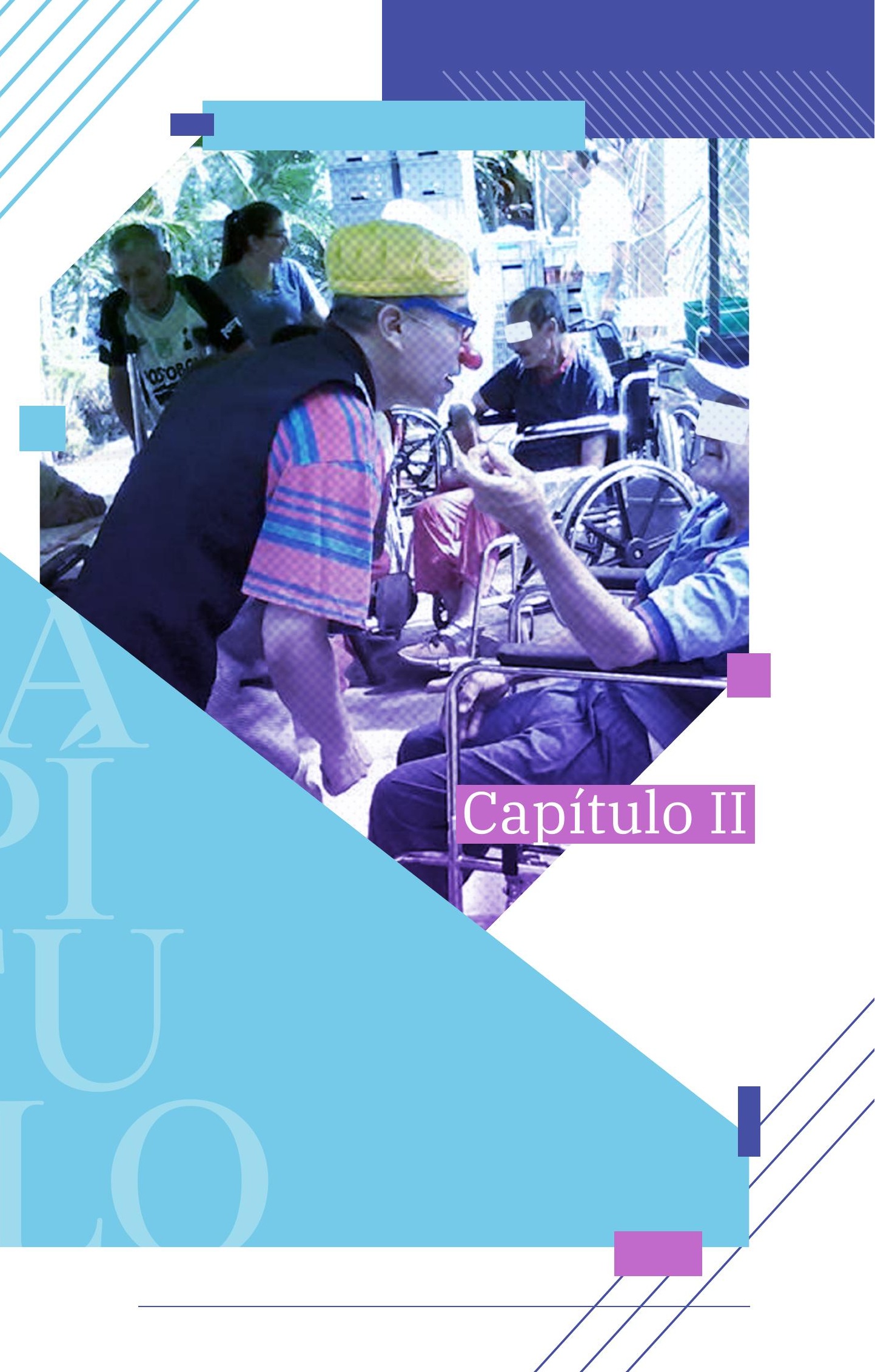




\section{Cambios fisiológicos y niveles de cortisol en adultos mayores residentes en hogares gerontológicos después de la aplicación de terapia de la risa}

María Mercedes Villamil Gallego ${ }^{1,7}$, Jairo León Cardona Jiménez², Edwin Andrés Higuita David ${ }^{3}$, María Eucaris Henao Villa ${ }^{2}$, Ángela Quintero Echeverri $^{4}$, Lina M. Ramírez Velásquez ${ }^{5}$ y José D. Domínguez Sierra ${ }^{6}$

\section{Introducción}

El uso terapéutico del humor ha crecido de manera importante. Este puede producir beneficios físicos y psicológicos en las personas ${ }^{[1]}$ al favorecer la relación emocional y social, ya que ayuda a subir las defensas y permite una buena comunicación;:[2] además, es fundamental en el trabajo creativo y posibilita tratar al individuo como parte de una totalidad que incluye lo físico, lo mental y lo espiritual.[3]

En el ambiente hospitalario, el humor favorece las relaciones entre el personal de salud y los pacientes. En el estudio de Astedt-Kurki e Isola se señaló que el humor permitió el manejo de situaciones difíciles y mejoró tanto el clima laboral como el hospitalario. ${ }^{[4]}$

Kinsman y Gregory, en su estudio con pacientes moribundos, mostraron que el humor favoreció las relaciones terapéuticas y alivió la

\footnotetext{
1 Facultad de Humanidades y grupo GISAM, Uniremington.

2 Facultad de Ciencias de la Salud y grupo GISAM, Uniremington.

3 Universidad del Sinú.

4 Grupo GISAM.

5 Clínica León XIII.

6 Institución de cuarto nivel de complejidad.

7 Contacto: mercevill@hotmail.com
} 
tensión, destacaron su función dinamizadora y el hecho de que esté ligado a proteger la dignidad y el sentido vital. ${ }^{[5]}$

En un estudio realizado por Kimata ${ }^{[6]}$ se encontró que la risa puede aumentar la hormona de la melatonina y en los lactantes puede disminuir las alergias. Otro estudio realizado por el mismo autor mostró que ver películas humorísticas redujo significativamente la capacidad de respuesta bronquial y puede ser útil para el tratamiento del asma. ${ }^{[7]}$

Los efectos benéficos de la terapia de la risa se presentan en el ámbito psicosocial y en la salud; también se han obtenido resultados favorables en pacientes hospitalizados, tanto niños como adultos; ${ }^{\left[{ }^{[8]}\right.}$ y además se ha demostrado que impacta en la salud mediante la reducción de la depresión y el aumento de la satisfacción con la vida. ${ }^{[9]}$

Bennett y col. hallaron que participantes en un grupo de humor disminuyeron de manera importante el estrés; además, que la risa fue el principal factor para el aumento de la inmunidad. ${ }^{[10]}$

Asimismo, se ha mostrado que el alivio del estrés en pacientes mejora la comunicación de estos con el personal médico. ${ }^{[11]}$ Berk y col. realizaron un estudio en 10 pacientes: ellos debían ver un video de humor por 60 minutos y a cada paciente se le midieron los niveles de diferentes hormonas, tales como la epinefrina, la dopamina y el cortisol, con el fin de comprobar la eficacia de la terapia de la risa. Un grupo de cinco pacientes vio el video, mientras otro grupo no lo hizo. Al final del estudio pudieron concluir que dicha terapia disminuyó los niveles séricos de cada una de las hormonas, en contraste con el grupo control, en el cual se mantuvieron iguales. ${ }^{[12]}$ Por otra parte, Chang y col. realizaron un estudio aleatorizado, prospectivo y experimental con adolescentes: un grupo asistió a una terapia de la risa y el grupo de control se quedó leyendo o haciendo sus deberes; los autores encontraron que el estado de ánimo y el humor mejoraron en el grupo de la terapia y que disminuyeron los niveles de cortisol. ${ }^{[13]}$

En otro estudio se llevó a cabo un ensayo clínico que consistía en estudiar si la risa puede reducir la hiperinflación a través de esfuerzos respiratorios repetitivos en los pacientes con EPOC grave. Tomaron 19 pacientes con esta patología y 10 controles sanos y observaron que el 
humor fue capaz de reducir la hiperinflación debido a la disminución del volumen residual. ${ }^{[14]}$

Igualmente, en un estudio con pacientes diabéticos se comprobó que la terapia de la risa puede ser utilizada como tratamiento farmacológico para la prevención de complicaciones microvasculares diabéticas. ${ }^{[15]}$ Otra investigación evaluó el efecto de la risoterapia en el manejo del dolor en pacientes pediátricos postoperados de apendicectomía y pacientes que reciben tratamiento farmacológico y concluyó que tiene un impacto equitativo a la administración del medicamento; adicionalmente, quienes participaron de la terapia tuvieron una disminución de la frecuencia respiratoria y un aumento de la saturación de oxígeno, al contrario de lo que sucede con el fármaco. ${ }^{[16]}$

En Pereira se hicieron 108 intervenciones de terapia de la risa en dos hospitales: el resultado fue un mejor ambiente hospitalario y una satisfacción por parte del personal de salud, de los niños y de sus familias. ${ }^{[17]}$ Otro estudio de Sánchez y Col midió el cortisol antes y después de la terapia de la risa en 306 niños hospitalizados y halló que puede disminuir el estrés, además de contribuir a una mejor respuesta para el tratamiento asignado. ${ }^{[18]}$

En Envigado ya se había realizado un estudio cualitativo con mujeres adultas mayores. Este resaltó como principales beneficios de la terapia una mirada más positiva, aceptación de la realidad, mayor agrado del acompañamiento familiar e incremento de la confianza en los demás. ${ }^{[19]}$

Dado lo anterior, el presente estudio pretende identificar algunos cambios fisiológicos tales como astenia, adinamia, incontinencia urinaria, presión arterial y frecuencia respiratoria, entre otros, e identificar cambios psicológicos y en el nivel de cortisol después de la aplicación de la terapia de la risa en adultos mayores institucionalizados en dos centros gerontológicos de Antioquia (Colombia). 


\section{Metodología}

\section{Tipo de estudio}

Exploratorio con metodología cuasiexperimental.

\section{Población de estudio}

24 adultos mayores de dos centros gerontológicos de Antioquia, uno de Medellín y otro de Envigado.

\section{Consideraciones éticas}

A los participantes se les informaron los objetivos, beneficios y riesgos de la aplicación de la terapia de la risa y se tomó el consentimiento informado; el estudio es considerado con riesgo mínimo[20] y fue aprobado por el Comité de Ética de la Corporación Universitaria Remington.

\section{Variables}

Demográficas: Edad, género, estado civil, procedencia, lugar de institucionalización, antecedentes patológicos, antecedentes familiares; síntomas relacionados directamente con la actividad somática de los participantes y su estado de ánimo: Astenia, adinamia, hiporexia, pérdida de peso; síntomas relacionados con su dimensión mental: Culpa, tristeza, vacío, llanto, ideas de muerte, ideas delirantes; manifestaciones orgánicas: Fiebre, palpitación, dolor precordial, disnea, diarrea, constipación, dolor abdominal, incontinencia, mialgia, artralgia, memoria, parestesia, cefalea; signos vitales: Pulso, frecuencia cardiaca, frecuencia respiratoria, presión arterial, temperatura, saturación de oxígeno y cortisol. 


\section{Criterios de inclusión}

Mayores de 60 años residentes en el hogar gerontológico con capacidad de responder las preguntas realizadas en el interrogatorio médico.

\section{Criterios de exclusión}

Pacientes medicados con cortisol (hidrocortisona), acetona, dexametasona, estrógenos, anovulatorios, carbamazepina, reserpina, salicilato, levodopa, inhibidores de MAO, metirapona.

Pacientes con patologías asociadas como síndrome de Cushing, síndrome adrenogenital, acromegalia, tumor e hiperplasia suprarrenal, síndrome de ACTH ectópico, panhipopituitarismo, insuficiencia suprarrenal (déficit de 21-hidroxilasa), enfermedad de Addison. Además, pacientes en duelo (pérdida afectiva cercana y reciente), dolor, trastornos del sueño, con cualquier déficit cognitivo (alzhéimer, demencia senil, entre otros) o con glaucoma.

\section{Métodos}

Se aplicaron ocho sesiones de terapia de la risa, una cada semana (de entre 10 y 15 minutos) con el apoyo del grupo de Payasos Hospitalarios de la Fundación Mediclaun. Los estudiantes de Medicina de la Corporación Universitaria Remington hicieron tres tomas de cortisol vía intravenosa: originalmente tomaron cortisol e hicieron un examen médico para conocer referidos y signos vitales. Después de las ocho sesiones aplicaron la segunda toma de cortisol y efectuaron nuevamente el examen médico. Un mes después hicieron una tercera toma.

\section{Análisis estadístico}

Se utilizó el paquete SPSS versión 21 para Windows. En el análisis univariado se emplearon frecuencias absolutas y proporciones. Dada la distribución normal de los datos (prueba de Shapiro-Wilk), se utilizaron pruebas paramétricas para la comparación de los dos momentos; se 
empleó la prueba CHI cuadrado y estadístico de Fisher para las variables nominales y el indicador t de student para la diferencia de medias en variables cuantitativas. El nivel de significación se fijó en $p \leq 0,05$.

\section{Resultados}

En este estudio participaron 24 adultos mayores, la mayoría (83,3\%) menores de 75 años; el sexo predominante fue femenino (62,5\%), el 79,1\% eran solteros (Tabla $\mathbf{2 - 1}$ ).

Tabla 2-1. Datos sociodemográficos.

\begin{tabular}{|l|l|c|c|}
\cline { 2 - 4 } \multicolumn{1}{c|}{} & \multicolumn{1}{c|}{ Variable } & $\mathbf{n}$ & \% \\
\hline \multirow{3}{*}{ Edad en años } & Menor de 75 & 20 & 83,3 \\
\cline { 2 - 4 } & 75 o más & 4 & 16,6 \\
\hline \multirow{3}{*}{ Sexo } & Femenino & 15 & 62,5 \\
\cline { 2 - 4 } & Masculino & 9 & 37,5 \\
\hline \multirow{2}{*}{ gerontológico } & Envigado & 11 & 45,8 \\
\hline \multirow{2}{*}{ Estado civil } & Medellín & 13 & 54,1 \\
\hline
\end{tabular}

Los síntomas somáticos que presentaron variación positiva y significancia estadística fueron la astenia y la adinamia; dentro de los síntomas que reflejan el estado de ánimo fueron significativos la culpa, la tristeza, el vacío y el llanto; en cuanto a los signos orgánicos, fueron significativos la disnea, la constipación, la incontinencia y la memoria. Puede apreciarse también que la mitad de los adultos que manifestaron dolor general y dolor abdominal tuvo una mejoría. Los síntomas tomados en cuenta fueron los que refirieron los mayores antes de la terapia de la risa y que presentaron mejoría posterior. No fueron 
determinados los pacientes que no refirieron síntomas antes de la terapia y luego sí lo hicieron (Tabla 2-2).

Tabla 2-2. Sintomatología referida por los adultos mayores antes y después de la aplicación de la terapia de la risa.

\begin{tabular}{|c|c|c|c|c|c|c|}
\hline 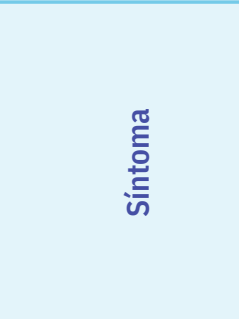 & 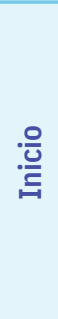 & $\begin{array}{l}\text { 흔 } \\
\frac{\pi}{\frac{\pi}{2}} \\
\frac{0}{0} \\
\sum\end{array}$ & 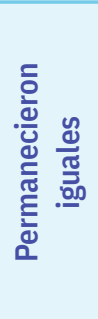 & 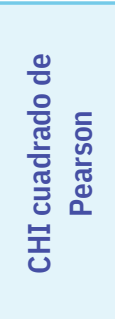 & 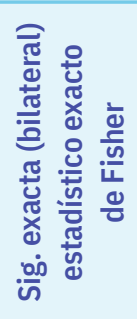 & 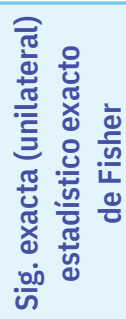 \\
\hline Culpa & 3 & 1 & 2 & 9,648 & $0,029^{*}$ & $0,029^{*}$ \\
\hline Tristeza & 12 & 2 & 10 & 6,997 & $0,015^{\star}$ & $0,011^{*}$ \\
\hline Vacío & 14 & 3 & 11 & 9,000 & $0,005^{\star}$ & $0,004^{*}$ \\
\hline Llanto & 8 & 3 & 5 & 5,029 & 0,061 & $0,039^{*}$ \\
\hline Ideas de muerte & 6 & 4 & 2 & 1,765 & 0,234 & 0,234 \\
\hline Ideas delirantes & 1 & 1 & 0 & 0,910 & 1,000 & 0,920 \\
\hline Anhedonia & 6 & 6 & 0 & 0,348 & 1,000 & 0,750 \\
\hline Astenia & 6 & 2 & 4 & 5,855 & $0,032^{*}$ & $0,032^{*}$ \\
\hline Adinamia & 7 & 2 & 5 & 6,946 & $0,017^{\star}$ & $0,017^{\star}$ \\
\hline Hiporexia & 6 & 4 & 2 & 0,758 & 0,568 & 0,366 \\
\hline Fiebre & 3 & 2 & 1 & 0,686 & 0,437 & 0,437 \\
\hline Pérdida de peso & 8 & 4 & 4 & 4,000 & 0,129 & 0,069 \\
\hline Insomnio & 7 & 3 & 4 & 3,744 & 0,134 & 0,077 \\
\hline Diaforesis & 6 & 3 & 3 & 1,000 & 0,362 & 0,302 \\
\hline Palpitaciones & 7 & 5 & 2 & 2,334 & 0,194 & 0,194 \\
\hline Dolor precordial & 6 & 3 & 3 & 4,126 & 0,078 & 0,078 \\
\hline Disnea & 6 & 1 & 5 & 11,361 & $0,003^{*}$ & $0,003^{*}$ \\
\hline Diarrea & 4 & 2 & 2 & 3,840 & 0,115 & 0,115 \\
\hline Constipación & 10 & 4 & 6 & 5,486 & $0,032^{*}$ & $0,028^{*}$ \\
\hline Dolor abdominal & 4 & 2 & 2 & 6,176 & 0,061 & 0,061 \\
\hline Incontinencia & 8 & 4 & 4 & 6,189 & $0,280^{*}$ & $0,028^{*}$ \\
\hline Mialgia & 9 & 3 & 6 & 3,703 & 0,092 & 0,067 \\
\hline
\end{tabular}




\begin{tabular}{|c|c|c|c|c|c|c|}
\hline $\begin{array}{l}\stackrel{\widetilde{\Xi}}{\Xi} \\
\stackrel{\stackrel{0}{*}}{\text { ज }}\end{array}$ & 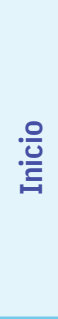 & $\begin{array}{l}\frac{5}{0} \\
\frac{\pi}{\frac{\pi}{2}} \\
\frac{0}{2} \\
\end{array}$ & 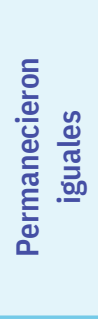 & 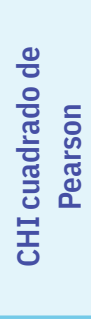 & 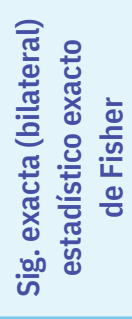 & 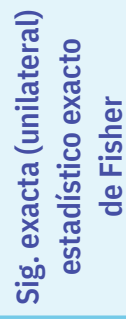 \\
\hline Artralgia & 14 & 5 & 9 & 4,608 & 0,047 & 0,040 \\
\hline Memoria & 9 & 1 & 8 & 8,711 & $0,009^{*}$ & $0,005^{*}$ \\
\hline Parestesias & 11 & 6 & 5 & 0,001 & 1,000 & 0,647 \\
\hline Cefalea & 4 & 2 & 2 & 2,476 & 0,179 & 0,179 \\
\hline
\end{tabular}

Solo se encontró significancia estadística en la frecuencia respiratoria (12 la tenían aumentada) y $10(83,3 \%)$ mejoraron posterior a la terapia con una disminución en promedio de 22 respiraciones por minuto a 16. No se encontró significancia estadística en el resto de los signos vitales, pero se logró observar lo siguiente: tres pacientes que tenían la presión arterial sistólica aumentada al inicio $(162,7$ mmHg en promedio) presentaron mejoría (120,7 mmHg en promedio); otro paciente tenía el valor del pulso alterado inicialmente y presentó mejoría también luego de la terapia. En cuanto a la saturación de oxígeno, nueve pacientes tenían alteración al inicio, con un promedio del 91\%, y cinco presentaron mejoría después de la terapia de la risa con un promedio del $93 \%$ (Tabla 2-3). 
Tabla 2-3. Cambio en los signos vitales en los adultos mayores después de la aplicación de la terapia de la risa.

\begin{tabular}{|c|c|c|c|c|c|c|c|}
\hline 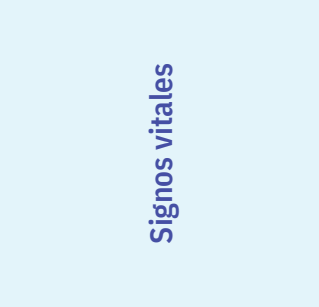 & 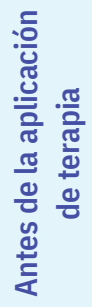 & 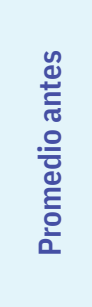 & $\begin{array}{l}\text { 흔 } \\
\frac{\pi}{\frac{\pi}{0}} \\
\frac{0}{\Sigma}\end{array}$ & $\begin{array}{l}\text { 응 흔 } \\
\text { 흘 } \\
\text { 혼 } \\
\text { 을 }\end{array}$ & 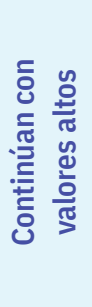 & 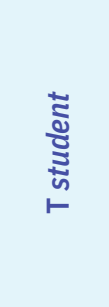 & $\frac{2}{\frac{1}{\pi}}$ \\
\hline $\begin{array}{l}\text { Presión arterial sistólica } \\
\text { > de } 140 \text { mmHg }\end{array}$ & 3 & 162,7 & 3 & 120,7 & 0 & 3,772 & 0,064 \\
\hline $\begin{array}{l}\text { Presión arterial } \\
\text { diastólica. De } 90 \text { mmHg }\end{array}$ & 1 & 90 & 1 & 96 & 2 & $-1,065$ & 0,298 \\
\hline Pulso > 100 lpm & 1 & 101 & 1 & 57 & 0 & $-0,661$ & 0,516 \\
\hline $\begin{array}{l}\text { Frecuencia respiratoria } \\
>20 \text { rpm }\end{array}$ & 12 & 22,4 & 10 & 16,5 & 2 & 7,209 & $0,000^{*}$ \\
\hline PSO2 (<92\%) & 8 & 91 & 5 & 93 & 3 & $-1,402$ & 0,204 \\
\hline
\end{tabular}

En cuanto a los valores del cortisol, se logra observar en las mujeres (entre la primera toma, antes de la terapia de la risa, y la segunda toma, posterior a la misma) un aumento, para luego descender en la tercera toma (un mes después). Por otra parte, los hombres y adultos menores de 75 años tienen un descenso progresivo de los niveles del cortisol con la risoterapia. En los pacientes que eran viudos se observó una disminución progresiva, mientras que en los solteros se observó un leve aumento en la segunda toma, con posterior disminución marcada en la tercera. Finalmente, los adultos provenientes de Envigado tuvieron disminución progresiva de los niveles de cortisol, mientras que los de Medellín tuvieron aumento en la segunda toma y disminución en la tercera (Tabla 2-4). 
Tabla 2-4. Cambios en el cortisol posterior a terapia de la risa.

\begin{tabular}{|c|c|c|c|c|}
\hline & \multirow{3}{*}{$\begin{array}{c}\text { Cortisol } 1 \mu \mathrm{g} / \mathrm{dl} \\
8,927\end{array}$} & \multirow{3}{*}{$\begin{array}{c}\text { Cortisol } 2 \mu \mathrm{g} / \mathrm{dl} \\
10,200\end{array}$} & \multirow{3}{*}{$\begin{array}{c}\text { Cortisol } 3 \boldsymbol{\mu g} / \mathrm{dl} \\
8,960\end{array}$} \\
\hline & & & & \\
\hline \multirow{2}{*}{ Sexo } & Femenino & & & \\
\hline & Masculino & 9,433 & 8,644 & 7,678 \\
\hline \multirow{2}{*}{ Edad en años } & Menor de 75 & 8,150 & 7,975 & 7,350 \\
\hline & 75 o más & 9,310 & 9,945 & 8,705 \\
\hline \multirow{2}{*}{ Estado civil } & Soltero & 9,132 & 9,974 & 8,668 \\
\hline & Viudo & 9,060 & 8,260 & 7,760 \\
\hline \multirow{2}{*}{$\begin{array}{l}\text { Lugar del centro } \\
\text { gerontológico }\end{array}$} & Envigado & 11,073 & 9,973 & 9,245 \\
\hline & Medellín & 7,462 & 9,315 & 7,831 \\
\hline
\end{tabular}

\section{Discusión}

La terapia de la risa es un desafío a la labor de siempre, a la rutina repetida que hace en el individuo un molde, un molde que le impide explorar dimensiones, verse diferente y actuar diferente. Incluso, esta terapia a cada momento está diciéndoles a las técnicas tradicionales de salud "ey, hay maneras muy efectivas que ayudan a los tratamientos de los pacientes y que favorecen las apuestas para su salud".

En este orden de ideas, los resultados significativos que mejoraron, como el de la astenia (sensación de debilidad) y la adinamia (extrema debilidad muscular que impide los movimientos), están relacionados también con aspectos anímicos como la culpa, la tristeza, el vacío, el llanto, síntomas que mejoraron significativamente en este estudio y que forman parte de aquello que tantas veces se oculta, pero que es clave a la hora de preguntarse por el ser.

Dichos resultados concuerdan, por otro lado, con la investigación de Hirsch y col., ${ }^{[21]}$ quienes en su trabajo con adultos mayores deprimidos y después de sesiones de terapia de la risa hallaron en su población más satisfacción con la vida y resiliencia. Asimismo, Mota y col. ${ }^{[22]}$ en su estudio encontraron aumento de la felicidad, el humor, y disminución de la depresión. 
Además, entre los adultos que manifestaron dolor general y dolor abdominal, el $50 \%$ mejoró después de la terapia, lo que concuerda con lo hallado por Osorio y col..[16] estos autores concluyeron que disminuyó la frecuencia respiratoria y aumentó la saturación de oxígeno (el $83,3 \%$ de los adultos mayores mejoraron en estos aspectos con diferencias significativas).

Los cambios significativos corporales como la disnea (dificultad para respirar), constipación, incontinencia y memoria también mejoraron en este estudio, lo que demuestra que de algún modo varios sistemas del cuerpo humano pueden favorecerse (el sistema respiratorio, el urinario), y otros aspectos como la memoria. Beneficios para la salud también fueron reportados por el estudio de Hirosaki y col., ${ }^{[23]}$ quienes hallaron mejoría en la salud de 27 adultos mayores después de unas sesiones de risa y ejercicios durante tres meses.

Posterior a la terapia de la risa se presentó disminución progresiva de los niveles de cortisol en los hombres y en los menores de 75 años; asimismo, una disminución progresiva en el centro gerontológico de Envigado en comparación con el de Medellín, donde hubo un leve aumento en la segunda toma. Esta situación podría explicarse porque gran parte de los adultos mayores de Medellín pertenece a estratos bajos, lo cual genera más estrés, mientras que los de Envigado están en un centro gerontológico privado. La disminución en los niveles de cortisol se relaciona en lo hallado por Vlachopoulos y col.,, ${ }^{[24]}$ quienes mostraron que 18 personas, después de ver películas de humor, lograron disminuir sus niveles de cortisol, y que se puede mejorar la función arterial.

Similares resultados fueron hallados por Toda y col.,"25] quienes en las 11 personas que estudiaron vieron que después de una película cómica disminuyó el estrés. ${ }^{[24]}$ Igualmente, se presentó disminución del cortisol en otros estudios. ${ }^{[10,12,13]}$

Por otra parte, el equipo de trabajo se cuestiona sobre aquellos pacientes que tuvieron niveles de cortisol aumentados: los mayores de 75 años y las mujeres. Es claro que dichas mujeres pertenecían a un centro gerontológico financiado por el Estado, mientras que el otro centro es particular y muchas personas se costean su propia estadía. 
Sin embargo, es importante preguntar lo siguiente: ¿qué aspectos en los pacientes de edad avanzada y sobre todo en el género femenino dificultan la disminución del estrés? Será necesario indagar en estudios posteriores.

Como una aproximación a la respuesta, podría inferirse que la vida en una institución implica para el adulto mayor muchos aspectos nuevos que no siempre son aceptados favorablemente. Guevara ${ }^{[26]}$ refiere que para los adultos institucionalizados hay muchos aspectos conflictivos como la adaptación, la ruptura de relaciones sociales y familiares, la rutina que se vive dentro de los espacios, la pérdida de la libertad, entre otros, que si bien promueven condiciones óptimas, no siempre les permiten sentirse a gusto consigo mismos.

\section{Limitaciones}

Los adultos mayores institucionalizados presentaron en oportunidades muchas variaciones en su estado de ánimo: en momentos estaban dispuestos a recibir la terapia y en otros momentos mostraban resistencias. Por otra parte, la toma de la sangre para medir el cortisol también generó resistencia por mitos ligados con la pérdida de la salud.

\section{Conclusiones}

La terapia de la risa disminuyó la astenia, la adinamia, aspectos anímicos como la culpa, la tristeza, el vacío, el llanto, además de dolor general y dolor abdominal, la disnea, la frecuencia respiratoria y los niveles de cortisol en los adultos mayores; así que debería aplicarse con más frecuencia, puesto que como terapia complementaria no solo proporciona bienestar físico, sino también psicológico.

La literatura acompaña dichos hallazgos, pero también revela que en Colombia hace falta realizar más estudios que acerquen a las realidades e invertir en este tipo de terapias en pro de una mejor calidad de vida. 
Reírse es fácil: hay que propiciar las condiciones para todos; los adultos institucionalizados, por su condición, tienen más retos, necesitan terapias como estas. Falta que se invierta aún más.

\section{Referencias}

1. Gelkopf M. The Use of Humor in Serious Mental Illness: A Review. EvidenceBased Complementary and Alternative Medicine. 2011; 1-8. Disponible en: http://downloads.hindawi.com/journals/ecam/2011/342837.pdf

2. Brandon M, Savage H, Lujan L, Thipparthi R, DiCarlo S. Humor, Laughter, Learning, and Health! A brief Review. Adv. Physiol. Educ. 2017; 41: 341347. Disponible en: https://journals.physiology.org/doi/pdf/10.1152/ advan.00030.2017

3. Astudillo W, Mendinueta C. El efecto terapéutico del buen humor en los cuidados paliativos: a propósito de Patch Adams (1998) y Planta 4. ${ }^{a}$ (2003). Rev. Med. Cine. 2009; 5: 3038. Disponible en: https://revistas.usal.es/index. php/medicina_y_cine/article/view/15918/16410

4. Astedt-Kurki P, Isola A. Humour Between Nurse and Patient, and Among Staff: Analysis of Nurses' Diaries. J. Adv. Nurs. 2001; 35 (3): 452-458.

5. Kinsman Dean R, Gregori DM. Humor and Laughter in Palliative Care: An Ethnographic Investigation. Palliat Support Care. 2004; 2 (2): 139-148

6. Kimata H. Laughter Elevates the Levels of Breast-Milk Melatonin. J. Psychosom Res. 2007; 62 (6): 699-702.

7. Kimata H. Effect of Viewing a Humorous vs. Non humorous Film on Bronchial Responsiveness in Patients with Bronchial Asthma. Physiol. Behav. 2004; 81 (4): 681-684.

8. Jaimes J, Claro A, Pere S, Jaimes E. La risa, un complemento esencial en la recuperación del paciente. Medicas UIS. 2011; 24 (1): 91-95. Disponible en: https://revistas.uis.edu.co/index.php/revistamedicasuis/article/ view/2584/2906

9. Shahidi M, Mojtahedi A, Modabbernia A, Mojtahedi M, Shafiabady A, Delavar A, Honari H. Laughter Yoga Versus Group Exercise Program in Elderly Depressed Women: a Randomized Controlled Trial. Int. J. Geriatr. Psychiatry. 2011; 26: 322-327. Disponible en: https://onlinelibrary.wiley.com/doi/ abs/10.1002/gps.2545 
10. Bennett M, Zeller J, Rosenberg L, McCann J. The Effect of Mirthful Laughter on Stress and Natural Killer Cell Activity. Alternative Therapies. 2003; 9 (2): 38-44. Disponible en: https://digitalcommons.wku.edu/cgi/viewcontent. cgi?article=1008\&context=nurs_fac_pub

11. Bennett H. Humor in Medicine. South Med. J. 2003; 96: 1257-61. Disponible en: https://www.utmb.edu/gem/pdfs/humor_in_medicine.pdf

12. Berk L, Tan S, Fry W, Napier B, Wei Lee J, Hubbard R, Lewis J, Eby Less W. Neuroendocrine and Stress Hormone Changes During Mirthful Laughter. Am. J. Med. Sci. 1989; 298: 391-396.

13. Chang C, Tsai G, Hsieh CJ. Psychological, Immunological and Physiological Effects of a Laughing Qigong Program (LQP) on Adolescents. Complement Ther. Med. 2013; 21: 660-668.

14. Brutsche M, Grossman P, Muller R, Wiegand Pello J, Baty F, Ruch W. Impact of Laughter on Air Trapping in Severe Chronic Obstructive Lung Disease. Int. J. Chron. Obstruct. Pulmon. Dis. 2008; 3 (1): 185-192. Disponible en: https:// www.ncbi.nlm.nih.gov/pmc/articles/PMC2528214/

15. Nasir U, Iwanaga S, Nurun A, Urayama O, Hayashi K, Hayashi T, Kawai K, Sultana A, Murakami K, Suzuki F. Laughter Therapy Modulates the Parameters of Renin-Angiotensin System in Patients With Type 2 Diabetes. Int. J. Mol. Med. 2005; 16 (6): 1077-1081.

16. Osorio J, Torres A, Tenahua I, De-Ávila M, Morales F, García M. Efectividad de la risoterapia en manejo del dolor en pacientes pediátricos postoperados de apendicectomía. J. Health NPEPS. 2019; 4 (2): 44-57.

17. Sánchez J, Gutiérrez J, Santacruz J, Romero C, Ospina J. El humor como estrategia terapéutica en niños hospitalizados en unidades pediátricas en Pereira (Colombia). Reporte de una experiencia. Rev. Colomb. Psiquiatr. 2009; 38 (1): 99-113. Disponible en: http://www.scielo.org.co/pdf/rcp/v38n1/ v38n1a08.pdf

18. Sánchez J, Echeverri L, Londoño M, Ochoa S, Quiroz A, Romero C, Ruiz J. Effects of a Humor Therapy Program on Stress Levels in Pediatric Inpatients. Hospital Pediatrics. 2017; 7 (1): 46-54. Disponible en: https://hosppeds. aappublications.org/content/7/1/46.long

19. Villamil, M, Quintero Á, Henao E, Cardona J. Terapia de la risa en un grupo de mujeres adultas. Revista Facultad Nacional de Salud Pública. 2013; 31 (2): 202-208. Disponible en: https://pdfs.semanticscholar. org/9cad/1faf512ba61abe6576337d70967e0cf3b45c.pdf 
20. Ministerio de Salud. Resolución 8430 de octubre 4 de 1993. Por la cual se establecen las normas científicas, técnicas y administrativas para la investigación en salud. Bogotá; 1993. Disponible en: https://www.minsalud. gov.co/sites/rid/Lists/BibliotecaDigital/RIDE/DE/DIJ/RESOLUCION-8430DE-1993.PDF

21. Hirsch R, Junglas K, Lonradt B, Jonitz MF. Humortherapie bei alten Menschen mit einer Depression. Z. Gerontol Geriat. 2010; 43: 42-52.

22. Mota L, Antunes A, Alves C, López P, Severino S, Guerreiro H. Effect of Humor Intervention on Well-Being, Depression, and Sense of Humor in Hemodialysis Patients. Enferm. Nefrol. 2019; 22 (3): 256-65. Disponible en: https://www.researchgate.net/publication/335472515_Effect_ of_humor_intervention_on_well-being_depression_and_sense_of_ humor_in_hemodialysis_patients/link/5d9c69d4458515c1d39e81ea/ download

23. Hirosaki M, Ohira T, Kajiura M, Kiyama M, Kitamura A, Sato S, Iso H. Effects of a laughter and exercise program on physiological and psychological health among community dwelling elderly in Japan: Randomized controlled trial. Geriatr. Gerontol Int. 2013; 13 (1): 152-160.

24. Vlachopoulos C, Xaplanteris P, Alexopoulos N, Aznaouridis K, Vasiliadou C, Baou K. Divergent Effects of Laughter and Mental Stress on Arterial Stiffness and Central Hemodynamics. Psychosom Med. 2009; 71 (4): 446-453.

25. Toda M, Kusakabe S, Nagasawa S, Kitamura K, Morimoto K. Effect of Laughter on Salivary Endocrinological Stress Marker Chromogranin A. Biomedical Research. 2007; 28 (2): 115-118.

26. Guevara N. Impactos de la institucionalización en la vejez. Análisis frente a los cambios demográficos actuales. Entramado. 2016; 12 (1): 138-149. Disponible en: http://www.scielo.org.co/pdf/entra/v12n1/v12n1a10.pdf 


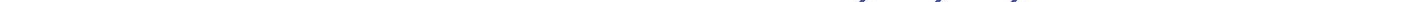




\section{Efectos clínicos de la terapia de la risa en los adultos mayores de un centro geriátrico en la ciudad de Medellín}

Juan C. Ortiz Pérez ${ }^{1}$, Julieth A. Franco Mira², Flor V. Correa Gil ${ }^{3}$, Luisa F. Arboleda Restrepo ${ }^{4}$, Jairo León Cardona Jiménez ${ }^{5}$, María Eucaris Henao

Villa $^{5}$, María Mercedes Villamil Gallego ${ }^{6}$ y Ángela Quintero Echeverri ${ }^{7}$

\section{Introducción}

En la actualidad, la salud integral constituye un indicador importante de la calidad de vida; por tanto, es necesario promocionarla, es decir, propiciar mejores condiciones para que permanezca y hacer un mayor control sobre ella con el fin de alcanzar un estado adecuado de bienestar mental, físico y social, garantizando que el trabajo y el ocio sean una fuente de salud y puedan darse condiciones de vida gratificantes. ${ }^{[1]}$

Así, entendiendo el envejecimiento como un proceso que involucra diferentes cambios fisiológicos, morfológicos, sociales, psicológicos y funcionales, se hace necesario tener en cuenta intervenciones de tipo complementario e integral, como lo es la terapia de la risa, descrita como una técnica auxiliar que, junto con otras técnicas terapéuticas, ayuda a la recuperación del paciente o previene futuros trastornos físicos y psíquicos. ${ }^{[2,3]}$

1 Hospital San Antonio del municipio de Cisneros.

2 Hospital Universitario del Caribe.

3 Grupo de investigación SAM, Uniremington.

4 Universidad del Sinú.

5 Facultad de Ciencias de la Salud y grupo GISAM, Uniremington.

6 Facultad de Humanidades y grupo GISAM, Uniremington. Contacto: mercevill@hotmail.com

7 Grupo GISAM, Uniremington. 
La práctica de la terapia de la risa es actualmente una opción que le apuesta al mejoramiento de la calidad de vida de los pacientes y que se abre camino en países como Colombia creando expectativa en la práctica médica. Esta terapia se aplica y se ha presumido su eficacia en diferentes investigaciones; de hecho, dentro de los cambios fisiológicos que genera se ha encontrado una respuesta benéfica al sistema circulatorio por la estimulación del sistema nervioso simpático, al incrementar la velocidad en el flujo sanguíneo por el aumento de la frecuencia cardiaca, lo cual permite que el corazón tenga mayor capacidad para bombear sangre: llega a entre 140 y 210 mililitros por minuto, cuando en el estado basal es 70 mililitros. ${ }^{[4,5]}$

Se ha reportado que la risoterapia disminuye las altas concentraciones de cortisol, una hormona que se libera en situaciones de estrés; por lo tanto, su reducción mejora el sistema cardiovascular. ${ }^{[6,7]}$ Algunos autores afirman que 20 minutos de carcajadas corresponden a un ejercicio cardiaco similar a tres minutos de remo. ${ }^{[8]}$

En el momento de la terapia, en la presión arterial se evidencia un leve aumento, debido al incremento de la velocidad sanguínea, ${ }^{[6,9]}$ seguido de una disminución después del episodio de risa. La tensión arterial baja, se regularizan la respiración y la digestión, pues al descender el diafragma se produce un efecto de masaje sobre el hígado y la vesícula biliar, evitando con esto complicaciones diarias como el estreñimiento. ${ }^{[7,10]}$

Debido al papel fundamental de la función pulmonar en la oxigenación de los órganos y los tejidos, la risoterapia puede mejorar la respiración por medio de la activación de músculos laríngeos y respiratorios; igualmente, produce una mayor eficiencia en la inhalación y exhalación de aire, dando como resultado una mejoría en la capacidad ventilatoria. ${ }^{[10,11]}$

La risa o la sensación de felicidad generan en el organismo la liberación de endorfinas y serotonina; así, las respuestas sistémicas a estas hormonas son más rápidas y esto, a su vez, permite que la persona que presenta síntomas como astenia, adinamia y falta de apetito asociado a su estado de ánimo mejore su capacidad para disminuirlos e, incluso, superarlos por completo. ${ }^{[12,13,14]}$ Además, la liberación de 
estas hormonas mejora sustancialmente la tolerancia al dolor como síntoma general, logrando así una expectativa en el manejo paliativo de diferentes enfermedades como la cefalea crónica.

En el ámbito neuromuscular, la risoterapia conduce a la disminución del tono muscular y a una relajación general, impactando así en las enfermedades con afección muscular, como lo son la lumbalgia crónica y fibromialgia; asimismo, hay evidencia de que tiene incidencia en el mejoramiento de la artritis reumatoide. ${ }^{[15]}$

La risa tiene un efecto positivo en el ámbito cerebral, ya que mejora la función mental, aumenta la memoria, el pensamiento creativo y la capacidad resolutiva de problemas. ${ }^{[5,16]}$ Desde la psiquiatría se han abarcado trastornos tales como la depresión, esquizofrenia, desorden bipolar, trastorno obsesivo compulsivo (TOC), estrés postraumático, trastorno de ansiedad; así modifica la percepción que tiene el paciente con respecto a sí mismo y a su entorno. ${ }^{[17,18]}$

De acuerdo con lo descrito anteriormente, se puede afirmar que la terapia de la risa favorece una serie de estímulos positivos que mejoran la sintomatología del paciente durante el padecimiento de algunas enfermedades por medio de respuestas fisiológicas con gran impacto sobre la salud. Es fundamental, eso sí, que las instituciones y los pacientes crean en este tipo de terapias.

Este trabajo pretendió identificar los efectos clínicos, es decir, los cambios en la salud de los adultos mayores después de recibir la terapia de la risa en el hogar geriátrico Colonia Belencito de la ciudad de Medellín en el año 2013, con el propósito de difundir los beneficios de este tipo de terapias en nuestro medio.

\section{Metodología}

\section{Tipo de estudio}

Exploratorio con metodología cuasiexperimental. 


\section{Población}

42 adultos mayores que habitan el centro geriátrico Colonia Belencito, ubicado en Medellín.

\section{Instrumentos utilizados}

Historia clínica de cada paciente; además, se utilizó un cuestionario, el cual fue aplicado por los estudiantes de Medicina a cada uno de los participantes. Adicional a ello, se empleó el pulsómetro para medir la frecuencia cardiaca y el tensiómetro para medir la presión arterial.

\section{Variables}

Se tomaron aquellas relacionadas directamente con la actividad somática de los participantes y su estado de ánimo (astenia, adinamia, pérdida de peso); relacionadas con su dimensión mental (depresión, ansiedad, anorexia, ideación suicida); con la manifestación de dolor (cefalea, mialgias, artralgias, disfagia, onicofagia y dolor abdominal). Además, las variables relacionadas con el sistema respiratorio y cardiovascular: disnea, cianosis, frecuencia respiratoria, frecuencia cardiaca y presión arterial. Para el sistema gastrointestinal, la constipación.

\section{Criterios de inclusión}

Mayores de 55 años, con capacidad para responder a la anamnesis, que hubieran asistido mínimo a cinco sesiones de terapia de la risa, que desearan libremente participar en ellas, que firmaran el consentimiento informado, ${ }^{[19]}$ y residentes del centro gerontológico Colonia Belencito del municipio de Medellín (Antioquia) contactadas entre abril y julio de 2013. 


\section{Criterios de exclusión}

Adultos mayores que asistieran a terapias incompletas o se mostraran inconformes con la revisión médica.

\section{Aspectos éticos}

A los adultos mayores se les informó en qué consistía el estudio y se les leyó el consentimiento informado. Los adultos firmaron conscientes de su participación. El estudio no tiene ningún riesgo para ellos.

\section{Métodos}

Se aplicaron ocho sesiones de terapia de la risa con el apoyo del grupo de Payasos Hospitalarios de la Fundación Mediclaun; cada sesión tuvo una duración entre 10 y 15 minutos, dependiendo de la aceptación y participación de los adultos. Se hizo valoración médico-clínica a quienes asistieron mínimo a cinco sesiones; la evaluación se hizo mediante anamnesis y examen físico completo con énfasis en sus patologías de base (los hicieron los estudiantes de Medicina de la Corporación Universitaria Remington) antes del inicio de las sesiones y después de terminadas. Las terapias fueron hechas por cuatro payasos hospitalarios con una amplia experiencia en su aplicación en ambientes hospitalarios.

\section{Análisis estadístico}

Se utilizó el paquete SPSS versión 21 para Windows. Para el análisis univariado se emplearon frecuencias absolutas y proporciones. Dada la distribución normal de los datos (prueba de Shapiro-Wilk), se recurrió a pruebas paramétricas para la comparación de los dos momentos, así como a la prueba CHI cuadrado, al estadístico de Fisher para las variables nominales y al indicador t de student para la diferencia de medias en variables cuantitativas. El nivel de significación se fijó en $p \leq 0,05$. 


\section{Resultados}

La población estuvo conformada por 49 adultos mayores institucionalizados, 40,8\% hombres; la edad que más se presentó está entre los 65 a los 75 años (55,1\%), con un promedio de 70; el estrato socioeconómico de los participantes predominante fue el 2 con un 46,9\%, seguido del 1 con un 30,6\%. En cuanto a la escolaridad, más de la mitad $(51 \%)$ cursaron primaria completa e incompleta. Además, dentro de estos participantes predominó el estado civil soltero, con un valor porcentual de 59,2 seguido de viudo, con un 20,4\% (Tabla 3-1).

Tabla 3-1. Variables sociodemográficas de los adultos residentes en el hogar gerontológico Colonia Belencito, Medellín, Antioquia.

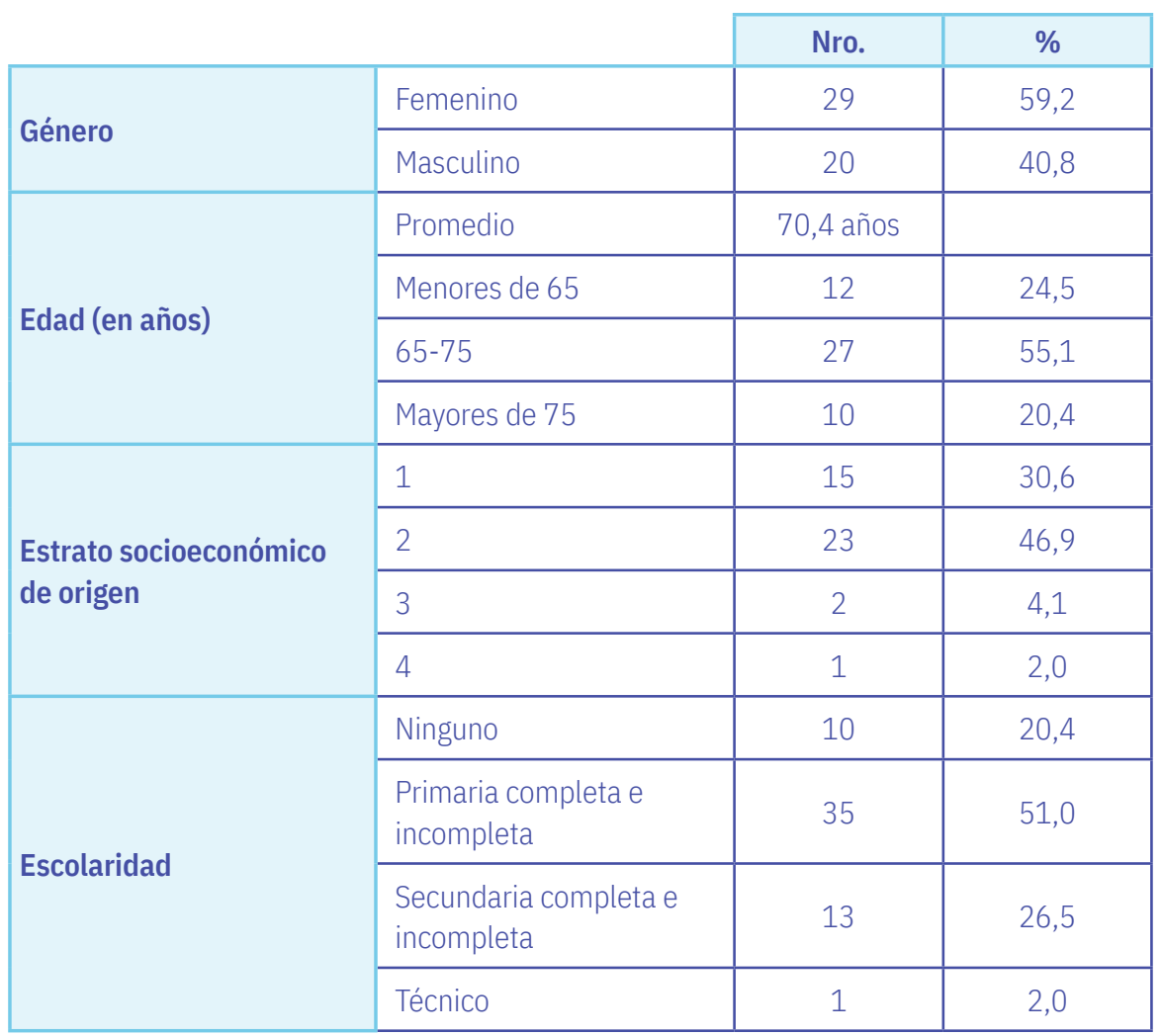


Continuación de la Tabla 3-1.

\begin{tabular}{|l|l|c|c|}
\cline { 2 - 4 } \multicolumn{2}{c|}{} & Nro. & $\%$ \\
\hline \multirow{3}{*}{ Estado civil } & Con pareja & 6 & 12,2 \\
\cline { 2 - 4 } & Separado & 4 & 8,2 \\
\cline { 2 - 4 } & Soltero & 29 & 59,2 \\
\cline { 2 - 4 } & Viudo & 10 & 20,4 \\
\hline \multirow{3}{*}{ Reciben visitas } & Sí & 27 & 55,1 \\
\cline { 2 - 4 } & No & 22 & 44,9 \\
\hline
\end{tabular}

Los signos que presentaron una variación estadísticamente significativa fueron la anorexia, ansiedad, depresión, la ideación suicida, constipación, disnea y dolor abdominal. Se consideró la respuesta de las personas a través de un cuestionario aplicado antes y después de la terapia de la risa. En la Figura 3-1 aparece cada uno de los aspectos, los que mejoraron y los que permanecieron igual.

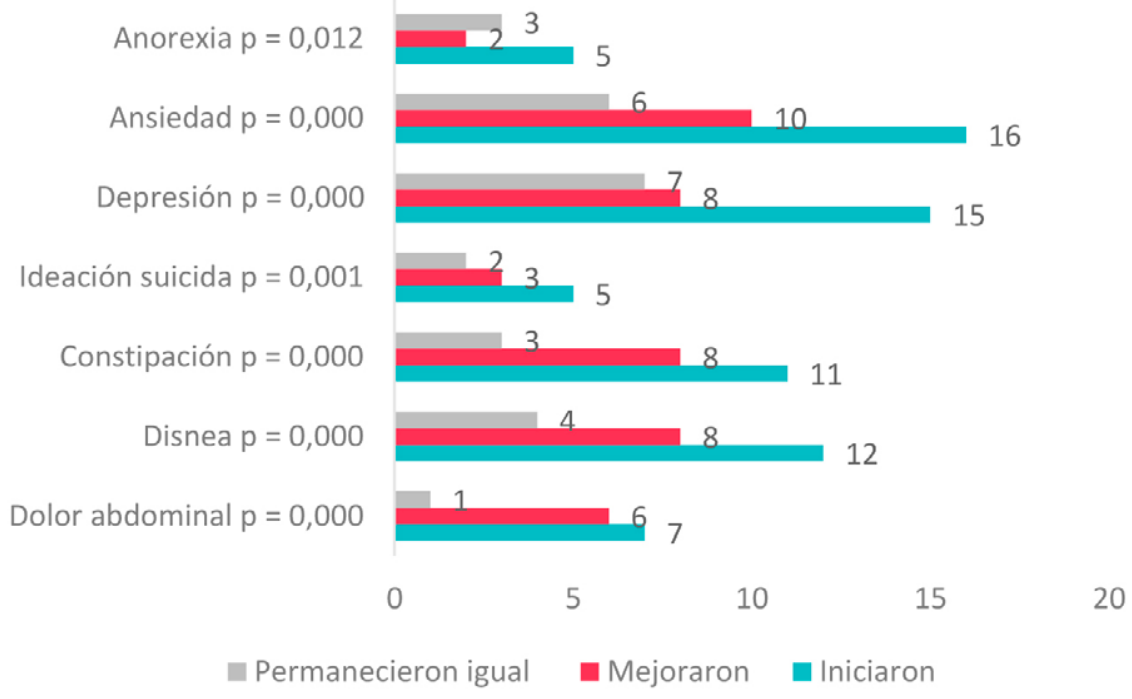

Prueba F de Fisher.

Figura 3-1. Cambio en la sintomatología en los adultos mayores después de la aplicación de la terapia de la risa. 
En cuanto a los cambios encontrados en los signos vitales después de la aplicación de la terapia de la risa, la presión arterial sistólica disminuyó el promedio de 155,83 mmHg a 118,8 mmHg y hubo mejoría en el 85,7\% de los adultos; la presión arterial diastólica disminuyó el promedio de 99,75 mmHg a 69,0 mmHg y mejoró en el 33,3\% de los participantes. Con respecto a la frecuencia respiratoria, se hallaron variaciones estadísticamente significativas: se presentó un leve aumento en el promedio y el 52,9\% de los adultos mejoraron (Tabla 3-2).

Tabla 3-2. Cambio en los signos vitales en los adultos mayores después de la aplicación de la terapia de la risa.

\begin{tabular}{|c|c|c|c|c|c|c|c|c|}
\hline \multirow{2}{*}{$\begin{array}{l}\text { Signos } \\
\text { vitales }\end{array}$} & \multirow{2}{*}{$\begin{array}{l}\text { Antes de } \\
\text { la terapia }\end{array}$} & \multirow{2}{*}{$\begin{array}{c}\text { Promedio } \\
\text { antes }\end{array}$} & \multicolumn{2}{|c|}{ Mejoraron } & \multirow{2}{*}{$\begin{array}{l}\text { Promedio } \\
\text { después }\end{array}$} & \multicolumn{2}{|c|}{$\begin{array}{l}\text { Continúan con } \\
\text { valores altos }\end{array}$} & \multirow[t]{2}{*}{ Valor $\mathrm{p}$} \\
\hline & & & N..$^{\circ}$ & $\%$ & & N. ${ }^{\circ}$ & $\%$ & \\
\hline $\begin{array}{l}\text { Presión arterial } \\
\text { sistólica > } \\
\text { de } 140 \text { mmHg }\end{array}$ & 7 & 155,8 & 6 & 85,7 & 118,8 & 1 & 14,3 & 0,006 \\
\hline $\begin{array}{l}\text { Presión arterial } \\
\text { diastólica > de } \\
90 \mathrm{mmHg}\end{array}$ & 6 & 99,8 & 4 & 66,7 & 69,0 & 2 & 33,3 & 0,007 \\
\hline $\begin{array}{l}\text { Frecuencia } \\
\text { respiratoria }\end{array}$ & 17 & 22,3 & 9 & 52,9 & 17,2 & 8 & 47,1 & 0,002 \\
\hline
\end{tabular}

\section{Discusión}

En esta investigación se pudo demostrar que la terapia de la risa impacta en el bienestar del ser humano en los ámbitos fisiológico y mental; se trata de una necesidad apremiante dado el número de adultos mayores en aumento y la pertinencia de apuestas en pro de la salud.

En el sistema digestivo se notaron cambios generales. Hubo mejoras tanto en el dolor como en la constipación; específicamente, la manifestación de dolor abdominal, pues este es consecuencia, en la mayoría de los casos, de la constipación, que se vuelve habitual en la población de adultos mayores por varios factores, entre los que se 
encuentran lentitud en los movimientos peristálticos del colon, liderada por vías de transducción de señales y mecanismos celulares que controlan la motilidad de la contracción del músculo liso intestinal, alteraciones y desgastes en el piso pélvico, disminución en las diferentes secreciones enzimáticas, con posteriores consecuencias sobre la absorción de ciertas vitaminas y oligoelementos, o una combinación de todos estos eventos. ${ }^{[20]}$

Respecto a la parte intestinal, la presencia de dolor abdominal en los adultos mayores como consecuencia de la constipación obedece a otros factores, como la presentación de alteraciones sensoriales, deterioro de la salud bucal y pérdida de los dientes, pues se produce una escasa ingesta de alimentos que aportan fibra y líquidos, acompañada de una reducida actividad física, con un consecuente descenso en el gasto energético, y todo confluye en la manifestación de dolor.

Esta mejoría es atribuible directamente a la movilidad generada por el diafragma al momento de reír, el cual por continuidad transmite dicha energía de movimiento al sistema gastrointestinal, principalmente a la primera porción del intestino delgado y al colon transverso; este último es fundamental dentro del proceso fisiopatológico de la retención o complicación en expulsión de materia fecal, catalogada constipación de origen primario; se compone de la constipación por tránsito lento, la defecación disnérgica y la constipación con predominancia del síndrome del intestino irritable, y se complementa directamente con la relajación en los movimientos respiratorios y la cantidad de energía al momento de reír, pues en esta investigación la disnea o dificultad respiratoria manifestada por los pacientes presentó una mejoría en más de la mitad de ellos. ${ }^{[7,10]}$

Por otra parte, se encontró que desde la medición de los signos vitales, el 52,9\% de los pacientes mejoraron su frecuencia respiratoria (disminuyó por debajo de 20 respiraciones por minuto) (Tabla 3-2), lo que favorece su calidad de vida y abre un ciclo de beneficios: el mejoramiento del estado de ánimo y de su condición respiratoria está directamente relacionado con el mejoramiento de los hábitos alimenticios y del hábito intestinal. ${ }^{[14]}$ 
En el sistema cardiocirculatorio se observaron cambios positivos con la disminución de la presión arterial sistólica; posterior a la aplicación de la terapia de la risa, en la medición realizada por el personal médico se encontró que un 85,7\% de los pacientes disminuyeron por debajo de 140 mmHg sus cifras tensionales para la segunda revisión (Tabla 3-2), lo que da un punto de partida para asegurar que esta terapia es efectiva, como lo han mencionado trabajos anteriores, para el control y mejoramiento de la presión arterial.

Los cambios confirman lo esperado y reportado en varios estudios que defienden el papel de la terapia de la risa en la reducción de los factores cardiovasculares, siendo el principal propósito el control de la hipertensión arterial, que inicialmente se eleva por el aumento de la presión sanguínea para posteriormente bajar y estabilizarse. ${ }^{[4,5,6]}$ Este punto representa un pilar fundamental en el mejoramiento de la calidad y pronóstico de vida de los adultos mayores, pues las enfermedades crónicas, y especialmente las relacionadas con el sistema circulatorio, son las que más afectan la salud de esta población y, a su vez, son las que generan mayor discapacidad y pérdida de vida potencialmente saludable. ${ }^{[21,22]}$

Además, se presentaron cambios psicológicos positivos, puesto que los adultos mejoraron notoriamente en los niveles de anorexia, depresión, ansiedad e ideación suicida con un valor estadísticamente significativo. Esto muestra que, como bien se plantea en diferentes estudios sobre la situación emocional y mental de las personas, estos son componentes fundamentales dentro de su calidad de vida y bienestar integral, y la risoterapia es una medicina complementaria que disminuye tales síntomas. ${ }^{[12,13,14]}$ Hay que tener en cuenta que la depresión, por ejemplo, se ha convertido en un problema de salud pública en todo el mundo y en uno de los principales problemas de salud mental de los adultos mayores, y que además está relacionado directamente con su condición de salud integral. ${ }^{[23]}$ Cabe destacar que un estudio realizado con esta misma población mostró que los niveles de depresión disminuyeron significativamente con la terapia. ${ }^{[24]}$

Asimismo, se sabe que en los adultos mayores institucionalizados (como fue el caso de los participantes en este estudio) o que viven en 
hogares geriátricos, las condiciones de vida y la falta de contacto social se han asociado con síntomas depresivos; por esto, poder interactuar en momentos puntuales con otros adultos mayores y con el personal asistencial dentro de una sesión de terapia de la risa trae beneficios evidenciados en los resultados de la presente investigación. [24, 25]

Estos espacios de esparcimiento tan necesarios para los adultos mayores están reglamentados en la Carta de Ottawa ${ }^{[1]}$ y en la Ley 1315 de 2009 de Colombia;[26] así que la necesidad de llevarlos a cabo es apremiante, y que no queden simplemente propuestos en el papel.

En conclusión, la terapia de la risa como tratamiento complementario es útil y coadyuvante para el mejoramiento de la salud física y mental desde la percepción de los adultos mayores institucionalizados, pues según lo hallado en el presente estudio, la interacción de aquellos con las sesiones de terapia mejoraron su percepción psicológica y la sintomatología gastrointestinal y respiratoria.

\section{Limitaciones}

Un tamaño de muestra de 42 adultos es pequeño. Por tanto, el equipo de investigadores, junto con el equipo de la institución, debe fomentar estrategias e incentivos adicionales que favorezcan la participación de los adultos mayores. Por otra parte, muchas de las variables no pueden ser controladas en el estudio, como cambios en la medicación y aparición de nuevas patologías, por lo que los resultados hallados deben ser confirmados por estudios experimentales, controlando posibles sesgos y con un tamaño de muestra mayor aunque se da en los resultados la mejoría en la sintomatología de los adultos que inicialmente la reportaron, queda por esclarecer otro tipo de síntomas que aparecieron luego en algunos adultos. 


\section{Referencias}

1. Organización Mundial de la Salud. Carta de Ottawa para la promoción de la salud. 1986. Disponible en: https://www.paho.org/hq/dmdocuments/2013/ Carta-de-ottawa-para-la-apromocion-de-la-salud-1986-SP.pdf

2. Alvarado A, Salazar A. Análisis del concepto de envejecimiento. Gerokomos. 2014; 25 (2): 57-62. Doi http://dx.doi.org/10.4321/ S1134-928X2014000200002

3. Ruiz C, Rojo C, Ferrer A, Jiménez L, Ballesteros M. Terapias complementarias en los cuidados. Humor y risoterapia. Index. Enferm. 2005; 14: 48-9. http:// dx.doi.org/10. 4321/S1132-12962005000100008

4. Christian R, Ramos J, Susanibar C, Balarezo G. Risoterapia: un nuevo campo para los profesionales de la salud. Rev. Soc. Per. Med. Inter. 2004; 17: 2.

5. Mora-Ripoll R, Quintana-Casado I. Risa y terapias positivas: enfoque moderno y aplicaciones prácticas en medicina. Rev. Psiquiatr. Salud Mental. 2010; 3 (1): 27-34.

6. Jaimes J, Claro A, Perea S, Jaimes E. La risa, un complemento esencial en la recuperación del paciente. Revista Médicas UIS. 2011; 24: 102-7.

7. Chazenbalk L. El valor del humor en el proceso psicoterapéutico. Revista Psicodebate: Psicología, Cultura y Sociedad. 2003. Disponible en: http:// www.palermo.edu/cienciassociales/investigacion-y-publicaciones/revistapsicodebate/revista-psicodebate-06.html

8. Jáuregui-Narváez E. Reseña de “El humor y el bienestar en las intervenciones clínicas” de William Fry y Waleed Salameh. Clínica y Salud. 2005; 16 (1): 111115. Disponible en: https://www.redalyc.org/articulo.oa?id=180616109007

9. Arias M. Neurología de la risa y del humor: risa y llanto patológicos. Neurología. 2011; 53: 415-421.

10. Royo-Ruiz AJ. La risoterapia y su aplicación en la Atención Primaria. [Tesis]. Departamento de Ciencias de la Salud de la Universidad Pública de Navarra. 2013. Disponible en: http://academica-e.unavarra.es/bitstream/ handle/2454/8045/Grado\%20Enfermeria\%20Alba\%20Jimena\%20Royo. pdf?sequence $=1$

11. Curioso-Chávez MC. La risa en el puerperio. Av. Psicol. 2013; 21 (1): 57. 
12. Carbelo-Vaquero B, Asenjo E, Rodríguez de la Parra S. Una aproximación terapéutica al humor en el cuidado paliativo. Atención Primaria. 2000; 26 (1): 58-62.

13. Schröeder M, Fontanals $\mathbf{M}$, Mateo $\mathbf{D}$. Estrés ocupacional en cuidados paliativos de equipos catalanes. Medicina Paliativa. 1996; 3(4): 26-31.

14. Ruiz M, Rojo C, Ferrer MA, Jiménez L, Ballesteros, M. Terapias complementarias en los cuidados: humor y risoterapia. Index. Enferm. 2005; 14 (48-49): 37-41.

15. Overeem S, Taal W, Ocal E, Lammers G, Van Dijk J. Is Motor Inhibition During Laughter Due to Emotional or Respiratory Influences? Psychophysiology. 2004; 41 (2): 254-258.

16. Sánchez J, Gutiérrez J, Santacruz J, Ramón C, Ospina J. El humor como estrategia terapéutica en niños hospitalizados en unidades pediátricas en Pereira (Colombia). Reporte de una experiencia. Rev. Colomb. de Psiquiatr. 2009; 38 (1): 99-113.

17. Gelkopf M. The Use of Humor in Serious Mental Illness: A Review. EvidenceBased Complementary and Alternative Medicine. 2009; 2011: 8.

18. Koller D, Gryski C. The Life Threatened Child and the Life Enhancing Clown: Towards a Model of Therapeutic Clowning. Evidence-Based Complementary and Alternative Medicine. 2008; 5 (1): 17-25.

19. Ministerio de Salud. Resolución 8430 de octubre 4 de 1993. Por la cual se establecen las normas científicas, técnicas y administrativas para la investigación en salud. Bogotá; 1993. Disponible en: https://www.minsalud. gov.co/sites/rid/Lists/BibliotecaDigital/RIDE/DE/DIJ/RESOLUCION-8430DE-1993.PDF

20. Bitar K, Patil S. Aging and Gastrointestinal Smooth Muscle. Mech. Ageing. Dev. 2004; 125 (12): 907-910. doi:10.1016/j.mad.2004.05.010.

21. Ahmed H. Assessment and Management of Nutrition in Older People and Its Importance to Health. Clin. Interv. Aging. 2010; 5: 207-216.

22. Duquesne A, López MA. Prevalencia de complicaciones ateroscleróticas y factores de riesgo aterogénicos asociados en adultos mayores cubanos. Panorama Cuba y Salud. 2009; 4 (2).

23. Estrada A, Cardona D, Segura A, Ordóñez J, Osorio J, Chavarriaga L. Síntomas depresivos en adultos mayores institucionalizados y factores asociados. Universitas Psychologica. 2012; 12: 81-94. 
24. Quintero A, Henao ME, Villamil MM, León J. Cambios en la depresión y el sentimiento de soledad después de la terapia de la risa en adultos mayores internados. Biomédica. 2015; 35: 90-100.

\section{Santos S, Tier C, Silva B, Barlem E, Felicianni A, Valcarenghi}

F. Diagnósticos e intervenciones de enfermería para ancianos con depresión y residentes en una institución de larga estancia (ILE). Enferm. Glob. 2010. Disponible en: http://scielo.isciii.es/scielo. php?script=sci_arttext\&pid=S1695-61412010000300003\&lng=es

26. Congreso de la República de Colombia. Ley 1315 de 2009. Por medio de la cual se establecen las condiciones mínimas que dignifiquen la estadía de los adultos mayores en los centros de protección, centros de día e instituciones de atención. Bogotá; 2009. 


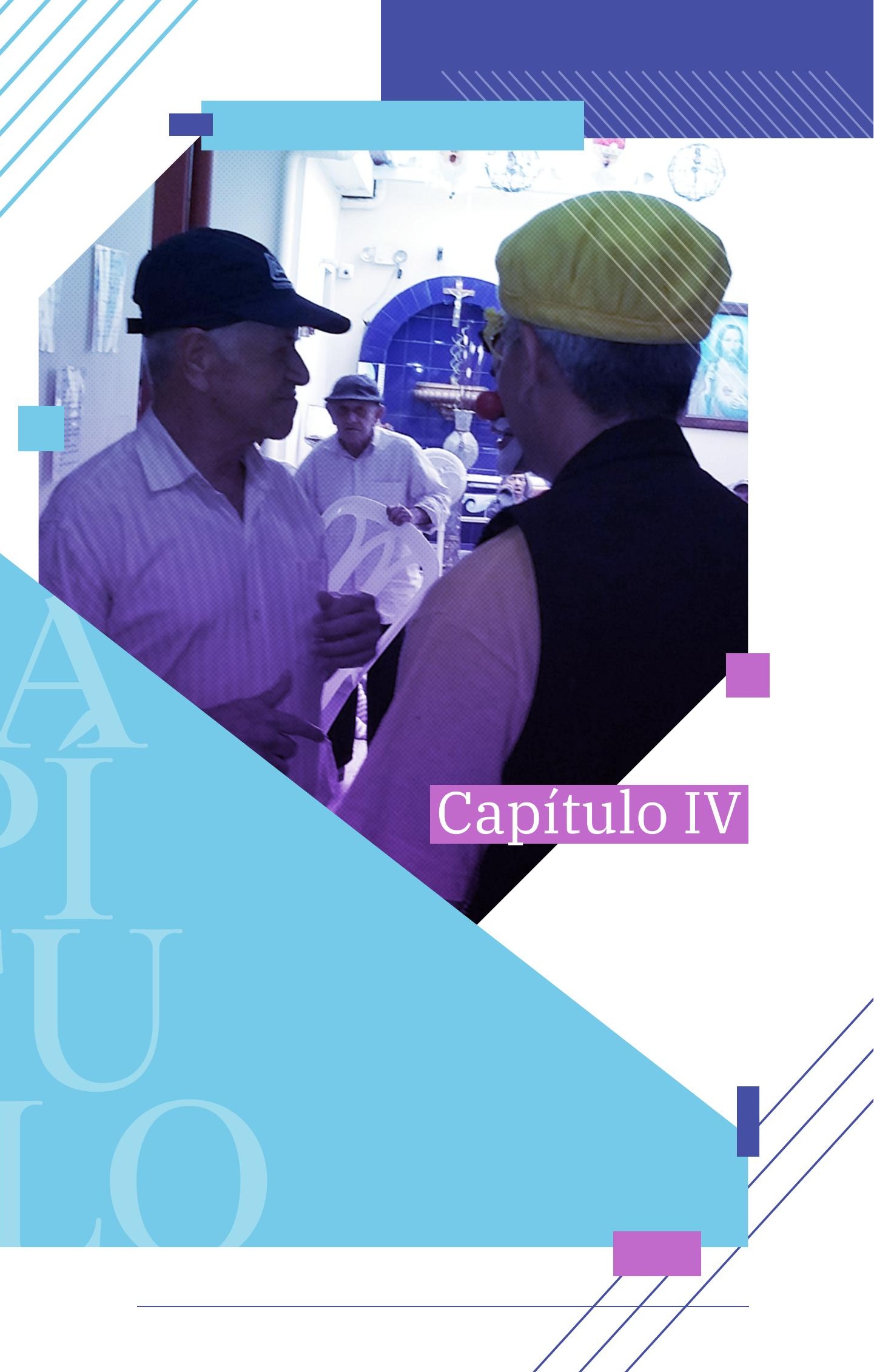




\section{Efectos de la terapia de la risa en el nivel de depresión de adultos mayores internados en centros gerontológicos, 2015}

Ángela Quintero Echeverri ${ }^{1}$, Jairo León Cardona Jiménez², María Eucaris Henao Villa² y María Mercedes Villamil Gallego ${ }^{3}$

\section{Introducción}

El envejecimiento de la población es una de las tendencias más significativas del siglo XXI y tiene consecuencias importantes y de vastos alcances en todos los aspectos de la sociedad. Este incremento se ha dado por el aumento de la esperanza de vida y el descenso de los índices de natalidad y de mortalidad. ${ }^{[1]}$

Por otro lado, debido al grado de dependencia de las personas mayores, se opta, en muchas ocasiones, por la institucionalización en los hogares. Las causas varían: escasos o nulos recursos económicos, falta de apoyo, abandono, marginación social, etc.; ${ }^{[2]}$ además, los cambios sociofamiliares actuales, como familias y viviendas más pequeñas y el ingreso de la mujer al mercado laboral (siendo ellas las que generalmente se dedican al cuidado y la atención de los mayores), aumentan la población en estos centros. ${ }^{[3]}$ Sumado a lo anterior, se incrementa la presencia de enfermedades crónicas y psicológicas, entre estas la depresión.

1 Grupo GISAM, Uniremington.

2 Facultad de Ciencias de la Salud y grupo GISAM, Uniremington.

3 Facultad de Humanidades y grupo GISAM, Uniremington.

Contacto: mercevill@hotmail.com 


\section{La depresión}

La depresión, según el Manual diagnóstico y estadístico de los trastornos mentales de la Asociación Americana de Psiquiatría (APA, en inglés) ${ }^{[4]}$ (DSM IV-TR), es considerada como un trastorno del estado de ánimo; la clasifica, además, de acuerdo con el número de síntomas y el grado de deterioro: leve, moderada y severa, que puede tener o no síntomas como delirios y alucinaciones.

La APA describe la depresión como "una enfermedad mental en la que la persona experimenta una tristeza profunda y la disminución de su interés para casi todas las actividades". ${ }^{[5]}$

La depresión representa un grave problema de salud pública: se estima que en las próximas décadas, debido a sus costos sociales y a la morbilidad, será considerada en el listado de las patologías de mayor impacto global. ${ }^{[6,7,8]}$ En Colombia, la Encuesta Nacional de Salud Mental publicada en 2015 reportó que el 19,2\% de los mayores de 45 años sufren de cuatro a seis síntomas de depresión y el 8,9\% más de siete, siendo mayor la prevalencia en mujeres (22,1\% y 10,6\%, respectivamente) que en hombres (14,8\% y 6,2\%, respectivamente). ${ }^{[9]}$

Dentro de la población geriátrica, la depresión es considerada como uno de los síndromes más frecuentes e incapacitantes; ${ }^{[10,11]}$ además, aumenta con la edad ${ }^{[12]}$ y es una de las sintomatologías más frecuentes. ${ }^{[13]}$

Las variables sociodemográficas (género, edad, estado civil, escolaridad, ingreso) están relacionadas con la depresión; con respecto al género, se presenta más en la mujer, con una frecuencia que casi dobla la del varón ${ }^{[14]}$ en la Encuesta Nacional de Salud Mental; ${ }^{[9]}$ las personas de 60 a 65 años presentaron una prevalencia anual de depresión mayor del 7,1\%, frente a un 2,4\% de todos los grupos poblacionales. Con respecto al estado civil, se presentó más en adultos separados y viudos que en los casados. ${ }^{[12]}$ El ingreso también influye significativamente: a menores ingresos, mayor presencia de depresión. ${ }^{[15]}$

Investigaciones especializadas revelan que entre el 10\% y el 15\% de la población anciana de una comunidad padece algún grado de depresión; esta proporción se acrecienta cuando el adulto mayor es 
ingresado en una institución. ${ }^{[16]}$ Se ha reportado que las personas que viven en residencias geriátricas, por las condiciones de vida y la falta de contacto social, han tenido síntomas depresivos; ${ }^{[17]}$ así que la institucionalización en sí misma puede generar depresión. [18]

Para detectar dicha patología en los ancianos se ha utilizado la escala de depresión geriátrica Yesavage. Existe una versión completa de 30 ítems y una reducida de 15 ítems; ${ }^{[19]}$ esta última ha sido validada en Colombia en dos ocasiones, en las cuales se encontró que es altamente confiable y que predice moderadamente el constructo de depresión. ${ }^{[20,21]}$ Categoriza la depresión en tres niveles: ausente o sin depresión (0 a 5), leve (6 a 10), establecida (más de 10); y evalúa síntomas depresivos cognoscitivos como estado de ánimo, esperanza, deseos de muerte y capacidad de disfrute; su principal ventaja es que no mezcla síntomas físicos con los depresivos. ${ }^{[19,20]}$

\section{Beneficios de la terapia de la risa}

La terapia de la risa es un tratamiento complementario para mantener el bienestar físico y mental. ${ }^{[22]}$ Los efectos de la risa sirven para superar problemas físicos, psicológicos y sociales. ${ }^{[23]}$ Al eliminar el estrés, alivia la depresión; además, mejora la autoestima y las relaciones interpersonales. ${ }^{[24]}$

Los beneficios de las intervenciones se han reportado en diversas áreas: geriatría, oncología, cuidados intensivos, psiquiatría, rehabilitación, reumatología, cuidados en el hogar, cuidados paliativos, cuidado de hospicio, atención al paciente, ${ }^{[25]}$ pediatría, educación, cirugía, psicoterapia y enfermos terminales; ${ }^{[22]}$ y se hace necesario emplearla como terapia complementaria para apoyar el tratamiento médico.

Sparks Bethea ${ }^{[26]}$ menciona cómo los adultos mayores hacen alusión al buen humor como una ayuda para mantener una actitud positiva y lograr una mejor comprensión sobre la vida. Esta autora refiere, además, que el buen humor podría contribuir a una experiencia de envejecer con éxito y, por tanto, es importante fortalecerla en todos los ciclos de la vida. 
Berk ${ }^{[27]}$ propone como beneficios psicológicos del humor los siguientes: reduce la ansiedad, estrés, tensión, depresión, soledad, mejora la autoestima, devuelve la esperanza y la energía, y proporciona una sensación de poder y control de situaciones.

Existen varios estudios en los cuales se han observado cambios con la terapia de la risa: uno midió el efecto del humor en el incremento de la calidad de vida y halló que las puntuaciones mejoraron en los pacientes depresivos, pero no en los pacientes con enfermedad de alzhéimer. ${ }^{[28]}$

Otro estudio fue hecho en un grupo experimental con tratamiento de terapia de la risa (52 pacientes participantes), comparado con un grupo control sin tratamiento específico (38 pacientes); los 90 participantes, adultos mayores, tenían síntomas clínicos de depresión. Se aplicaron varias pruebas antes y después de la terapia: la escala de depresión, la encuesta de salud, satisfacción con la vida y la resiliencia. El estudio comprobó mejoras significativas en la depresión, la percepción frente al suicidio, la satisfacción con la vida, la salud general y el estado de alegría; igualmente, comprobó la pertinencia de la terapia en pacientes con depresión y los beneficios de la misma. ${ }^{[29]}$

En el artículo escrito por Ko y Youn, ${ }^{[30]} 109$ sujetos mayores de 65 años fueron divididos en dos grupos: 48 en el grupo de terapia de la risa y 61 en el grupo control; los adultos del primero fueron sometidos a la terapia cuatro veces en un mes. Este estudio encontró mejoría con diferencias significativas en quienes recibieron la terapia en aspectos como depresión, función cognitiva y calidad del sueño en comparación con el grupo control.

Una investigación realizada en Colombia con adultas mayores institucionalizadas logró que con la terapia ellas tuvieran una mirada más positiva, aceptaran su realidad, disminuyeran los recuerdos tristes, mejoraran la confianza, estuvieran más satisfechas y sintieran mayor agrado al contacto con sus familias. ${ }^{[31]}$

Con relación al género, Mora-Ripoll y Ubal-López ${ }^{[32]}$ hallaron que los adultos que más ríen son los de sexo femenino; en las mujeres, la risa está más relacionada con la esfera social y se utiliza para afrontar situaciones de estrés. 
Quintero y col. ${ }^{[33]}$ realizaron un estudio con adultos mayores internados y hallaron que con la risoterapia hubo un descenso significativo en el nivel de depresión, especialmente en aquellos con depresión inicial establecida. Las personas más receptivas fueron aquellos adultos que no tienen pareja, que se encuentran entre las edades de 65 y 75 años, que proceden del estrato 2 y que reciben visitas.

Así que hay que reiterar la importancia de profundizar en la terapia de la risa aplicada en adultos mayores por los beneficios físicos y mentales que puede aportar en las personas institucionalizadas. Este trabajo pretende evaluar el impacto de su aplicación en el nivel de depresión en dos grupos de adultos mayores internados.

\section{Metodología}

El nivel de la investigación fue exploratorio con diseño cuasiexperimental comparando las medidas basales con las obtenidas después de la aplicación de las terapias.

\section{Consideraciones éticas}

A los participantes en el estudio se les informó de los objetivos, beneficios y riesgos de la aplicación de la terapia de la risa y se tomó la firma del consentimiento informado a quienes quisieron participar. El estudio se considera con riesgo mínimo (Resolución 8430 de 1993)34 y fue aprobado por el Comité de Ética de la Corporación Universitaria Remington en acta de agosto 12 de 2015.

\section{Unidad de análisis}

Adultos mayores de 60 años residentes en los hogares gerontológicos Revivir y SIGGEM. 


\section{Criterios de inclusión}

Mayores de 60 años residentes en los hogares gerontológicos con capacidad mental para responder la encuesta de depresión y participar al menos en cinco sesiones de la terapia.

\section{Variables}

Edad, género, estado civil, ocupación, estrato socioeconómico de origen, nivel de depresión medido por la escala Yesavage validada para Colombia. ${ }^{[20]}$

\section{- Recursos humanos}

Participaron los siguientes profesionales: una trabajadora social, un epidemiólogo, dos psicólogos, cuatro estudiantes de Medicina y cuatro de Enfermería de la Uniremington (encargados, además, de recolectar la información).

\section{Población y muestra}

La población estuvo conformada por todos los adultos residentes en los centros gerontológicos Revivir y SIGGEM. El tamaño de la muestra alcanzó 27 adultos mayores de 60 años internados y que voluntariamente participaron.

\section{Análisis estadístico}

Se realizó con SPSS versión 21 para Windows. Para el análisis univariado se emplearon frecuencias absolutas y proporciones. Para las variables cuantitativas se utilizaron medidas de tendencia central y el análisis no paramétrico, usando como indicador la prueba de Wilcoxon para muestras relacionadas; la significancia fue de $p<0,05$. 


\section{Descripción y estandarización de la terapia de la risa}

La terapia de la risa podría definirse como el uso terapéutico de técnicas e intervenciones aplicables (a una persona o a un grupo) que conducen a un estado/sentimiento controlado de desinhibición para conseguir experimentar risa que se traduzca en determinados beneficios de salud. ${ }^{[35]}$ Los payasos hospitalarios recorrían los hogares para lograr su efecto benéfico y terapéutico aplicando el tipo de risa inducida mediante la utilización de herramientas como el juego, la distracción, la música, el canto, siempre tratando de que el adulto mayor se expresara y participara activamente en la sesión, en un ambiente de diversión y humor. ${ }^{[35]}$ Se realizaron ocho sesiones de terapia (una semanal), cada una con una duración mínima de 10 minutos y máxima de 15 según la aceptación y participación del adulto mayor. El tiempo de intervención y el número de sesiones fueron supervisados por los investigadores. La terapia fue realizada por dos payasos del Mediclaun con una amplia experiencia en su aplicación.

\section{Resultados}

Se detallan los resultados más relevantes en cuanto a variables sociodemográficas, los promedios y las proporciones.

Se aplicó la terapia de la risa a 27 adultos mayores, 14 mujeres y 13 hombres pertenecientes a dos hogares gerontológicos, uno privado y otro público. El 14,8\% tiene entre 64 y 75 años, el 37\% entre 76 y 85 años y el resto son mayores de 85 . El 40,7\% pertenece al estrato 1 , el $25,9 \%$ al 2 , el $14,8 \%$ al 3 , solo tres al 4 y 5 , que corresponde al $11,1 \%$. La mayoría de los adultos (el $63 \%$ ) cursaron primaria incompleta, el 29,6\% son analfabetos y el resto no iniciaron la secundaria. Frente al estado civil, prevalecen los solteros, seguidos de los viudos y separados; solo dos adultos manifestaron tener pareja. Recibe visitas el 66,7\% de ellos (Tabla 4-1). 
Tabla 4-1. Variables sociodemográficas de adultos mayores residentes en centros gerontológicos.

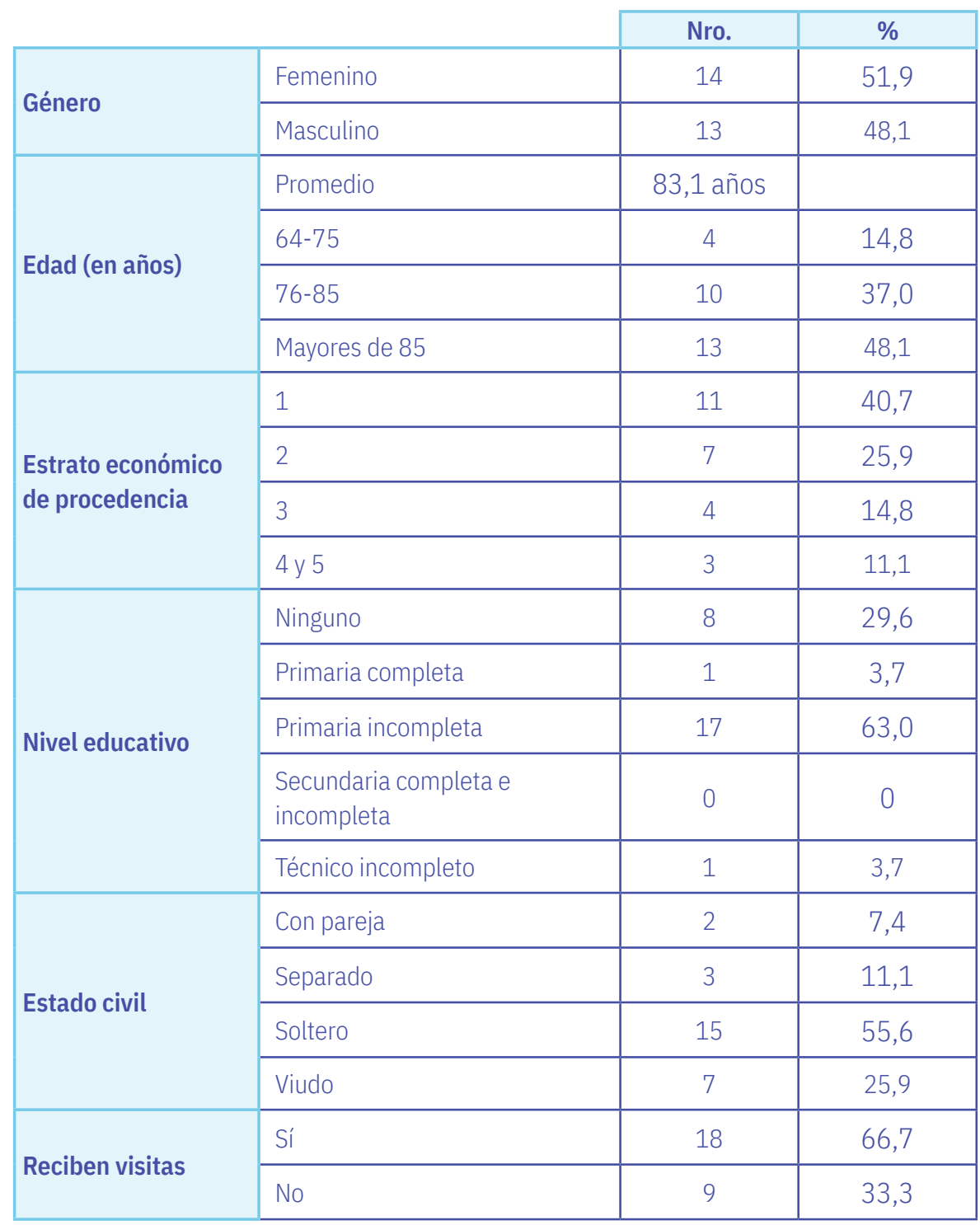

El 63,6\% de la población encuestada disminuyó sus niveles de depresión medidos por la escala Yesavage; estos porcentajes fueron muy semejantes en ambos centros gerontológicos (Figura 4-1). 


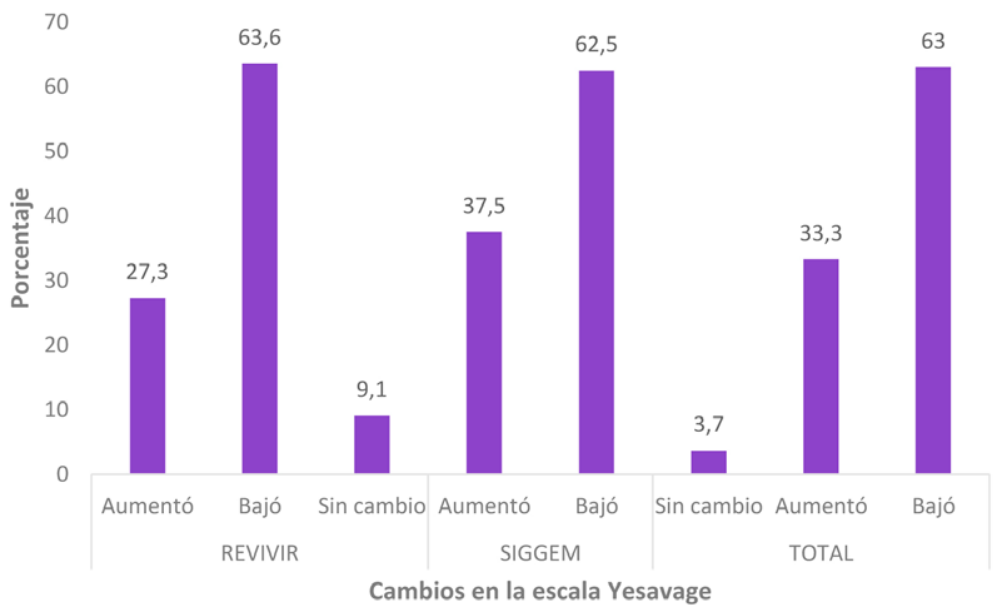

Figura 4-1. Distribución porcentual total y por centros gerontológicos de los cambios en la escala Yesavage.

Los puntajes iniciales y finales registrados con la escala Yesavage mostraron diferencias significativas en adultos internados con depresión leve después de la aplicación de la terapia de la risa; el puntaje en los inicialmente clasificados como "normales" incrementó levemente. Se destaca la disminución del puntaje en quienes tienen algún grado de depresión después de la aplicación de la terapia (Figura 4-2).

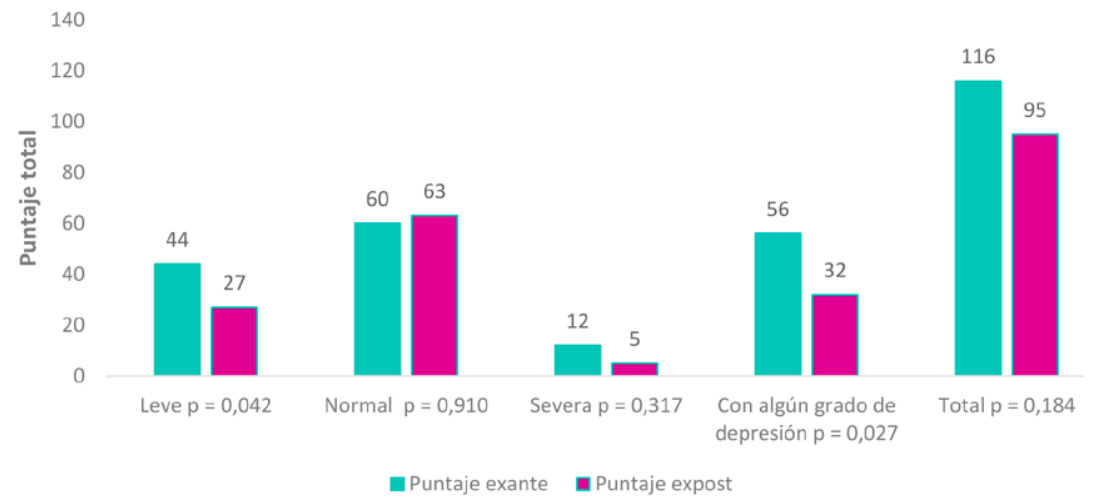

Prueba de Wilcoxon para muestras relacionadas. $P<0,05$.

Figura 4-2. Cambios en el puntaje de depresión de los adultos según la clasificación de la escala Yesavage después de la aplicación de la terapia de la risa. 
En la Tabla 4-2 se resaltan los ítems que mejoraron de manera más notable. En ambos hogares mejoraron los ítems "anhedonia" y "preocupación”. En el hogar SIGGEM mejoró el ítem "desamparo” y en Revivir "estado de ánimo", "problemas de memoria", "desesperanza" y "pesimismo". En SIGGEM desmejoraron los ítems "agradable vivir" e "ideas de minusvalía".

En Revivir, en promedio se presentó un descenso de 2,2 puntos por cada adulto mayor participante en la escala Yesavage contra 0,9 puntos en el hogar SIGGEM. Para toda la población los cambios fueron significativos ( $p=0,007)$.

Tabla 4-2. Cambio en cada ítem de la escala Yesavage después de la terapia de la risa según sede.

\begin{tabular}{|c|c|c|c|c|c|c|}
\hline 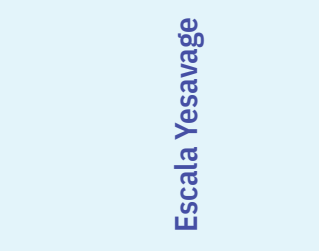 & 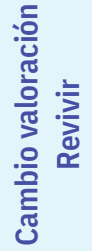 & 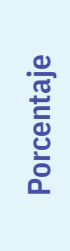 & 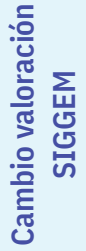 & $\begin{array}{l}\frac{0}{\frac{\pi}{\pi}} \\
\frac{0}{0} \\
\frac{0}{0}\end{array}$ & 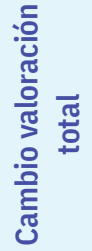 & 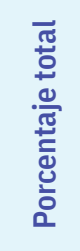 \\
\hline $\begin{array}{l}\text { Satisfacción } \\
\text { por la vida }\end{array}$ & 1 & 7,7 & 1 & 6,3 & 2 & 6,9 \\
\hline Anhedonia & 3 & 23,1 & 4 & 25,0 & 7 & 24,1 \\
\hline Vida vacía & 1 & 7,7 & 0 & 0,0 & 1 & 3,4 \\
\hline Aburrimiento & 2 & 15,4 & 2 & 12,5 & 4 & 13,8 \\
\hline Estado de ánimo & 3 & 23,1 & 0 & 0,0 & 3 & 10,3 \\
\hline Preocupación & 3 & 23,1 & 3 & 18,8 & 6 & 20,7 \\
\hline Felicidad & 1 & 7,7 & 1 & 6,3 & 2 & 6,9 \\
\hline Desamparo & 0 & 0,0 & 4 & 25,0 & 4 & 13,8 \\
\hline Apatía & 2 & 15,4 & 2 & 12,5 & 4 & 13,8 \\
\hline Problemas de memoria & 3 & 23,1 & 0 & 0,0 & 3 & 10,3 \\
\hline Agradable vivir & 1 & 7,7 & -4 & $-25,0$ & -3 & $-10,3$ \\
\hline
\end{tabular}


Continuación de la Tabla 4-2.

\begin{tabular}{|c|c|c|c|c|c|c|}
\hline 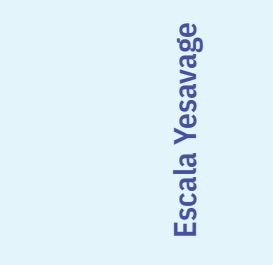 & 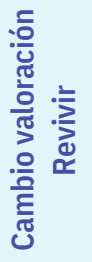 & 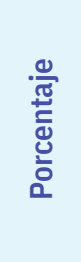 & 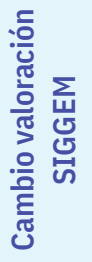 & 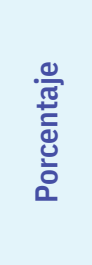 & 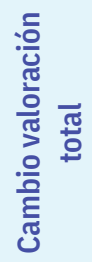 & 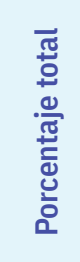 \\
\hline Ideas de minusvalía & 0 & 0,0 & -3 & $-18,8$ & -3 & $-10,3$ \\
\hline Nivel de energía & 1 & 7,7 & 1 & 6,3 & 2 & 6,9 \\
\hline Desesperanza & 3 & 23,1 & 2 & 12,5 & 5 & 17,2 \\
\hline Pesimismo & 4 & 30,8 & 1 & 6,3 & 5 & 17,2 \\
\hline Total descenso & 28 & & 14 & & & \\
\hline Promedio & 2,2 & & 0,9 & & & \\
\hline
\end{tabular}

Se destaca la mejoría en el puntaje de depresión en el género femenino, adultos entre 76 y 85 años (único significativo), aquellos procedentes del estrato 1, los que no tienen ningún nivel educativo, los separados y aquellos que reciben visitas. Cabe destacar que desmejoraron su puntaje de depresión los adultos menores de 75 años, aquellos procedentes del estrato 2 y los que están en unión libre (Tabla 4-3). 
Tabla 4-3. Diferencias en las medidas de Yesavage según variables sociodemográficas antes y después de la aplicación de la terapia de la risa.

\begin{tabular}{|c|c|c|c|c|c|c|c|c|c|}
\hline & \\
\hline & & & \multicolumn{3}{|c|}{ Prueba exante } & \multicolumn{3}{|c|}{ Prueba expos } & \multirow{2}{*}{ 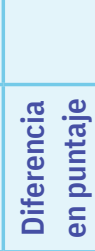 } \\
\hline \multicolumn{2}{|c|}{ Variable } & Nro. & 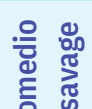 & 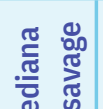 & 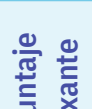 & .을 ఝ & 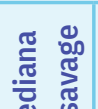 & 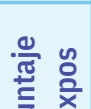 & \\
\hline \multirow{2}{*}{ Género } & Femenino & 14 & 4,6 & 4,5 & 64 & 3,2 & 3,0 & 45 & 19 \\
\hline & Masculino & 13 & 4,0 & 3,0 & 52 & 3,9 & 4,0 & 50 & 2 \\
\hline \multirow{3}{*}{ Edad } & $64-75$ & 4 & 3,5 & 3,5 & 14 & 7,8 & 7,5 & 31 & -17 \\
\hline & $76-85$ & 10 & 4,4 & 4,0 & 44 & 1,5 & 0,5 & 15 & $29^{*}$ \\
\hline & Mayor de 85 & 13 & 4,5 & 3,0 & 58 & 3,8 & 4,0 & 49 & 9 \\
\hline \multirow{4}{*}{$\begin{array}{l}\text { Estrato de } \\
\text { procedencia }\end{array}$} & 1 & 11 & 4,1 & 4,0 & 45 & 2,6 & 1,0 & 29 & 16 \\
\hline & 2 & 7 & 4,0 & 3,0 & 28 & 3,5 & 3,0 & 45 & -17 \\
\hline & 3 & 4 & 3,8 & 3,0 & 15 & 1,8 & 1,5 & 7 & 8 \\
\hline & 4 & 2 & 1,5 & 1,5 & 3 & 1,0 & 1,0 & 2 & 1 \\
\hline \multirow{2}{*}{ Escolaridad } & Ninguno & 8 & 4,4 & 4,0 & 35 & 2,8 & 1,5 & 22 & 13 \\
\hline & Primaria & 18 & 3,8 & 3,0 & 64 & 3,8 & 4,0 & 64 & 0 \\
\hline \multirow{4}{*}{ Estado civil } & Separado & 3 & 7,3 & 7,0 & 22 & 2,3 & 2,0 & 7 & 15 \\
\hline & Soltero & 15 & 3,3 & 3,0 & 50 & 4,9 & 4,0 & 50 & 0 \\
\hline & Unión libre & 2 & 3,5 & 3,5 & 7 & 7,0 & 7,0 & 14 & -7 \\
\hline & Viudo & 7 & 5,3 & 4,0 & 37 & 3,4 & 5,0 & 24 & 13 \\
\hline \multirow{2}{*}{ Recibe visitas } & Sí & 18 & 4,1 & 4,0 & 74 & 4,2 & 3,0 & 51 & 23 \\
\hline & No & 9 & 4,7 & 3,0 & 42 & 4,9 & 5,0 & 44 & -2 \\
\hline
\end{tabular}

\section{Discusión}

En la literatura se enuncia que la internación, de algún modo, da entrada a la depresión ${ }^{[16,18]} y$, sin embargo, los hogares para los adultos mayores se convierten en una necesidad debido a que muchas familias no cuentan con los recursos o muchos adultos mayores se quedan sin quien los acoja. Por tanto, es indispensable revisar de qué modo actividades como la terapia de la risa se pueden incluir para propiciar un ambiente agradable para dicha población en los hogares gerontológicos. 
Inicialmente, tal y como otros trabajos lo han mostrado, esta terapia ayudó a disminuir el nivel de depresión de manera importante en los adultos mayores residentes en dichos hogares, [22, 23, 24, 29, 30, 31] especialmente aquellos con algún grado de depresión inicial. ${ }^{[32]}$

Ahora bien, si la depresión conduce a mayores costos sociales y morbilidad, $[6,7,8]$ la apuesta por permitir este tipo de terapias debía ser una constante, y no debería considerarse simplemente a la atención médica y los cuidados en general como los únicos servicios de los centros de internado, para así darles un cambio a la rutina y un sentido a las actividades que se realizan. ${ }^{[22,23,24,25]}$ De igual forma, la risa permite la comprensión y la apertura en las relaciones sociales y, por ende, el individuo se comunica y puede sentirse mejor. ${ }^{[26,27]}$

Con relación a la escala Yesavage, es importante hacer alusión a los ítems en los que más se notó disminución en los dos hogares: anhedonia y preocupación. Frente al primero hay una tendencia al aumento con la edad por el deterioro en las condiciones de salud; la otra razón está ligada con el ánimo que presentan las personas. Ahora bien, si el ítem disminuyó, esto significa que los mayores se sintieron más motivados y, con ello, se inclinaron a retomar actividades; el hacer implica de algún modo sentirse útil e importante. En el estudio de Quintero y col. ${ }^{[33]}$ este ítem también mejoró ostensiblemente.

El temor a que algo malo pueda ocurrir (preocupación) también está relacionado con la salud y la dependencia de los adultos mayores; y si existe el temor, hay inhibición y, a la vez, desconfianza en el rol cotidiano, lo que puede despertar más enfermedades y aumentar la depresión. En la medida en que disminuye el temor, el adulto puede estar más tranquilo, aumenta la confianza y, por ende, está más saludable. Ambos ítems están relacionados con el hacer.

Siendo un hogar público y el otro privado, se encontraron en la escala Yesavage algunos puntos que mejoraron en cada uno: en el hogar público disminuyó la percepción de desamparo, lo cual demuestra que las actividades diversas pueden conducir al aumento de la confianza y la seguridad hacia los cuidadores; mientras que en el hogar privado mejoraron otros ítems como el estado de ánimo, la creencia de tener mala memoria, la esperanza y el pesimismo. La esperanza ha sido relacionada por Berk ${ }^{[27]}$ con el buen humor. 
Haciendo alusión a las variables sociodemográficas, en este estudio las personas que más se beneficiaron de la terapia fueron los adultos entre 76 y 85 años; diferente a los resultados de Quintero y col., ${ }^{[33]}$ donde el grupo que mayor beneficio obtuvo fue el de 65 a 75 años, y adujeron que con la edad, debido al estado de salud y grado de dependencia, se dificulta aún más dar apertura a la risoterapia. Los resultados son congruentes con los de Mora-Ripoll, ${ }^{[32]}$ según los cuales el género femenino fue el más beneficiado por la risa.

Frente a la educación, es importante anotar que las personas más receptivas fueron las de menor nivel educativo, ${ }^{[33]}$ tema que sería importante desarrollar en estudios posteriores. Sin embargo, si bien el nivel educativo puede constituir un factor protector, en algunos casos puede llevar al individuo a racionalizar más y cohibirse frente a estas terapias.

En el estrato socioeconómico y en concordancia con el nivel educativo, los adultos procedentes de los estratos bajos fueron los de mayor beneficio, igual que en el estudio de Quintero y col. ${ }^{[33]}$ Con respecto al estado civil, fueron los separados y los viudos los de mayor beneficio, al igual que aquellos que reciben visitas. ${ }^{[33]}$

En resumen, la depresión bajó en el 63,6\% de los adultos mayores residentes en ambos hogares y mejoraron los ítems de la escala Yesavage anhedonia y preocupación. En cada hogar se dieron otros beneficios de manera diferente.

Los adultos más receptivos a la terapia fueron del género femenino, entre 75 y 85 años, los procedentes del estrato 1, quienes no tienen ningún nivel educativo, los separados y viudos, y quienes reciben visitas.

\section{Conclusiones}

La risa sigue mostrando su eficacia como terapia complementaria frente a la disminución de la depresión en los adultos mayores internados, quienes, dependiendo de su condición, mejorarán en unos u otros aspectos. ¿Será necesario que la terapia de la risa sea incluida 
en las atenciones hospitalarias para implementarla más frecuentemente?, ¿o será conveniente seguir asumiendo los costos sociales y en salud que implica mayor afianzamiento de las enfermedades? Por otro lado, siendo la depresión un problema de salud pública, es necesario considerar todas las alternativas posibles para disminuirla, buscando la salud integral para este grupo poblacional.

\section{Referencias}

1. Cardona D, Estrada A, Agudelo H. Medellín envejece a pasos agigantados. Rev. Fac. Nac. Salud Pública. 2004; 22 (2): 7-19.

2. Aranda C, Pando M, Flores M, García T. Depresión y redes sociales de apoyo en el adulto mayor institucionalizado de la zona metropolitana de Guadalajara, Jalisco. Revista Psiquiatría, Facultad de Medicina Barna. 2001; 28 (2): 70.

3. Marín P, Guzmán J, Araya A. Adultos mayores institucionalizados en Chile: ¿cómo saber cuántos son? Rev. Med. Chile. 2004; 132: 832-8.

4. American Psychiatric Association. DSM IV - TR, criterios diagnósticos. 2003.

5. American Psychiatric Association. Major depressive disorder. En: Diagnostic and Statistical Manual of Mental Disorders DSM-IV-TR; 2000, pp. 349-56.

6. Gómez-Restrepo C, Ospina M, Diazgranados N. Trastornos psiquiátricos: su importancia en el campo de la salud. En: Gómez-Restrepo C, Hernández G, Rojas A, Santacruz H, Uribe M (eds.). Fundamentos de psiquiatría clínica: niños, adolescentes y adultos; 2002, pp. 221-6.

7. Vicente B, Rioseco $\mathbf{0}$, Saldivia S, Kohn R, Torres S. Prevalencia de trastornos psiquiátricos en Latinoamérica: revisión crítica. Rev. Colomb. Psiquiatr. 2005; 34: 506-14.

8. Caicedo $\mathbf{M}$, Jiménez K. Estudio descriptivo-exploratorio del trastorno depresivo mayor: aproximaciones psicológicas y sociodemográficas de pacientes hospitalizados en la Clínica Psiquiátrica Nuestra Señora de la Paz. Rev. Colomb. Psiquiatr. 2005; 34: 515-28.

9. Ministerio de Salud. Encuesta Nacional de Salud Mental, 2015. Bogotá: Ministerio de Salud; 2015.

10. Ayuso JL. La depresión en la tercera edad. Psiquiatr. Biol. 2008; 9: 76-104. 
11. Aguilar S, Ávila JA. La depresión: particularidades clínicas y consecuencias en el adulto mayor. Gac. Méd. Méx. 2007; 1: 141-6.

12. Menchón JM, Crespo JM, Antón JJ. Depresión del anciano en Curso de Formación Continuada en Geriatría. 2001; 3: 4-12.

13. Serrano P. Depresión. Guía de la Sociedad Española de Medicina Familiar y Comunitaria. 2001; 1: 10-11.

14. Molina Soto de Schubert IP. Depresión en el adulto mayor en miembros del Centro de Atención Médica Integral para Pensionados (CAMIP) en Guatemala. [Trabajo de grado Psicología]. Universidad Francisco Marroquín. Guatemala. 2005.

15. Calderón M Diego. Epidemiología de la depresión en el adulto mayor. Rev. Med. Hered. 2018; 29 (3): 182-191. http://dx.doi.org/https://doi.org/10.20453/ rmh.v29i3.3408

16. Oquendo ME, Soublet O. Hogar del Adulto Mayor "José Manuel Lazo de la Vega". Ciudad de La Habana. ¿Es la depresión un problema de salud en un hogar del adulto mayor? Rev. Cuba. Enferm. 2003; 19: 1-7.

17. Santos SS, Tier CG, Silva BT, Barlem EL, Felicianni AM, Valcarenghi FV. Diagnósticos e intervenciones de enfermería para ancianos con depresión y residentes en una institución de larga estancia (ILE). Enferm. Glob. 2010; 20.

18. Cerquera AM. Relación entre los procesos cognitivos y el nivel de depresión en las adultas mayores institucionalizadas en el asilo San Antonio de Bucaramanga. Universitas Psychologica. 2008; 7: 271-81.

19. López Trigo JA. La depresión en la tercera edad. Disponible en: https://www2. uned.es/psicofarmacologia/stahl4Ed/contenidos/Tema2/documentos/C6/ C6D_4.pdf

20. Bacca AM, González A, Uribe AF. Validación de la escala de depresión de Yesavage (versión reducida) en adultos mayores colombianos. Pensam. Psicol. 2005; 1: 53-63.

21. Campo A, Urruchurtu Y, Solano T, Vergara A, Cogollo Z. Consistencia interna, estructura factorial y confiabilidad del constructo de la escala de Yesavage para depresión geriátrica (GDS-15) en Cartagena (Colombia). Salud Uninorte. 2008; 24: $1-9$.

22. Ruiz C, Rojo C, Ferrer A, Jiménez L, Ballesteros M. Terapias complementarias en los cuidados. Humor y risoterapia. Index. Enferm. 2005; 14: 48-9. http:// dx.doi.org/10.4321/S1132-12962005000100008 
23. Christian R, Ramos J, Susanibar C, Balarezo G. Laugh Therapy: A New Field for Healthcare Professionals. Rev. Soc. Per. Med. Inter. 2004; 17: 57-64.

24. Godfrey JR. Conversation with the Experts. Toward Optimal Health: The Experts Discuss Therapeutic Humor. J Womens Health (Larchmt). 2004; 13: 474-9.

25. Rosner F. Therapeutic Efficacy of Laughter in Medicine. Cancer Invest. 2002; 20 (3): 434-436.

26. Sparks Bethea L. The Function of Humor within the Lives of Older Adults. Summer. 2001; 49-56.

27. Berk RA. The Active Ingredients in Humor: Psychophysiological Benefits and Risks for Older Adults. Educ. Gerontol. 2001; 27: 323-339.

28. Walter M, Hanni B, Haug M, Amrhein I, Krebs-Roubicek E, Muller-Spahn F. Humour Therapy in Patients with Late-Life Depression or Alzheimer's Disease: a Pilot Study. Int. J. Geriatr. Psychiatry. 2007; 22: 77-83.

29. Hirsch R, Junglas K, Lonradt B, Jonitz MF. Humortherapie bei alten Menschen mit einer Depression. Z. Gerontol Geriat. 2010; 43: 42-52.

30. Ko H, Youn CH. Effects of Laughter Therapy on Depression, Cognition and Sleep among the Community-Dwelling Elderly. Geriatr. Gerontol Int. 2011; 11: 267-74.

31. Villamil MM, Quintero A, Henao E, Cardona JL. Terapia de la risa en un grupo de mujeres adultas. Rev. Fac. Nac. Salud Pública. 2013; 31: 202-8.

32. Mora-Ripoll R, Ubal-López R. La risa: diferencias según el género. Rev. Clin. Esp. 2011; 211 (7): 360-6.

33. Quintero A, Henao ME, Villamil MM, Cardona JL. Cambios en la depresión y la soledad, después de la terapia de la risa en adultos mayores internados. Biomédica. 2015; 35 (1): 90-100.

34. Ministerio de Salud. Resolución 8430 de octubre 4 de 1993. Por la cual se establecen las normas científicas, técnicas y administrativas para la investigación en salud. Bogotá; 1993. Disponible en: https://www.minsalud. gov.co/sites/rid/Lists/BibliotecaDigital/RIDE/DE/DIJ/RESOLUCION-8430DE-1993.PDF

35. Lancheros E, Tovar J, Rojas C. Risa y salud: abordajes terapéuticos. MedUNAB. 2011; 14 (1): 69-75. 


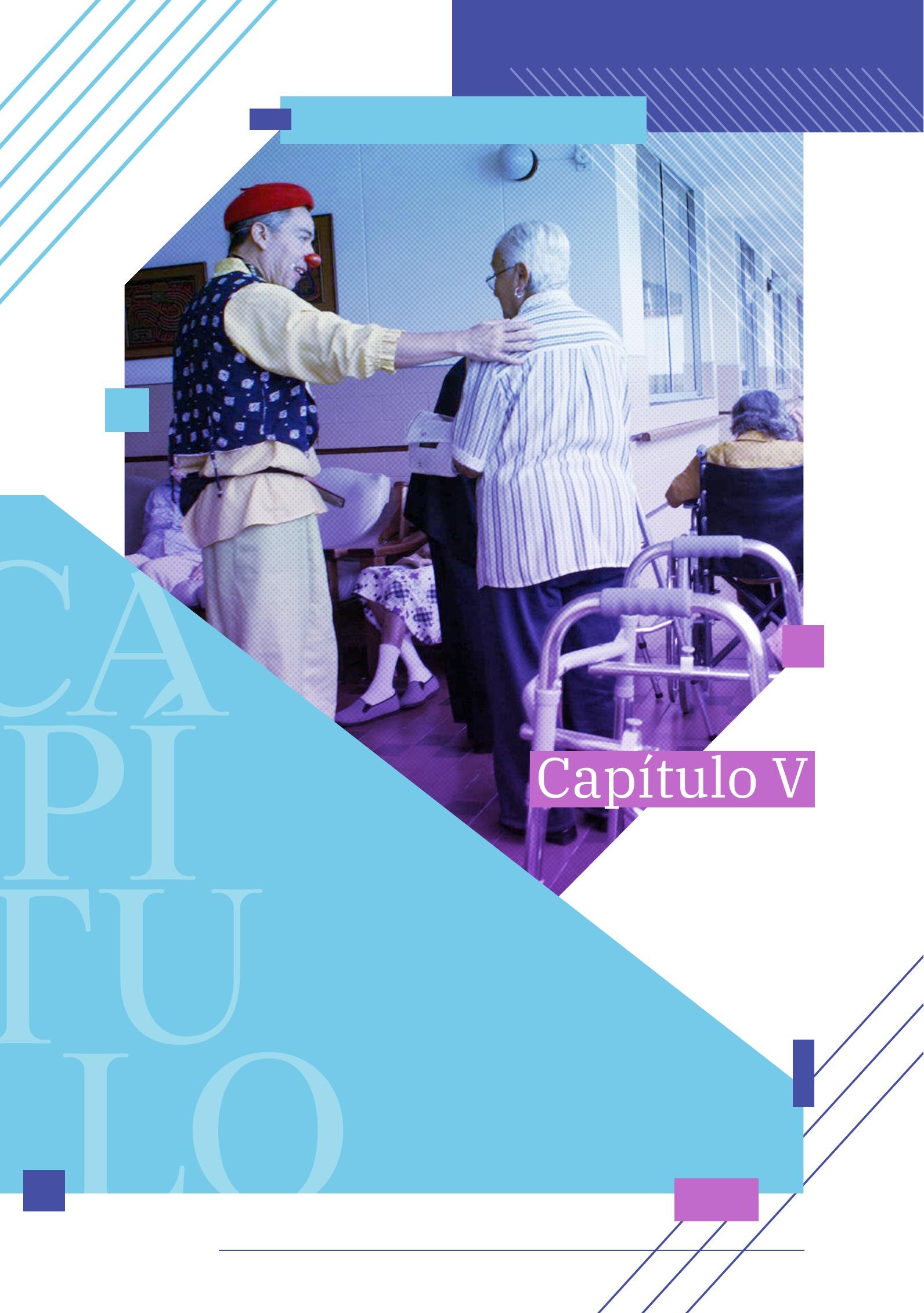




\section{Evaluación inmunológica en adultos} mayores residentes en hogares $\frac{\text { gerontológicos después de la aplicación }}{\text { de terapia de la risa } 2015}$

Jairo León Cardona Jiménez, María Eucaris Henao Villa ${ }^{1}$, María Mercedes Villamil Gallego² ${ }^{2}$ Ángela Quintero Echeverri³ Germán Sebastián Yepes $\mathrm{Cano}^{3} \mathrm{y}$ Andrés Higuita David ${ }^{4}$

\section{Introducción}

Para la Organización Mundial de la Salud, el envejecimiento poblacional es un cambio en la estructura por edades; según sus cálculos, se verá triplicada la cantidad de personas mayores de 65 años en el planeta para la primera mitad del siglo. ${ }^{[1]}$

Más de un cuarto de la población de los países del primer mundo tiene edades superiores a 65 años, y casi el $15 \%$ en los países en vías de desarrollarse. Las personas ubicadas entre este rango de edades están expuestas a varias patologías propias de esa etapa de la vida, así que los sistemas de salud deben estar preparados para afrontar un mayor volumen de pacientes con un servicio de calidad; y para ello es indispensable mantener un buen estado de salud y un envejecimiento activo de la población. ${ }^{[2]}$

Existe, en este orden de ideas, una necesidad de satisfacer y procurar el buen estado anímico y la salud de las personas de avanzada edad, ya que hay conexión entre los niveles de felicidad y la mortalidad;

1 Facultad de Ciencias de la Salud y grupo GISAM, Uniremington.

2 Facultad de Humanidades y grupo GISAM, Uniremington. Contacto: mercevill@hotmail.com

3 Grupo GISAM, Uniremington.

4 Universidad del Sinú. 
de hecho, la felicidad tiene un papel determinante en la morbilidad y mortalidad de la población en general. ${ }^{[3]}$

La edad y el sexo son otros de los factores para comprender el proceso de envejecimiento porque pueden reducir o aumentar, según el contexto, los cambios ocurridos en la etapa de la ancianidad. Junto a esto están las emociones más comunes en cada género: las personas mayores expresan sus sentimientos de manera diferente a otras etapas de la vida y según su género; así que estas diferencias deben ser tenidas en cuenta a la hora de abordar problemas y sobrellevar interacciones sociales. ${ }^{[4]}$

El bienestar también está ligado a la subjetividad de la calidad del envejecimiento; ha sido demostrado en estudios longitudinales que las personas con características como salud, estatus social, buenas relaciones interpersonales tienen una percepción más alta de su propio bienestar frente a quienes tienen falencias en estos ítems. Cabe resaltar que, contrario a lo que se piensa, no se goza de mayor felicidad a medida que se envejece, y esto lleva a una paradoja de la felicidad en la vejez. ${ }^{[5]}$

Según estudios previos, existe una interacción entre el bienestar y la fisiología, de tal modo que se cree en la posibilidad de que las emociones positivas tengan efectos en el funcionamiento del cuerpo. Estos estudios demuestran evidencia al respecto, ya que las emociones positivas impactan en la psicología y en la fisiología del organismo, por lo que se ve incrementada la actividad del córtex frontal izquierdo cuando se expone al paciente a olores agradables. Otro caso es la inducción de sonidos o expresiones verbales positivas: esto produce incrementos en la producción de inmunoglobulina-A (demuestra un sistema inmunológico en estado activo), y también disminuye los niveles de cortisol que se pueden encontrar en la saliva (un parámetro de la actividad del eje hipotalámico-hipofisario-adrenal que tiene una relación en la expresión de emociones y afecto). ${ }^{[3]}$

Al llegar a la edad madura, el cuerpo sufre cambios en las esferas psicológica, física y mental, lo cual convierte a esta etapa en un desafío (hay una mengua en todas estas esferas). El adulto se verá enfrentado a una crisis de identidad, que tiene relación con las pérdidas 
personales; una crisis de autonomía, dada por una pérdida en su estado general de salud que hace de él un ser vulnerable que necesita asistencia y, por tanto, pierde parte de la independencia; y una crisis de pertenencia, relacionada con modificaciones en el desarrollo de las actividades diarias en su cohabitación. ${ }^{[6]}$

Algunos estudios relacionan el estado de ánimo y la respuesta de los pacientes a patologías como el cáncer; se ha evidenciado un aumento linfocitario que combate la enfermedad y la disminución en los niveles de estrés físico; además, la autopercepción respecto al estado general aumenta en buena medida, maximizando los tratamientos médicos convencionales; asimismo, aparecen ambientes cómodos que propician la adherencia a los mismos. ${ }^{[7]}$

Varios ensayos abordan la relación que existe entre el cáncer de mama, gastrointestinal y leucemias con la terapia de la risa. Estos se centran en los aspectos psicológicos y no en los fisiológicos, por lo que no dan claridad sobre cómo podría generar cambios moleculares que ayuden a recobrar la homeostasis corporal. ${ }^{[8]}$

No obstante, estudios con artritis reumatoide y citocinas pro- y antiinflamatorias dan un panorama en el cual el movimiento inmunológico responde de manera diferenciada según el curso de la enfermedad y su manejo; así que sí existe una relación entre la terapia de la risa y las citocinas, mostrando su influencia en los niveles de estas de una manera beneficiosa. La terapia de la risa tiene un efecto en la respuesta inmunomoduladora ligado a la condición mental del paciente. ${ }^{[9]}$

La risa ha demostrado en estudios de neuroinmunología que los niveles de interferón (IFN) gamma aumentaron por 10 en los pacientes que se sometieron a un video humorístico; dicho interferón gamma se utiliza en procesos inflamatorios como tratamiento en infecciones de tipo viral, carcinomas sistémicos, infección por virus hepatitis B y virus hepatitis C; también en la fabricación de medicamentos de tipo antirretroviral. Asimismo, esta terapia ha estado asociada con la actividad y ejercicio linfocitario al fortalecer las células natural killer, linfocitos T y linfocitos B. Un aumento de los niveles de inmunoglobulinas, por tanto, es capaz de mejorar los puntos destructivos del estrés y 
robustecer el sistema inmune, lo que, en últimas, hará que pueda ejercer una influencia sobre las patologías inmunes. ${ }^{[10]}$

En concordancia con lo expuesto, en este trabajo se pretendió explorar los cambios en el perfil de citocinas pro- y antiinflamatorias dadas por la terapia de la risa en un grupo de adultos mayores pertenecientes a dos centros gerontológicos, a partir de la aplicación de sesiones de comedia practicada por profesionales, con muestras sanguíneas y una encuesta para conocer la historia clínica de cada paciente; a esto se le suman los análisis realizados en dos momentos: antes y después de la terapia.

\section{Metodología}

\section{Tipo de estudio}

Exploratorio con metodología cuasiexperimental.

\section{Población de estudio}

60 adultos mayores de los centros geriátricos Revivir (Envigado) y SIGGEM (Medellín); al final se obtuvo una muestra de 28 pacientes para citocinas anti- y proinflamatorias para síntomas y signos vitales.

\section{_ Criterios de inclusión}

Mayores de 59 años residentes en el hogar gerontológico que desearan participar y tuviera capacidad de responder las preguntas realizadas en el interrogatorio médico.

\section{Criterios de exclusión}

Pacientes con inmunodeficiencia primaria o secundaria no especificada. Se tomó la información de edad, género, estado civil y antecedentes patológicos. 


\section{Consideraciones éticas}

A todos los participantes en el estudio se les dio información sobre los objetivos, beneficios y riesgos de la aplicación de la terapia de la risa, y se tomó la firma del consentimiento informado a quienes desearon libremente participar. El estudio se considera con riesgo mínimo (Resolución 8430 de 1993) y fue aprobado por el Comité de Ética de la Corporación Universitaria Remington en acta de agosto 12 de 2015.

Se aplicaron ocho sesiones de terapia de la risa con la ayuda del grupo Payasos Hospitalarios de la Fundación Mediclaun (10 a 15 minutos por sesión). El personal del laboratorio clínico de la IPS universitaria hizo dos tomas de citocinas proinflamatorias y antiinflamatorias, una inicial antes de la terapia. Los estudiantes de Medicina hicieron un examen en el cual tomaron síntomas referidos y signos vitales; luego de la terapia realizaron la segunda toma, que contó nuevamente con examen médico.

\section{Análisis estadístico}

Se utilizó el paquete SPSS versión 21 para Windows. Para el análisis univariado se emplearon frecuencias absolutas y proporciones. Se empleó la prueba CHI cuadrado y el estadístico de Fisher para las variables nominales, además del indicador t de student para la diferencia de medias en variables cuantitativas. El nivel de significación se fijó en $p \leq 0,05$.

\section{Resultados}

La muestra estuvo compuesta por 28 adultos mayores con edades comprendidas entre los 59 y los 96 años, con un promedio de edad de 81,9 años, 16 mujeres (57\%) y 12 hombres (43\%). El estado civil con mayor predominio fue soltero (71\%), seguido de viudo (17,8\%). La ocupación en la cual se desempeñó la mayor parte de ellos fue oficios varios (21,4\%), seguida de labores domésticas (17,8\%). 
Se encontró un incremento entre la primera y la segunda muestra de citocinas, en las cuales se evidencia que el IFN gamma aumentó en cerca del $80 \%$ de la población y quedó muy cerca de la significancia estadística ( $p=0,07)$; también se logró apreciar una disminución en el TNF (factor de necrosis tumoral) alpha, que es proinflamatorio, en poco más de la mitad de los pacientes, y de las citocinas antiinflamatorias, como lo son IL-10 y IL-4, que se redujeron de manera similar en cuanto a la cantidad de pacientes se refiere. Respecto a la IL-6, se analiza una disminución en el promedio de la segunda medida frente al promedio de la primera, pero en el porcentaje de pacientes que vieron aumentado su nivel corresponde a más de la mitad (Tabla 5-1).

Tabla 5-1. Cambios en las citocinas en adultos mayores internados después de la aplicación de la terapia de la risa.

\begin{tabular}{|l|c|c|c|c|c|}
\hline \multicolumn{1}{|c|}{ Citocina } & $\begin{array}{c}\mathbf{1} \text { medida } \\
\text { (pre) Do* }\end{array}$ & $\begin{array}{c}\mathbf{2} \text { medida } \\
\text { (post) Do* }\end{array}$ & $\mathbf{t}$ & Cambio & $\begin{array}{c}\text { \% de pacientes } \\
\text { que cambió }\end{array}$ \\
\hline IFN gamma & 0,2103 & 0,23681 & 0,077 & Sube & 77,8 \\
\hline TNF alpha & 0,2021 & 0,2014 & 0,952 & Baja & 51,9 \\
\hline IL-10 & 0,2206 & 0,2212 & 0,972 & Baja & 51,9 \\
\hline IL-6 & 0,1711 & 0,1677 & 0,842 & Sube & 55,6 \\
\hline IL-4 & 0,1912 & 0,1798 & 0,318 & Baja & 51,9 \\
\hline *Do = Densidad óptica. $\mathrm{t}=\mathrm{t}$ de student. \\
\hline
\end{tabular}

En las mujeres se encontró una tendencia a la disminución en la mayoría de las citocinas, lo que está acorde con las cifras presentadas en la Tabla 5-1, pero hay una mayor cantidad de ellas con disminución en el TNF alpha que en la citocina con mayor poder inflamatorio (en el $66,7 \%$ se vio disminuida esta citocina). Se presenta un aumento del IFN gamma que queda muy cerca de la significancia estadística $(p=0,09)$

\section{(Tabla 5-2).}


Tabla 5-2. Cambios en las citocinas en las mujeres adultas mayores internadas después de la aplicación de la terapia de la risa.

\begin{tabular}{|l|c|c|c|c|c|}
\hline \multicolumn{1}{|c|}{ Citocina } & $\begin{array}{c}\text { 1 medida } \\
\text { (pre) Do* }\end{array}$ & $\begin{array}{c}\text { 2 medida } \\
\text { (post) Do* }\end{array}$ & $\mathbf{t}$ & Cambio & $\begin{array}{c}\text { \% de pacientes } \\
\text { que cambió }\end{array}$ \\
\hline IFN gamma & 0,2375 & 0,2626 & 0,091 & Sube & 80,0 \\
\hline TNF alpha & 0,2810 & 0,2897 & 0,646 & Baja & 66,7 \\
\hline IL-10 & 0,3090 & 0,3081 & 0,972 & Baja & 60,0 \\
\hline IL-6 & 0,1685 & 0,1751 & 0,797 & Sube & 60,0 \\
\hline IL-4 & 0,1893 & 0,1746 & 0,268 & Baja & 53,3 \\
\hline *Do = Densidad óptica. $t=t$ de student. \\
\hline
\end{tabular}

El promedio del perfil inmunológico masculino tiene una elevación de todas las citocinas, en especial en el IFN gamma: más del $80 \%$ de los varones mostraron cifras mayores en la segunda muestra (luego de realizar la terapia). Aunque ninguna de estas sea estadísticamente significativa, hay un porcentaje importante de la muestra con movimiento al alza. Pese a que la mayoría de los hombres tuvieron un aumento del TNF alpha y de IL-10, en comparación con el promedio de las mujeres tienen niveles mucho más bajos y en los movimientos en valores absolutos de las dos citocinas; los niveles de TNF alpha y IL-10 fueron similares a los de las femeninas (Tabla 5-3).

Tabla 5-3. Cambios en las citocinas en hombres adultos mayores internados después de la aplicación de la terapia de la risa.

\begin{tabular}{|l|c|c|c|c|c|}
\hline \multicolumn{1}{|c|}{ Citocina } & $\begin{array}{c}\mathbf{1} \text { medida } \\
\text { (pre) Do* }\end{array}$ & $\begin{array}{c}\mathbf{2} \text { medida } \\
\text { (post) Do* }\end{array}$ & t* & Cambio & $\begin{array}{c}\text { \% de pacientes } \\
\text { que cambió }\end{array}$ \\
\hline IFN gamma masculino & 0,1783 & 0,1989 & 0,480 & Sube & 83,3 \\
\hline TNF alpha masculino & 0,0814 & 0,0698 & 0,310 & Sube & 66,7 \\
\hline IL-10 masculino & 0,0918 & 0,0923 & 0,929 & Sube & 58,3 \\
\hline IL-6 masculino & 0,1665 & 0,1464 & 0,261 & Sube & 50,0 \\
\hline IL-4 masculino & 0,1830 & 0,1775 & 0,759 & Sube & 50,0 \\
\hline * Do = Densidad óptica. $t=t$ de student.
\end{tabular}




\section{Discusión}

Los estudios sobre la terapia de la risa han venido en aumento en el presente siglo y han logrado mostrar sus efectos positivos sobre la salud de las personas como tratamiento complementario de costo menor y pocos efectos secundarios o indeseables. ${ }^{[11,12]}$

Al observar el estudio se infiere que hombres y mujeres responden de forma particular a la terapia ${ }^{[13]}$ y que esta guarda relación con el estado emocional, psíquico, social y físico de cada individuo, aunque en general todos, de una u otra manera, son permeados por el tratamiento. Los pacientes se ven beneficiados cuando los niveles de citocinas proinflamatorias disminuyen, ya que estas son causantes de muchos de los síntomas negativos; y también resultan favorecidos cuando aumentan los niveles séricos de las citocinas antiinflamatorias, asociados a una mejor respuesta inmunológica. Así que la terapia contribuye a mejorar la sintomatología de los pacientes que tienen condiciones patológicas crónicas inflamatorias de base. ${ }^{[12]}$

También se debe tener en cuenta que existen muchos otros factores que podrían estar modificando los niveles de citocinas plasmáticos: factores genéticos, biológicos (infecciones, procesos autoinmunes, reagudización de las patologías de base), sociales (discusiones internas en el hogar geriátrico, problemas familiares, problemas económicos), psiquiátricos (depresión, ansiedad, etc.). Es difícil excluir estos factores: hay que considerarlos a la hora de generar una discusión sobre la terapia de la risa y los valores inmunológicos encontrados. ${ }^{[14]}$

La terapia puede no solo influir en el perfil inmunológico de los pacientes modificando los niveles en sangre de las citocinas y demás mediadores: también puede mejorar funciones cognitivas, influir sobre las emociones positivas que permiten reducir la respuesta al estrés, aliviar la tensión y menguar las hormonas generadoras de estrés como cortisol, epinefrina y hormona del crecimiento; todo esto desencadena efectos positivos sobre la fisiología cognitiva de los pacientes. ${ }^{[15]}$

Está documentado que la risoterapia favorece la resistencia al dolor y la percepción que el individuo tiene sobre el mismo, por lo cual induce a una mejor respuesta psicológica y a un cambio en la disposición 
que tiene frente a la enfermedad (no es lo mismo afrontarla con significativamente menos dolor); todo esto a través de mecanismos fisiológicos para la analgesia que implican la liberación de endorfinas, importantes estas a la hora de abordar un paciente holísticamente (considerando todas sus esferas: física, mental, social, etc.); cualquier desbalance que ocurra en una de ellas influirá en la otra, y es de vital importancia tener pacientes en equilibrio.

Los hallazgos se ven respaldados por estudios según los cuales una sola sesión de terapia de la risa es capaz de generar cambios en los pacientes sobre la percepción del dolor. ${ }^{[16,17,18]}$ En el estudio de Matsuzaki y col., ${ }^{[9]}$ las concentraciones séricas de las citocinas en pacientes con artritis reumatoide se vieron afectadas o influenciadas por la aplicación de la terapia; cabe anotar que en los pacientes sanos las variaciones no fueron tan importantes; la IL-6 citocina proinflamatoria se redujo significativamente en los pacientes con artritis reumatoide, igual que el TNF alpha en aquellos que tenían artritis reumatoide difícil de tratar.

Respecto a la IL-4, hubo una disminución en los pacientes enfermos y un aumento en los sanos (tal vez puede ser una normalización del mecanismo antiinflamatorio); así que se encuentra similitud entre la modulación del perfil de las citocinas antes y después de la terapia, entendiendo que cada individuo y cada patología deben ser vistos individualmente, ya que sus resultados varían de uno a otro según el estado inmunológico, la actividad de la enfermedad y el estado psicológico; este último es indispensable para el tratamiento de las patologías. ${ }^{[9]}$

\section{Limitaciones}

El tamaño de la muestra es reducido (esto puede influir en la significancia estadística de los resultados); factores que no se controlan de la subjetividad del paciente como abandono, pérdidas familiares, exacerbación de las patologías de base, crisis de carácter nerviosa, psicológica o psiquiátrica, falta de medicación apropiada o de adherencia 
a la misma, efectos secundarios de la medicación y reacciones idiosincráticas, exposición a riesgos o eventos adversos dentro del hogar geriátrico. Estos factores externos son de difícil control e influyen en la precisión del estudio para conocer con exactitud la variación plasmática de cada citocina.

\section{Conclusiones}

La terapia de la risa resulta favorable por sí misma. El aumento de IFN gamma resulta beneficioso, puesto que mejora los síntomas negativos en los pacientes (la terapia se asocia con una mejor respuesta inmunitaria). Existe una relación en el mejoramiento del perfil inmunológico después de la realización de aquella, lo cual potencia la capacidad del organismo para controlar la enfermedad. En dos terceras partes de los pacientes disminuyó el TNF alpha, que es un gran productor de malestar general y mejor predictor en las enfermedades crónicas como HTA, EPOC, entre otras.

Se recomienda realizar estudios experimentales con un tamaño de muestra mayor y en un entorno mejor controlado para obtener datos más precisos sobre la terapia de la risa que puedan corroborar los resultados iniciales hallados en este trabajo.

\section{Referencias}

1. Organización Mundial de la Salud. Estadísticas sanitarias

mundiales 2012. Disponible en: https://apps.who.int/iris/ bitstream/handle/10665/44858/9789243564449_spa. pdf;jsessionid=A26BD60C6C2169D27AFBF712C3994F04? sequence=1

2. Salive ME. Multimorbidity in older adults. Epidemiologic Reviews. 2013; 35 (1): 75-83. Disponible en: https://academic.oup.com/epirev/ article/35/1/75/552863 
3. Vázquez C, Hervás G, Rahona JJ, Gómez D. Bienestar psicológico y salud: aportaciones desde la Psicología Positiva. Anu. Psicol. Clín. Salud. 2009; 5 (1): 1528. Disponible en: http://institucionales.us.es/apcs/doc/APCS_5_esp_15-28.pdf

4. Navarro AB, Bueno B, Delgado J. Bienestar emocional en la vejez avanzada: estudio comparativo por edad y género. Psychol. Soc. Educ. 2013; 5: 41-57. Disponible en: http://repositorio.ual.es:8080/bitstream/handle/10835/2884/ Navarro_et_al.pdf?seq

5. Sarabia CM. Envejecimiento exitoso y calidad de vida. Su papel en las teorías del envejecimiento. Gerokomos. 2009; 20 (4): 172-174. Disponible en: http://scielo.isciii.es/scielo. php?pid=S1134-928X2009000400005\&script=sci_arttext\&tlng=en

6. Cardona JL, Villamil M, Quintero A, Henao E. Terapia de la risa en un grupo de mujeres adultas. Rev. Fac. Nac. Salud Pública. 2013; 31 (2): 202-208. Disponible en: http://www.scielo.org.co/scielo. php?script=sci_arttext\&pid=S0120-386X2013000200006\&lang=es

7. Christie W, Moore $\mathbf{C}$. The Impact of Humor on Patients with Cancer. Clin. J. Oncol. Nurs. 2005; 9 (2): 211-218. Disponible en: https://search. proquest.com/openview/9b818a2fb3aaa67e16f6a5b947774aaf/1? pq-origsite=gscholar\&cbl=33118

8. Morishima T, Miyashiro I, Inoue N, Kitasaka M, Akazawa T, Higeno A. Effects of Laughter Therapy on Quality of Life in Patients with Cancer: An Open-Label, Randomized Controlled Trial. PloS one. 2019; 14 (6). Disponible en: https:// journals.plos.org/plosone/article?id=10.1371/journal.pone.0219065

9. Matsuzaki T, Nakajima A, Ishigami S, Tanno M, Yoshino S. Mirthful Laughter Differentially Affects Serum Pro-and Anti-Inflammatory Cytokine Levels Depending on the Level of Disease Activity in Patients with Rheumatoid Arthritis. Rheumatology. 2006; 45 (2): 182-186. Disponible en: https://academic.oup. com/rheumatology/article/45/2/182/1784358

10. Hasan H, Hasan TF. Laugh Yourself Into a Healthier Person: A Cross Cultural Analysis of the Effects of Varying Levels of Laughter on Health. Int. J. Med. Sci. 2009; 6 (4): 200. Disponible en: https://www.medsci.org/v06p0200.htm

11. Lefcourt HM, Thomas S. Humor and Stress Revisited. The Sense of Humor: Explorations of a Personality Characteristic. 1998; 179-202. 


\section{Shahidi M, Mojtahedi A, Modabbernia A, Mojtahedi M, Shafiabady A,}

Delavar A, Honari H. Laughter Yoga Versus Group Exercise Program in Elderly Depressed Women: a Randomized Controlled Trial. Int. J. Geriatr. Psychiatry. 2011; 26: 322-327. Disponible en: https://onlinelibrary.wiley.com/doi/ abs/10.1002/gps.2545

13. García JR, Capilla C, García O, Moreno I. Correlation Between Cytokines and Anxious-Depressive Symptoms in Patients with Fibromyalgia. Reumatología Clínica. 2008; 4 (4): 136-139. Disponible en: https://www.reumatologiaclinica. org/en-pdf-S1699258X08718229

14. Berk LS, Tan SA, Fry WF, Napier BJ, Lee JW, Hubbard RW. Neuroendocrine and Stress Hormone Changes During Mirthful Laughter. Am. J. Med. Sci. 1989; 298: 390-396. pmid:2556917. Disponible en: https://www.sciencedirect.com/ science/article/abs/pii/S0002962915361929?via\%3Dihub

15. Weisenberg M, Tepper I, Schwarzwald J. Humor as a Cognitive Technique for Increasing Pain Tolerance. Pain. 1995; 63: 207-212. pmid:8628586 Disponible en: https://www.sciencedirect.com/science/article/abs/pii/030439599500046U

16. Dunbar RI, Barón R, Frangou A, Pearce E, Van Leeuwen EJ, Stow J. Social Laughter is Correlated With an Elevated Pain Threshold. Proc. Biol. Sci. 2012; 279: 1161-1167. pmid:21920973. Disponible en: https:// royalsocietypublishing.org/doi/full/10.1098/rspb.2011.1373

17. Linge-Dahl LM, Heintz S, Ruch W, Radbruch L. Humor Assessment and Interventions in Palliative Care: A Systematic Review. Front Psychol. 2018; 9: 890. pmid:29973892 Disponible en: https://www.frontiersin.org/ articles/10.3389/fpsyg.2018.00890/full

18. Yoshino S, Fujimori J, Kohda M. Effects of Mirthful Laughter on Neuroendocrine and Immune Systems in Patients With Rheumatoid Arthritis. J. Rheumatol. 1996; 23: 793-794. pmid:8730156. Disponible en: https:// europepmc.org/article/med/8730156 


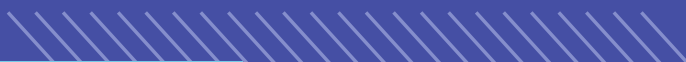
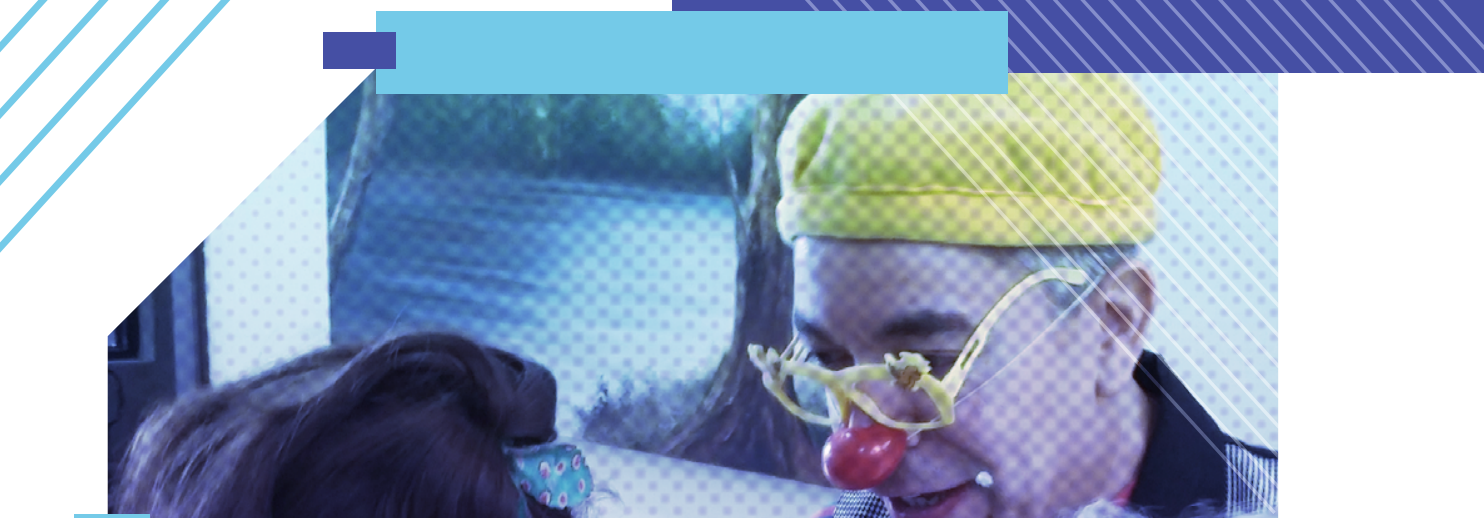


\section{Effect of Laughter Therapy on the Level of Depression in the Institutionalized female elderly}

María Mercedes Villamil Gallego ${ }^{1,5}$, María Eucaris Henao Villa ${ }^{2}$, Ángela Quintero Echeverri ${ }^{3}$, Kate Thurlow ${ }^{4}$ y Jairo León Cardona Jiménez ${ }^{2}$

\section{Introduction}

Depression is the most common emotional disorder in the elderly population. ${ }^{[1]}$ Depression in later life refers to depressive syndromes defined in the International Classification of Diseases (ICD-10) and the American Psychiatric Association's Diagnostic and Statistical Manual (DSM-IV) which occur over the age of 65 years..$^{[2]}$

According to the DSM-IV, there are three classifications for depression, which are based on the number of symptoms and degree of impairment; mild, moderate and severe, which can be with or without psychotic symptoms (which usually consist of delusions and hallucinations).

Depression is an important disease to address within the increasing ageing population as it is a major contributor to healthcare costs and is estimated to be the leading cause of disease in older populations by 2020. ${ }^{[3]}$ Depression is estimated to be almost 3,5 times more prevalent in the institutionalized elderly than in a community environment. ${ }^{[4]}$ Laughter therapy could therefore be a cost-effective treatment to help

1 Facultad de Humanidades y grupo GISAM, Uniremington.

2 Facultad de Ciencias de la Salud y grupo GISAM, Uniremington.

3 Grupo GISAM, Uniremington.

4 Instituto de Psiquiatría, Psicología y Neurociencia del King’s College London.

5 Contacto: mercevill@hotmail.com 
combat depression within care homes, where the need is greatest. Depression is twice as prevalent in women as in men. ${ }^{[5]}$

In a study of Mental Health in Colombia ${ }^{[6]}$ patients between the age of 60 and 65 years showed an annual prevalence of severe depression of $7.1 \%$ compared to $2.4 \%$ in general population groups. Concerning marital status, it was found that depression was present at a higher frequency in separated and widowed women than in those who were married. A similar investigation undertaken in Guatemala found single patients had a lower level of depression than those who were married or widowed, and furthermore, those who were separated or divorced had an even higher score. ${ }^{[7]}$ Other factors that have been shown to affect levels of depression include income and level of education. With a lower income correlating to a higher level of depression ${ }^{[8]}$ and a higher level of education correlating to a lower level of depression. ${ }^{[9]}$

Education level and marital status have been mentioned in this report, however are not the main focus of this study.

Depression is a serious public health problem. It is estimated that in the coming decades it will be considered one of the diseases of greater global impact because of the social cost and morbidity. It is expected that major depression will reach second place among all these diseases. ${ }^{[10,11,12]}$ In Colombia, the Study of Mental Health took 23 mental disorders listed in the DSM-IV 18 to 65 and found that major depression ranked fourth with $5.3 \%$ prevalence. ${ }^{[6]}$

The three following physiological parameters are risk factors for depression in the elderly; the severity of physical illness, pain and the degree of functional disability. Disease risk factors for depression include acute infections, malignancies, neurological abnormalities (such as Parkinson's, Alzheimer's), stroke and myocardial infarction. Medication risk factors include radiation therapy and steroid hormones.

Moreover, from a psychological point of view, three stress factors that can lead to depression in the elderly: the death of a loved one, serious health problems and the economic crisis. ${ }^{[13]}$

The Geriatric Depression Scale Short Form (GDS 15) is the most widely used method to assess depression in the elderly; there is a full version of 30 variables (GDS-30) and a reduced version with 15 
variables (GDS-15). ${ }^{[14]}$ The GDS-15 categorizes depression at three levels: normal (score of 0 to 5), mild (score of 6 to 9) and established (score of 10 or more) ${ }^{[15]}$ and is the form used in this study and validated for Colombia. ${ }^{[16]}$

Among the items measured on the scale are anhedonia, satisfaction with life, the emptiness of life, boredom, mood, worry, happiness, helplessness, apathy, memory problems, love of life, ideas of disability, level of energy, hopelessness and pessimism. ${ }^{[16]}$

Anhedonia was a term appointed by Ribot ${ }^{[17]}$ to discuss the decline in positive emotions and a lack of interest or pleasure. Later Chapman et al. ${ }^{[18]}$ speaks of two types of anhedonia, physical and social, disinterest in physical pleasures in the case of the first and disinterest regarding relationships with other people, in the second. Social anhedonia is a risk factor for several mental health problems and can predict loneliness. ${ }^{[19]}$

For Iranzo ${ }^{[20]}$ the energy level can relate to the emotional energy provided on the individual initiative, clarity and wisdom which generates complacency and somehow, these aspects are intertwined with solidarity, the symbolic, the neurological and dignity of the individual.

Apathy realizes the absence of emotions or passions. ${ }^{[21]}$ The depressed person feels apathetic and unwilling to care for their own physical needs, thus prolonging the recovery period.

Life satisfaction relates to the level of pleasure towards life. In a study by Liberalesso ${ }^{[22]}$ the existence of a high proportion of older adults who are satisfied with their lives is highlighted and this satisfaction decreases with age. For Deiner and Suh ${ }^{[23]}$ the concept of subjective well-being has three meanings: happy old age (being healthy), feeling satisfied and positive emotions that are pleasant experiences.

\section{Laughter therapy}

Laughter therapy is widely considered to be a useful, cost-effective and easily accessible intervention with positive effects on depression in the 
elderly. ${ }^{[24]}$ The benefits of laughter therapy are both psychological and physiological. There are numerous physical effects, which encompass multiple systems including the muscular, respiratory, cardiovascular, endocrine, immune and central nervous system. The heart, respiratory rate and residual air exchange are accelerated, thus improving oxygen levels in the blood and increased tissue oxygenation. The body's immune system is improved, thus helping to fight infection. Increased catecholamine levels may also improve mental function, the ability of interpersonal response, alertness and memory. ${ }^{[25]}$ The physical effects of laughter therapy are further illustrated by Ruiz et al., as compiled in Table 6-1, where the chain of effect on different systems within the body are shown ${ }^{[26]}$ (Table 6-1).

Table 6-1. Effects on different systems of the body resulting from laughter therapy.

\begin{tabular}{|c|c|c|c|}
\hline System & Direct effect & Secondary effect & Tertiary effect \\
\hline Respiratory & $\begin{array}{l}\text { Diaphragm } \\
\text { vibrates because it } \\
\text { compresses. }^{[18]}\end{array}$ & $\begin{array}{l}\text { Reduced snoring and } \\
\text { increased lung } \\
\text { capacity. }{ }^{[19,20]}\end{array}$ & $\begin{array}{l}\text { More effective } \\
\text { oxygenation. }^{[21]}\end{array}$ \\
\hline Circulatory & $\begin{array}{l}\text { Vibratory massage } \\
\text { and relaxation of } \\
\text { muscles. }{ }^{[20]}\end{array}$ & $\begin{array}{l}\text { Improved venous } \\
\text { circulation. }{ }^{[20]}\end{array}$ & $\begin{array}{l}\text { Strengthens heart } \\
\text { and reduces blood } \\
\text { pressure. }{ }^{[19,22,23]}\end{array}$ \\
\hline Hormonal & $\begin{array}{l}\text { Released } \\
\text { endorphins, } \\
\text { adrenaline, } \\
\text { dopamine and } \\
\text { serotonin. }{ }^{[19,23,24]}\end{array}$ & $\begin{array}{l}\text { Combat pain and } \\
\text { produce a feeling of } \\
\text { well-being. }{ }^{[19,23,2425,26]}\end{array}$ & $\begin{array}{l}\text { Decreased level of } \\
\text { depression. }{ }^{[22,27]}\end{array}$ \\
\hline $\begin{array}{l}\text { Skeletal } \\
\text { Muscular }\end{array}$ & $\begin{array}{l}\text { Increases flexibility } \\
\text { and muscle tone. }{ }^{[23]}\end{array}$ & $\begin{array}{l}\text { Relaxes muscle } \\
\text { tension. }{ }^{[28,29]}\end{array}$ & $\begin{array}{l}\text { Allows both } \\
\text { mental and physical } \\
\text { rest. Combats } \\
\text { insomnia. }{ }^{[26]}\end{array}$ \\
\hline Digestive & $\begin{array}{l}\text { Vibration of the } \\
\text { liver. }^{[30]}\end{array}$ & 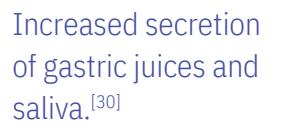 & $\begin{array}{l}\text { Burns calories } \\
\text { and improves } \\
\text { constipation. }{ }^{[23,25]}\end{array}$ \\
\hline
\end{tabular}

Compiled from data collected by Ruiz et al. ${ }^{[26]}$ 
Amongst the psychological benefits found, humor reduces anxiety, stress, tension, depression and loneliness as well as improving selfesteem, bringing hope energy and giving a feeling of power and control. ${ }^{[27]}$ In cancer patients, laughter therapy has been shown to decrease anxiety, discomfort and fears. ${ }^{[28]}$ The Geriatric Depression Scale Short Form (GDS-15) assesses the psychological effect of laughter therapy by showing the individuals' belief in the quality of life and life satisfaction, these may be due to physiological changes due to laughter therapy, but these were not explored in this study.

Other studies have observed changes in the level of depression with laughter therapy. One of them measured the effect of humor on quality of life, finding that scores improved in depressed patients, but not for those with Alzheimer's disease. ${ }^{[29]}$ Another study was conducted with a total of 90 participants of older adults who had clinical symptoms of depression according to ICD-10 classification. An experimental treatment group for laughter therapy (52 patients) was compared with a control group without specific treatment (38 patients). Several tests were applied before and after the laughter therapy such as the depression scale, the survey of health, life satisfaction and resilience. Significant improvements were found in depression, perception versus suicide, life satisfaction, general health and the state of joy. This study also concluded the appropriateness of laughter therapy in patients with depression and the benefits people get from it. ${ }^{[30]}$

A study by Ko Youn $\mathrm{HJ}$ and $\mathrm{CH}$ on the effects of laughter therapy on depression in community-dwelling elderly showed a significant difference between pre-test and post-test scores of GDS-15. ${ }^{[31]} \mathrm{A}$ similar study in Mangalore, India on depression in the elderly living in nursing homes also found that laughter therapy reduces the level of depression, with an average score of 16.97 GDS-15 before therapy and 11.97 after the therapy. ${ }^{[32]}$ Laughter therapy is used in many hospitals around the world as a means to help create happiness and improve the mental, social and emotional status of patients. ${ }^{[33]}$

Thus, all the benefits both physical and psychological can propitiate a better quality of life, in the elderly population. This is particularly important to address due to the continual increase of the elderly 
population. However, most studies have been done in other countries and so it is required to clarify the effect of this therapy in our environment and therefore, in this research, we explore changes in the levels of depression in elderly women after the application of laughter therapy.

\section{Materials and methods}

Type of study. Exploratory with quasi-experimental methodology. Instruments used. The Yesavage scale was used, which was applied by the researchers to each of the participants.

Variables. The sociodemographic variables age, education and marital status were used. The variables were also taken: Life Satisfaction, Anhedonia, Emptiness, Boredom, Mood, Anxiety, Happiness, Abandonment, Apathy, Memory Problems, Pleasure in being alive, Worthlessness, Energy, Levels of Hopelessness and Pessimism.

The inclusion criteria consisted of being of an age over 55 years (since in the home there were several older adults with that age who wanted to participate), able to respond to the interviews, able to attend a minimum of 3 laughter therapy sessions, willing to freely participate and a resident of the gerontology center "Revivir" Envigado, Colombia in 2011. In the process of collecting the information, each participant signed a document where the anonymity and confidential handling of information was specified and authorization for the interview given, thus supplying informed consent and the study was approved by the ethics committee of the University ${ }^{[34]}$ following the parameters of resolution 8430 of 1993 for Colombia. A social worker, an epidemiologist and two psychologists performed the collection of information.

The population size for this experiment was 18, all of whom were female. The variable of the level of depression was measured using GDS-15, described above. Exploratory research was carried out with quasi-experimental design, applying GDS-15, validated for Colombia, ${ }^{[16,17]}$ before and after intervention with laughter therapy. In total 5 sessions of laughter therapy were performed by a group of hospital clowns every week between July and August 2010. 
Statistical analysis was performed using SPSS version 14 for Windows. For univariate analysis absolute frequencies and proportions were used. Due to the non-normal distribution of data, non-parametric tests for comparison of the two data points were used. The Wilcoxon rank test was used for quantitative variables. The significance level was set at $p \leq 0.05$.

\section{Results}

The participants were all female with an average age of 80.6 years old. $80 \%$ of them had attended primary or secondary education. 12 women were single and 6 women were widowed.

As shown in Table 6-2, Depression Scale Yesavage showed improvement in twelve of the 15 items displayed, there being a noticeable improvement in anhedonia items, energy level, memory problems, pessimism and empty life.

Table 6-2. Frequency of positive responses to GDS-15 questions to indicate depression before and after the application of laughter therapy, the difference in number of responses before and after therapy and the change noted.

\begin{tabular}{|c|l|c|c|c|c|c|}
\hline Nro. & \multicolumn{1}{|c|}{ Item } & $\begin{array}{c}\text { Response } \\
\text { to Indicate } \\
\text { depression }\end{array}$ & $\begin{array}{c}\text { Original } \\
\text { Score }\end{array}$ & $\begin{array}{c}\text { Score } \\
\text { Post- } \\
\text { therapy }\end{array}$ & $\begin{array}{c}\text { Change in } \\
\text { score }\end{array}$ & Difference \\
\hline 1. & Life Satisfaction & No & 1 & 0 & Decrease & -1 \\
\hline 2. & Anhedonia & Yes & 10 & 4 & Decrease & -6 \\
\hline 3. & Emptiness & Yes & 6 & 2 & Decrease & -4 \\
\hline 4. & Boredom & Yes & 5 & 2 & Decrease & -3 \\
\hline 5. & Mood & No & 1 & 1 & No change & 0 \\
\hline 6. & Anxiety & Yes & 3 & 4 & Increase & 1 \\
\hline 7. & Happiness & No & 1 & 0 & Decrease & -1 \\
\hline 8. & Abandonment & Yes & 3 & 1 & Decrease & -2 \\
\hline 9. & Apathy & Yes & 8 & 5 & Decrease & -3 \\
\hline 10. & Memory Problems & Yes & 7 & 3 & Decrease & -4 \\
\hline
\end{tabular}


Continuation of Table 6-2.

\begin{tabular}{|l|l|c|c|c|c|c|}
\hline Nro. & \multicolumn{1}{|c|}{ Item } & $\begin{array}{c}\text { Response } \\
\text { to Indicate } \\
\text { depression }\end{array}$ & $\begin{array}{c}\text { Original } \\
\text { Score }\end{array}$ & $\begin{array}{c}\text { Score } \\
\text { Post- } \\
\text { therapy }\end{array}$ & $\begin{array}{c}\text { Change in } \\
\text { score }\end{array}$ & Difference \\
\hline 11. & Pleasure in being alive & No & 2 & 5 & Increase & 3 \\
\hline 12. & Worthlessness & Yes & 6 & 5 & Decrease & -1 \\
\hline 13. & Energy Levels & No & 6 & 1 & Decrease & -5 \\
\hline 14. & Hopelessness & Yes & 4 & 2 & Decrease & -2 \\
\hline 15. & Pessimism & Yes & 5 & 1 & Decrease & -4 \\
\hline Wilcoxon $p=0.008$. & & & & \\
\hline
\end{tabular}

When we asked about other aspects of life such as pleasantness three adults were negatively affected and when we asked about worry one adult was negatively affected in the second measurement. No adult showed changes in mood item.

After application of therapy, changes were registered in the average Yesavage scale score for each adult. Table 6-3 shows the collected data, where $72 \%$ (13 individuals) of participants showed an improvement in the GDS-15 score with a total decrease of 32 points and an average decrease of 2 points per person. Deterioration (increase in Yesavage score) was observed in $22 \%$ (4 people) of the population, with a total increase of 7 points and an average increase of 1.8 points per person. This group was identified as having a "normal" level of depression by the initial GDS-15 test and remained so for the second measurement. No change was found in the overall scale score of $6 \%$ of the participants ( 1 individual).

Table 6-3. Changes in the raw score and level of depression according to the GDS-15 from original testing to testing after the application of laughter therapy.

\begin{tabular}{|c|c|c|c|c|c|c|}
\hline Participant & $\begin{array}{c}\text { Original } \\
\text { Score }\end{array}$ & $\begin{array}{c}\text { Original } \\
\text { level of } \\
\text { depression }\end{array}$ & $\begin{array}{c}\text { Score } \\
\text { Post- } \\
\text { therapy }\end{array}$ & $\begin{array}{c}\text { Level of } \\
\text { depression } \\
\text { post-therapy }\end{array}$ & $\begin{array}{c}\text { Change in } \\
\text { score }\end{array}$ & $\begin{array}{c}\text { Difference } \\
\text { in Score }\end{array}$ \\
\hline & 9 & Mild & 1 & Normal & Decrease & -8 \\
\hline 2 & 1 & Normal & 0 & Normal & Decrease & -1 \\
\hline
\end{tabular}


Continuation of Table 6-3.

\begin{tabular}{|c|c|c|c|c|c|c|}
\hline Participant & $\begin{array}{c}\text { Original } \\
\text { Score }\end{array}$ & $\begin{array}{c}\text { Original } \\
\text { level of } \\
\text { depression }\end{array}$ & $\begin{array}{l}\text { Score } \\
\text { Post- } \\
\text { therapy }\end{array}$ & $\begin{array}{c}\text { Level of } \\
\text { depression } \\
\text { post-therapy }\end{array}$ & $\begin{array}{c}\text { Change in } \\
\text { score }\end{array}$ & $\begin{array}{c}\text { Difference } \\
\text { in Score }\end{array}$ \\
\hline 3 & 1 & Normal & 0 & Normal & Decrease & -1 \\
\hline 4 & 4 & Normal & 2 & Normal & Decrease & -2 \\
\hline 5 & 6 & Mild & 0 & Normal & Decrease & -6 \\
\hline 6 & 8 & Mild & 3 & Normal & Decrease & -5 \\
\hline 7 & 4 & Normal & 2 & Normal & Decrease & -2 \\
\hline 8 & 9 & Mild & 6 & Mild & Decrease & -3 \\
\hline 9 & 1 & Normal & 2 & Normal & Deterioration & 1 \\
\hline 10 & 2 & Normal & 0 & Normal & Decrease & -2 \\
\hline 11 & 6 & Mild & 5 & Normal & Decrease & -1 \\
\hline 12 & 2 & Normal & 1 & Normal & Decrease & -1 \\
\hline 13 & 0 & Normal & 4 & Normal & Increase & 4 \\
\hline 14 & 2 & Normal & 3 & Normal & Increase & 1 \\
\hline 15 & 0 & Normal & 0 & Normal & Equal & 0 \\
\hline 16 & 1 & Normal & 0 & Normal & Decrease & -1 \\
\hline 17 & 9 & Mild & 3 & Normal & Decrease & -6 \\
\hline 18 & 3 & Normal & 4 & Normal & Increase & 1 \\
\hline Total & 68 & & 36 & & & -32 \\
\hline
\end{tabular}

12 adults were classified as normal by the initial test and remained so until the end of the test. In this population, the overall improvement was only 3 points. Of the 6 initially classified with mild depression (median 8.5), five went to a normal classification, this group showed a decrease of 29 points, adults who were classified with mild depression for the initial test were the most improved. Of these, one improved by 3 points, but remained classified as mild depression by the test. In the second application, no significant difference between the scores of those who were initially qualified with mild depression and normal (medians of 3 and 1.5, respectively) was recorded (Figure 6-1). 


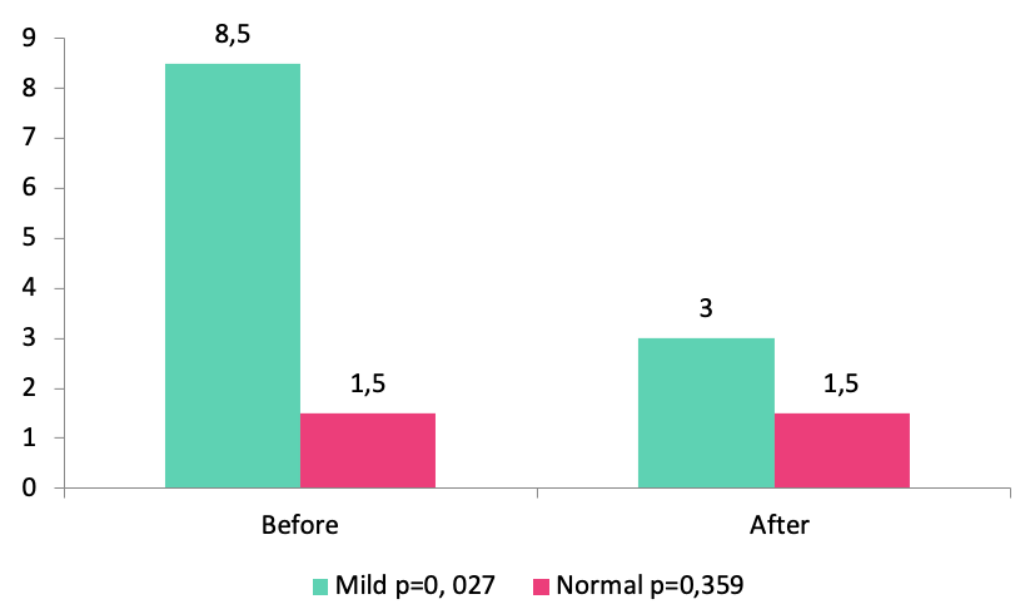

Rank test was performed using Wilcoxon test with p-values obtained shown.

Figure 6-1. Changes in median score of both normal and mild depression before and after treatment with laughter therapy.

\section{Discussion}

It is a challenge to analyze the effect of laughter therapy on depression and further our understanding of the mechanism of action due to the complexity of the affected population. Depression is a disease that severely impacts the quality of life, whilst laughter therapy is a known complementary therapy and yet rarely applied.

It is apparent that the participants in this study show many risk factors for depression in that they are women, ${ }^{[6,33]}$ seniors with an average age of 80.6 years, ${ }^{[6]}$ without a partner $(100 \%),{ }^{[6,7]}$ and not living independently (100\%). $80 \%$ of the population attended primary or secondary education and $61 \%$ were single with $39 \%$ widowed.

There is a higher risk of depression in old age, results show four times higher risk of suicide in the depressed elderly than in other age groups. Additionally, depressed elderly are at an increased risk of failing to recover or relapse. ${ }^{[13]}$

In this study positive changes were observed with respect to the level of depression after laughter therapy, supporting several other 
studies. ${ }^{[30,31,32]}$ It could therefore be concluded that laughter therapy is a potential complementary treatment for depression in the elderly.

Improvement was found in 12 of the 15 criteria of the GDS-15, the positive change of which occurred in $72 \%$ of the surveyed population. These results are consistent with previous studies on the same topic concluding that therapeutic humor relieves stress, can reduce the negative impact of poor health and helps promote general well-being, particularly in the presence of depression. ${ }^{[30,31,32]}$

In addition, the findings of this study support those of Hirsch et al., ${ }^{[30]}$ in that improvement of mood, increased joy and increased life satisfaction occurred as a result of laughter therapy in the elderly. Boredom, pessimism, apathy, ideas of worthlessness, memory loss and a feeling of helplessness all affect mental health and therefore can affect the level of depression. There is a direct link between life satisfaction and quality of life, which presents a challenge to address today.

Five aspects of the GDS-15 criteria improved significantly after the application of laughter therapy in this study; Anhedonia, energy level, memory problems, pessimism and emptiness of life. Anhedonia is important to address in order to strengthen the personal experience of the patient or to enhance their interest in the present moment. A reduction in anhedonia can result in not only increased life satisfaction and therefore quality of life, but also a potential decreased risk of mental disorders. ${ }^{[20]}$

Pessimism is defined as negatively viewing things and displaying a lack of interest in favorite activities. ${ }^{[13]}$ To improve self-esteem and thus increase self-care in the elderly, pessimism is an important aspect of depression to address. Similarly, by increasing the level of emotional energy, the individual experiences satisfaction and this predisposes the patient to perform daily activities in a more positive frame of mind, perhaps due to feeling included in a group. ${ }^{[27]}$

It could be concluded that increasing energy levels and decreasing anhedonia can help improve memory, ${ }^{[24]}$ the feeling of helplessness and therefore increase optimism towards life. This could be initially provided by something as simple and natural as laughter. 
The changes in GDS-15 score for depression before and after laughter therapy were found to be statistically significant using the Wilcoxon test, especially for those participants initially categorized with mild depression pre-treatment, but normal post-treatment. This supports Hirsch et al. ${ }^{[30]}$ in the conclusion that patients with a greater level of depression benefit most from laughter therapy. Hirsch further concludes that laughter therapy helps people with depression by improving their health and wellbeing.

It would be an interesting point for further study to investigate whether this trend extends to those initially categorized with severe depression. It is worth noting that two aspects of the GDS-15 scale were answered in a negative way post-treatment when initially positively answered pre-treatment. This could be due to uncontrollable variables mentioned above such as family loss, however further study into this point would be desirable.

\section{Conclusion}

The results of this study show a decreased level of depression in the elderly who received laughter therapy, especially at the psychosomatic level, supporting findings of other similar studies. ${ }^{[24,25,26,27,31]}$ Laughter therapy provides benefits to those with depression inclusive of increased well-being ${ }^{[30,31,32]}$ and compliments current drug treatments. Improvement in 12 of the items, especially anhedonia, energy level, pessimism, memory problems and feeling an empty life is highlighted.

According to this study, it is clear that laughter therapy makes a significant contribution to the health of the elderly and is a practical solution in our environment.

\section{Limitations}

The sample size was small with only 18 members. Older adults were summoned on several occasions but they were not motivated to 
participate in the study. During the application of therapy it was not possible to control different potentially significant aspects of each participant such as family losses, behavioral changes and mental health among others.

\section{Acknowledgements}

The research group on Health of the Elderly (GISAM) acknowledges the valuable assistance of María Sol Gaviria, Revivir director of the geriatric center and their adult users; and the governing body the Faculty of Health Sciences and Research Directorate of the University Corporation Remington for their unconditional support.

\section{References}

1. Rani GJ, Vineetha J. A Study to Assess the Effectiveness of Laughter Therapy on Depression Among Elderly People in Selected Old Age Homes at Manalore. International Journal of Nursing Education. 2014; 6 (1): 152-154.

2. Alecopoulous GS. Depression in the Elderly. The Lancet. 2005; 365 (9475): 1961-1970.

3. Goodwin RD. Association Between Physical Activity and Mental Disorder Among Adults in the US. Prev. Med. 2003; 36: 698-70.

4. Leon FG, Ashton AK, DMello DA, Dantz B. Depression and Comorbid Medical Illness: Therapeutic and Disgnostic Challenges. J. Fam. Pract. 2003; 19-23 suppl.

5. Lehtinen V, Joukamaa M. Epidemiology of Depression: Prevalence, Risk Factors and Treatment Situation. 2007; 89 (s377): 7-10.

6. Social FES Foundation National Survey of Mental Health Colombia. 2003 Document review. Bogotá: Ministerio de la Protección Social; 2004.

7. Molina Soto Shubert IP. Depression in the elderly members of the Center for Comprehensive Care Pensioners (CAMIP) in Guatemala. [Trabajo de grado Psicología]. Universidad Francisco Marroquín. Guatemala. 2005.

8. Rivera Navarro J, León JB, Pazzi Olazarán KA. La depresión en la vejez: un importante problema de salud en México. América Latina Hoy. 2015; 71: $103-$ 118. Disponible en: https://www.redalyc.org/pdf/308/30843703006.pdf 


\section{Martínez PC, Lozano Flórez JA, Ancizu I, Valdés CA, Adeva Cárdenas J.}

Psychological and Social Implications of Early Retirement. Psicothema. 2003; 15 (1): 49-53.

10. Gómez-Restrepo C, Ospina M, Diazgranados N. Trastornos psiquiátricos: su importancia en el campo de la salud. En: Gómez-Restrepo C, Hernández G, Rojas A, Santacruz H, Uribe M (eds.). Fundamentos de psiquiatría clínica: niños, adolescentes y adultos; 2002, pp. 221-6.

11. Vicente B, Rioseco O, Saldivia S, Kohn R, Torres S. Prevalencia de trastornos psiquiátricos en Latinoamérica: revisión crítica. Revista Colombiana de Psiquiatría. 2005; 34: 506-14.

12. Caicedo M, Jiménez K. Estudio descriptivo-exploratorio del trastorno depresivo mayor: aproximaciones psicológicas y sociodemográficas de pacientes hospitalizados en la Clínica Psiquiátrica Nuestra Señora de la Paz. Rev. Colomb. Psiquiatr. 2005; 34: 515-28.

13. Ayuso, JL. La depresión en la tercera edad. Avances en psiquiatría biológica. 2008; 9: 76-104.

14. López Trigo JA. Depression in the Elderly. Disponible en: https://www2.uned.es/ psicofarmacologia/stahl4Ed/contenidos/Tema2/documentos/C6/C6D_4.pdf

15. Bacca AM, González A, Uribe AF. Validation of Yesavage Depression Scale (short version) in Senior Colombians. Psychological Thought. 2005; 1: 53-63.

16. Campo A, Urruchurtu Y, Solano T, Vergara A, Cogollo Z. Internal Consistency, Factorial Structure and Construct Reliability of Yesavage Scale for Geriatric Depression (GDS-15) in Cartagena (Colombia). Health Uninorte. 2008; 24 (1): 1-9

17. Ribot TH. The psychology of Emotions. Londres: Scott; 1897.

18. Chapman LJ, Chapman JP, Raulin ML. Scales for Physical and Social Anhedonia. J. Abnorm. Psychol. 1976; 87: 374-407.

19. Silvia P, Kwapil T. Aberrant Asociality: How Individual Differences in Social Anhedonia Illuminate the Need to Belong. Journal of Personality. 2011; 79 (6): 1013-1030.

20. Iranzo J. De la energía emocional a la dignidad personal y colectiva. RES. 2010; 13: 109-115.

21. Fernández A. De la apatía. El catoblepas. 2008; 75: 3. Disponible en: www. nodulo.org/ec/2008/n075p03.htm 
22. Liberalesso, A. Bienestar subjetivo en la vida adulta y vejez: hacia una psicología positiva en América Latina. Revista Latinoamericana de Psicología. 2002; 34 (1-2): 55-74.

23. Deiner E, Suh M. Subjetive Well-Being and Old Age: An International Analysis. En: Schaie KW, Lawton MP (editors). Annual Review of Gerontology and Geraytics Focus on Emotion and Adult Development. Nueva York: Springer; 1997, p. 304-324.

24. Sparks Bethea L. The Function of Humor Within the Lives of Older Adults. Summer. 2001; 49-56.

25. Rosner F. Therapeutic Efficacy of Laughter in Medicine. Cancer Investigation. 2002; 20 (3): 434-436.

26. Ruiz C, Rojo C, Ferrer A, Jiménez L, Ballesteros M. Complementary Therapies in Care. Humor and the Laugh. Enferm. Index. 2005; 14: 48-49.

27. Berk RA. The Active Ingredients in Humor: Psychophysiological Benefits and Risks for Older Adults. Educational Gerontology. 2001; 27: 323-339.

28. Christie W, Moore $\mathbf{C}$. The Impact of Humor on Patients With Cancer. Clinical Journal of Oncology Nursing. 2005; 9 (2): 211-218.

29. Walter M, Hanni B, Haug M, Amrhein I, Krebs-Roubicek E, Muller-Spahn F, Savaskan E. Humour Therapy in Patients With Late-Life Depression or Alzheimer's Disease: A Pilot Study. Int. J. Geriatr. Psychiatry. 2007; 22 (1): 77-83.

30. Hirsch R, Junglas K, Lonradt B, Jonitz MF. Humortherapie bei alten Menschen mit einer Depression. Z. Gerontol Geriat. 2010; 43: 42-52.

31. Ko H, Youn CH. Effects of Laughter Therapy on Depression, Cognition and Sleep among the Community-Dwelling Elderly. Geriatr. Gerontol Int. 2011; 11: 267-74.

32. Madrid A, Garcés E. La preparación para la jubilación: revisión de los factores psicológicos y sociales que inciden en un mejor ajuste emocional al final del desempeño laboral. An. psicol. 2000; 16 (1): 87-99.

33. Miranda S. Depresión en el anciano. Medicina General. 2002; 40: 28-31.

34. Ministerio de Salud. Resolución 8430 de octubre 4 de 1993. Por la cual se establecen las normas científicas, técnicas y administrativas para la investigación en salud. Bogotá; 1993. Disponible en: https://www.minsalud. gov.co/sites/rid/Lists/BibliotecaDigital/RIDE/DE/DIJ/RESOLUCION-8430DE-1993.PDF 


\section{Consideraciones finales}

La terapia de la risa, como complemento a las terapias tradicionales, puede contribuir a mejorar la calidad de vida y la salud de las personas. Sus beneficios no llegan solamente a las personas que participan en ella: también beneficia a los cuidadores, las familias y el personal de salud que acompaña.

Esta terapia además puede favorecer la prevención ya que los adultos al gozar más, se enferman menos y resignifican su cotidianidad. Se debe sensibilizar a los estudiantes de las ciencias de la salud y a los administradores de las instituciones de salud y de centros geriátricos para que incorporen las terapias complementarias en sus rutinas diarias, lo cual redundaría en beneficio general.

En otros países los payasos son parte de la nómina como el médico, enfermeras y personal de aseo pero pese a todas las investigaciones sobre sus beneficios, las personas a cargo de los contratos, no visualizan la pertinencia de incorporarlos.

Finalmente, es necesario que haya un cambio de paradigma con respecto a la vejez, por cuanto este concepto ha sido equiparado con enfermedad e incapacidad; así que hay que preparar a los niños y jóvenes para cambiar dicha idea, de suerte que, por un lado, logren un envejecimiento activo y, por el otro, le den un buen trato al adulto mayor; de esta manera se logra una mejor y más gratificante convivencia. 
Este libro se terminó de editar

en diciembre de 2020 
Investigar sobre el efecto de las terapias complementarias en los contextos institucionales que vivencia el adulto mayor se convierte en un gran reto para la Corporación Universitaria Remington por la tendencia mundial de aumento de esta población y a su vez la necesidad imperante de mejorar su calidad de vida (una vida más sana y de disfrute). Es necesario promocionar la salud, tal y como lo señala la medicina familiar y comunitaria: prevenir, mejorar la salud y realizar un mayor control sobre la misma con el fin de alcanzar un estado adecuado de bienestar mental, físico y social, como lo expresa la Carta de Ottawa y la Ley 1315 de 2009 (Colombia). 